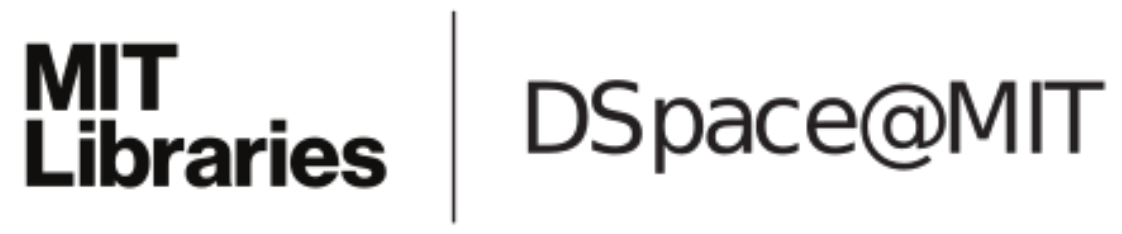

MIT Open Access Articles

Incremental melting in the ureilite parent body: Initial composition, melting temperatures, and melt compositions

The MIT Faculty has made this article openly available. Please share how this access benefits you. Your story matters.

Citation: Collinet, M. and Grove, T.L. (2020), Incremental melting in the ureilite parent body: Initial composition, melting temperatures, and melt compositions. Meteorit Planet Sci, 55: 832-856.

As Published: $10.1111 /$ MAPS.13471

Publisher: Wiley

Persistent URL: https://hdl.handle.net/1721.1/132712

Version: Original manuscript: author's manuscript prior to formal peer review

Terms of use: Creative Commons Attribution-Noncommercial-Share Alike 


\section{Meteoritics \& Planetary SCIEnCE}

\section{Incremental melting in the ureilite parent body: initial composition, melting temperatures and melt compositions}

\begin{tabular}{|c|c|}
\hline Journal: & Meteoritics \& Planetary Science \\
\hline Manuscript ID & MAPS-3307.R1 \\
\hline Manuscript Type: & Article \\
\hline $\begin{array}{l}\text { Date Submitted by the } \\
\text { Author: }\end{array}$ & $20-F e b-2020$ \\
\hline Complete List of Authors: & $\begin{array}{l}\text { Collinet, M; Massachusetts Institute of Technology, Earth, Atmospheric. } \\
\text { and Planetary Sciences } \\
\text { Grove, Timothy; MIT, Earth, Atmospheric and Planetary Sciences }\end{array}$ \\
\hline Keywords: & $\begin{array}{l}\text { Geothermometry, Melting experiments, ureilite(s) < Meteorite(s), } \\
\text { Planetesimal }\end{array}$ \\
\hline \multicolumn{2}{|c|}{$\begin{array}{l}\text { Note: The following files were submitted by the author for peer review, but cannot be converted to PDF. } \\
\text { You must view these files (e.g. movies) online. }\end{array}$} \\
\hline
\end{tabular}

\section{SCHOLARONE ${ }^{m}$ \\ Manuscripts}


1 Incremental melting in the ureilite parent body: initial composition,

\section{2 melting temperatures and melt compositions}

3 Max Collinet* and Timothy L. Grove

4 Massachusetts Institute of Technology

5 Department of Earth, Atmospheric and Planetary Sciences

677 Massachusetts avenue, 02139, MA, USA

$7{ }^{*}$ current address of corresponding author: Institute of Planetary Research, German Aerospace

8 Center (DLR), Rutherfordstraße 2, 12489 Berlin, Germany. E-mail: max.collinet@dlr.de

\section{Abstract:}

Ureilites are carbon-rich ultramafic achondrites that have been heated above the silicate

11 solidus, do not contain plagioclase, and represent the melting residues of an unknown planetesimal

12 (i.e. the ureilite parent body, UPB). Melting residues identical to pigeonite-olivine ureilites

13 (representing $80 \%$ of ureilites) have been produced in batch melting experiments of chondritic

14 materials not depleted in alkali elements relative to the sun's photosphere (e.g. CI, H, LL 15 chondrites), but only in a relatively narrow range of temperature $\left(1120-1180^{\circ} \mathrm{C}\right)$. However, many 16 ureilites are thought to have formed at higher temperature $\left(1200-1280^{\circ} \mathrm{C}\right)$. New experiments, 17 described in this study, show that pigeonite can persist at higher temperature (up to $1280^{\circ} \mathrm{C}$ ) when 18 CI and LL chondrites are melted incrementally and while partial melts are progressively extracted. 19 The melt productivity decreases dramatically after the exhaustion of plagioclase with only 5-9 20 wt.\% melt being generated between 1120 and $1280{ }^{\circ} \mathrm{C}$. The relative proportion of pyroxene and 21 olivine in experiments are compared to 12 ureilites, analyzed for this study, together with ureilites 22 described in the literature to constrain the initial $\mathrm{Mg} / \mathrm{Si}$ ratio of the UPB (0.98-1.05). Experiments 23 are also used to develop a new thermometer based on the partitioning of $\mathrm{Cr}$ between olivine and 24 low-Ca pyroxene that is applicable to all ureilites. The equilibration temperature of ureilites 25 increases with decreasing $\mathrm{Al}_{2} \mathrm{O}_{3}$ and Wo contents of pyroxene and decreasing bulk REE 26 concentrations. The UPB melted incrementally, at different $f \mathrm{O}_{2}$, and did not cool significantly (0$2730^{\circ} \mathrm{C}$ ) prior to its disruption. It remained isotopically heterogenous but the initial concentration of 28 major elements $\left(\mathrm{SiO}_{2}, \mathrm{MgO}, \mathrm{CaO}, \mathrm{Al}_{2} \mathrm{O}_{3}\right.$, alkali elements) was similar in the different mantle 29 reservoirs. 


\section{Introduction}

Ureilites are the largest group of ultramafic achondrites (550 samples at the time of writing) and the second largest group of achondrites after howardites-eucrites-diogenites. Most ureilites are composed of olivine and pigeonite with a significant fraction of metal $(<5 \mathrm{wt} . \%)$, graphite $(\sim 3$ wt.\%), and traces of sulfide concentrated along silicate grain boundaries. Fewer samples contain orthopyroxene and augite instead of or in addition to pigeonite (e.g. Takeda et al. 1989; Goodrich et al. 2001). With the exception of brecciated ureilites (i.e. polymict ureilites) and a single monomict ureilite (Goodrich et al., 2016), they are completely devoid of plagioclase. Their bulk composition is depleted in incompatible lithophile elements and chalcophile elements relative to all chondrites.

While they were once described as ultramafic igneous cumulates (Berkley et al. 1980; Goodrich et al. 1987), most ureilites are now recognized as residues of partial melting representing 43 the mantle of a planetesimal that lost abundant FeNi-sulfide eutectic melts (e.g. Warren et al. 2006; 44 Goodrich et al. 2013a; Barrat et al. 2015) and silicate melts (Warren and Kallemeyn 1992; Scott 45 et al. 1993; Kita et al. 2004, Goodrich et al. 2007; Warren 2012; Barrat et al. 2016). The Ureilite 46 Parent Body (UPB) was violently disrupted while its internal temperature was still high (1150471300 ' C; e.g. Takeda et al. 1989; Sinha et al. 1997; Goodrich et al. 2004; Downes et al. 2008; 48 Herrin et al. 2010). Because cooling was rapid following the destruction of the UPB $\left(2-20{ }^{\circ} \mathrm{C} / \mathrm{h}\right.$; 49 Miyamoto 1985; Takeda et al. 1989; Goodrich et al. 2001; Herrin et al. 2010), the high temperature 50 mineral assemblage has been preserved. Ureilites represent "quenched melting residues", the only 51 ones in the meteorite record, and document how planetesimals melted in the early solar system. 52 However, the initial bulk composition of the UPB, the melting conditions and the composition of 53 the melts that were extracted have proved challenging to decipher. No chondritic sample 54 representing the primitive material has been found and remnants of the associated silicate melts 55 are extremely scarce. They include feldspatic clasts in polymict ureilites (Ikeda and Prinz 2001; 56 Cohen et al. 2004; Goodrich et al. 2004; Kita et al. 2004), a single 24 g trachyandesitic clast 57 (Bischoff et al. 2014) and ambiguous pyroxene-rich samples bearing melt inclusions (Goodrich et 58 al. 2001, 2009; Rosén et al. 2019) or plagioclase (Goodrich et al. 2016).

It is clear that the UPB was initially isotopically heterogeneous and remained so during 60 partial melting until it was disrupted. Ureilites have heterogeneous oxygen isotope compositions 61 and form a trend of mass-independent fraction (i.e. slope 1 in the three-isotope plot) which 
62 correlates with the $\mathrm{Mg \#}(\mathrm{MgO} /(\mathrm{MgO}+\mathrm{FeO})$ in mol.\%) of ferromagnesian silicates (Clayton and 63 Mayeda 1988; Greenwood et al. 2017). The forsterite content of olivine cores (Fo, equivalent to 64 the $\mathrm{Mg \# )}$ varies between 74 and 96 with increasing ${ }^{16} \mathrm{O}$ contents. In addition, ureilites are 65 characterized by heterogeneities in C (Barrat et al. 2017), Cr (van Kooten et al. 2017; Zhu et al. 66 2020) and noble gas isotopes (Broadley et al. 2020), which also appear to correlate with O isotope 67 compositions.

68 The initial composition of the UPB in major elements has long been unknown. The 69 abundance of graphite and the oxygen isotopes point to a connection with carbonaceous chondrites 70 (Clayton and Mayeda 1988; Goodrich et al. 2015) while nucleosynthetic anomalies in Cr, Ti and $71 \mathrm{Ni}$ are more akin to ordinary chondrites and characteristic of the "non-carbonaceous group" 72 (Warren 2011). We have recently described batch melting experiments of a representative 73 spectrum of chondritic materials (LL, H, CI, CM, and CV) and shown that pigeonite-olivine 74 residues resembling ureilites can be produced by melting high $\mathrm{NaK \#} \mathrm{compositions} \mathrm{such} \mathrm{as} \mathrm{CI}, \mathrm{H}$ 75 and LL chondrites $(50$; with $\mathrm{NaK} \#=(\mathrm{Na}+\mathrm{K}) /(\mathrm{Na}+\mathrm{K}+\mathrm{Ca})$ in atom.\%). The UPB could not have 76 been depleted in alkali elements because low NaK\# compositions (CV and CM) produce 77 orthopyroxene-olivine residues (Collinet and Grove 2020b).

78 Batch melting experiments of $\mathrm{H}, \mathrm{LL}$ and $\mathrm{CI}$ chondrites produce pigeonite-olivine residues 79 in a relatively narrow temperature interval, between 1120 and $1180^{\circ} \mathrm{C}$, while many ureilites are 80 thought to have formed at $1200-1270{ }^{\circ} \mathrm{C}$ (e.g. Takeda et al. 1989; Sinha et al. 1997). Here, we 81 investigate whether pigeonite can persist at higher temperature when CI and LL chondrites are 82 melted incrementally and while partial melts are progressively extracted. Experimental results are 83 compared to 12 ureilites that were analyzed for this study and ureilites described in the literature 84 to constrain the initial composition of the UPB and its $\mathrm{Mg} / \mathrm{Si}$ ratio in particular. Then, we develop 85 a new thermometer based on the partitioning of $\mathrm{Cr}$ between olivine and Low-Calcium Pyroxene 86 (LCP; orthopyroxene or pigeonite) that can be used to constrain the temperature of equilibration 87 of all ureilites. The $\mathrm{D}_{\mathrm{Cr}}^{\mathrm{oliv}}$ - LCP thermometer is used to distinguish between ureilites representing 88 simple melting residues and ureilites representing cumulates or the products of more complex 89 igneous processes. We compare the former (most pigeonite-olivine ureilites) to our experiments 90 to constrain melting processes and estimate the composition of the last silicate melts that were in 91 equilibrium with ureilites. We also use the new temperature of equilibration of ureilites to discuss 
92 the thermal history of the UPB and the nature of the heterogeneity in $\mathrm{fO}_{2}$ and oxygen isotopes of 93 the UPB.

\section{Methods}

\subsection{Experimental approach}

All experiments were performed in the MIT Experimental Petrology Laboratory in a Molybdenum Hafnium Carbide pressure vessel (MHC-PV) placed in a Deltech vertical furnace 100 equilibrated simultaneously in individual graphite capsules positioned vertically in a single Pt 101 outer capsule. The temperature gradient is small at the base of the MHC-PV $\left(<3{ }^{\circ} \mathrm{C}\right.$ over the length 102 of the $\mathrm{Pt}$ capsule) and all experimental charges were equilibrated under the same $\mathrm{P}-\mathrm{T}-\mathrm{fO}_{2}$ 103 conditions. The outer Pt capsule was loosely crimped but not sealed to allow for equilibration with 104 the $\mathrm{CO}$ pressure medium and set the $f \mathrm{O}_{2}$ to the CCO buffer (French and Eugster 1965). In all but 105 two experiments, the temperature was fixed for the duration of the experiments. In the other two 106 experiments (CHS 46 and 71), the temperature was first raised $20-50{ }^{\circ} \mathrm{C}$ above the final 107 temperature for two hours. After seven hours to five days, experiments were terminated by pulling 108 the MHC-PV out of the furnace, inverting it and hitting it with a wrench to ensure that the capsule 109 dropped into the water-cooled head of the pressure vessel and quench. Experiment conditions are 110 summarized in Table 1.

111 This study is a complement to a larger series of melting experiments of chondritic materials 112 (Collinet and Grove 2020a, 2020b). In previous manuscripts, we reported on experimental charges 113 that contain strictly chondritic bulk compositions (H, LL, CI, CM and CV) and simulate the batch 114 melting of planetesimals. In this study, we describe distinct experimental configurations that 115 simulate incremental melting processes. The batch melt compositions of (Collinet and Grove 116 2020a) were mathematically subtracted from the CI and LL compositions to obtain melting residue 117 analogs. These new compositions were synthetized by mixing high purity oxides, silicates $118\left(\mathrm{CaSiO}_{3}\right)$, carbonates $\left(\mathrm{Na}_{2} \mathrm{CO}_{3}, \mathrm{~K}_{2} \mathrm{CO}_{3}\right)$ and $\mathrm{Fe}$ metal (Grove and Bence 1977). Starting materials 119 were mixed for four hours in an automatic mortar and pestle and pre-conditioned for three days in 120 a gas-mixing furnace at $100{ }^{\circ} \mathrm{C}$ and $\mathrm{QFM}-1(\mathrm{IW}+2.5)$. These starting compositions (CIR1, 121 CIR2, CIR3 and LLR1, LLR2, Table 2) represent melting residues of either a LL or a CI 
122 composition from which increasing fractions of batch melts were removed $(11,15.5,19.5$ wt. $\%$ 123 and 8.5, 16 wt.\%, respectively).

124 During incremental melting, successive or "instantaneous" melt compositions are expected 125 to vary as melting progresses and become rapidly depleted in incompatible elements (e.g. $\mathrm{K}_{2} \mathrm{O}$, $126 \mathrm{Na}_{2} \mathrm{O}$ ) relative to batch melts. However, the composition of the aggregate melt (i.e. the sum of all 127 melt increments) and the composition of the residue are virtually identical to the composition of 128 the melt and residue produced by batch melting, after the same total degree of melting (e.g. see 129 pMELTS simulations in the supplementary material; Ghiorso et al., 2002). Accordingly, CIR1-3 130 and LLR1-2 compositions can also be understood as the melting residues from which the melt was 131 extracted as successive increments of any size. The LL and CI compositions were selected because, 132 like the initial composition of the UPB (Collinet and Grove 2020b), they are not depleted in alkali133 elements relative to the sun's photosphere $(\mathrm{NaK} \#=50)$. Yet, they are characterized by contrasting $134 \mathrm{Mg} / \mathrm{Si}$ (0.92 and 1.03, respectively) and $\mathrm{Ca} / \mathrm{Si}$ ratios (0.052 and 0.06). In addition, CI and LL 135 compositions are relatively close in $\mathrm{Mg \#} \mathrm{(68.5-70)} \mathrm{to} \mathrm{the} \mathrm{most} \mathrm{FeO-rich} \mathrm{ureilites} \mathrm{(74),} \mathrm{after}$ 136 removal of sulfur as FeS. Two additional compositions, $\mathrm{RCa}$ and $\mathrm{RCa} 2$, represent arbitrary "near137 chondritic" compositions depleted in $\mathrm{Al}_{2} \mathrm{O}_{3}, \mathrm{Na}_{2} \mathrm{O}$ and $\mathrm{K}_{2} \mathrm{O}$ but enriched in $\mathrm{CaO}$. They were 138 included to produce two-pyroxene assemblages that could be compared to orthopyroxene-augite 139 ureilites. Electron Microprobe Facility was used to acquire quantitative analyses of experimental run

\subsection{EPMA analyses}

The JEOL-JXA-8200 SuperProbe electron probe micro analyzer (EPMA) of the MIT 144 beam, a voltage of $15 \mathrm{kV}$ and a current intensity of $10 \mathrm{nA}$. All elements were measured for $40 \mathrm{~s}$ 145 (20 s for backgrounds) except $\mathrm{Na}$, which was counted first for $8 \mathrm{~s}$ (4 s for backgrounds). In many 146 experiments, the small quantity of melt ( $<5 \mathrm{wt} . \%)$ wetting grain boundaries, but rarely pooling, 147 precluded reliable measurement of its composition (quenched-modified glass). When attempted, 148 the analysis of experimental glasses was done with a $5 \mathrm{nA}$ current intensity, a spot size of 2-4 $\mu \mathrm{m}$ 149 and a counting time of $4 \mathrm{~s}$ for $\mathrm{Na}$.

150 Elemental X-ray maps of $\mathrm{Si}, \mathrm{Mg}, \mathrm{Fe}, \mathrm{Ca}$ and $\mathrm{Al}$ were acquired for 10 of the 12 ureilites. 151 The maps were performed with a beam size of 5-10 $\mu \mathrm{m}$, a step size of $15-25 \mu \mathrm{m}$, a voltage of 15 
$152 \mathrm{kV}$, a current intensity of $30 \mathrm{nA}$ and a counting time of $40 \mathrm{~ms}$. Elemental intensities were acquired 153 simultaneously with five wavelength dispersive spectrometers (WDS).

\subsection{Calculation of the mode of ureilites and experiments}

Elemental X-ray maps were compiled with MultiSpec(C) and used to create automatically 50 clusters of pixels in 5-dimensions with the algorithm ISODATA. Pixel clusters were then manually grouped into classes representing the different phases: (1) Fe-metal, sulfide and oxides, 158 (2) olivine, (3) low-Ca pyroxene and, if present, (4) augite. Graphite, the residual porosity and all 159 ambiguous clusters were grouped as background. The number of pixels in each class, representing 160 the modal composition of ureilites in vol.\%, were counted with ImageJ. This treatment was applied 161 to the 10 ureilite thin sections mapped for this study and to eight additional ureilites studied by 162 Singletary and Grove (2003) using their original X-ray maps.

The phase proportions in experiments were estimated by mass balancing the composition 164 of the different phases against the bulk composition of the starting material with the function fitlm 165 in MatlabC. However, because the chemical composition of most melts could not be analyzed, we 166 first had to estimate their composition by altering the composition of experimental batch melts at 167 the same temperature and $f \mathrm{O}_{2}$ conditions (Collinet and Grove 2020a). The concentrations of $\mathrm{SiO}_{2}$, $168 \mathrm{Al}_{2} \mathrm{O}_{3}$ and alkali elements were progressively lowered while the concentrations of $\mathrm{CaO}$ and, to a 169 lesser extent, $\mathrm{FeO}$ and $\mathrm{MgO}$ were slightly increased. Five to ten multiple linear regressions were 170 performed and the one with the lowest sum of squared residuals was selected. In practice, we find 171 that as long as a melt is included in mass balance calculations, the relative proportions of olivine 172 and pyroxene are not very sensitive to small variations in the estimated melt composition. 173 However, when no melt is included, mass balances tend to overestimate the proportion of pyroxene 174 relative to olivine by $\sim 5 \mathrm{wt.} \%$ (or $5 p y$ unit; where $p y$ is the ratio $\mathrm{px} /(\mathrm{px}+\mathrm{oliv}) * 100$ in wt.\%) even 175 in experiments that apparently contain only a few percent of liquid (e.g. LLR2 in CHS 47, 51). 176 Finally, to confirm that this method provides reasonable estimates of $p y$, we calculated phase 177 proportions in vol.\% by image analysis of 10 backscattered electron (BSE) images for two 178 experimental charges: LLR2 in CHS 47 and CIR2b in CHS 63. Modal compositions in vol.\% were 179 converted in wt.\% by multiplying the phase proportions by the densities of olivine and pyroxene 180 of appropriate composition. The $p y$ calculated by images analyses are consistent (within $\sim 3 p y$ 181 units) with the ones calculated by mass balance: 23.1 (vs. 21.2) and 42 (vs. 44.6) for CHS 47 and 182 CHS 63, respectively. 


\section{Results}

\subsection{Experiments on chondritic residues}

Most experimental charges performed using the LLR1-2 and CIR1-3 bulk compositions (chondritic residues) contain olivine, orthopyroxene or pigeonite, glass and metal (Fig. 1). Only one charge, CIR2 in CHS $65\left(1201{ }^{\circ} \mathrm{C}\right.$, IW -2.3), has minor augite in addition to pigeonite. All crystalline phases are homogenous in composition. Experimental runs using CIR1 and LLR1, the least refractory residues, contain more melt than CIR2-3 and LLR2 runs at a given temperature. We calculate the aggregate melt fraction (i.e. the total amount of melt produced from the initial chondritic composition), by adding the melt fraction in CIR1-3 or LLR1-2 experiments to the melt fractions associated with the different starting compositions (Table 2). At a given temperature, aggregate melt fractions are significantly smaller (15-22 wt.\%) in re-melted residues than in batch melting experiments (up to 35 wt.\%; Fig. 2). The main effect of removing partial melts as melting progresses is to considerably lower the melt productivity at higher temperature.

Because melt removal slows down the melting process considerably, the pigeonite (i.e. LCP with Wo content greater than 5, when defined based on composition) can persist in experimental residues up to $\sim 1280{ }^{\circ} \mathrm{C}, 80{ }^{\circ} \mathrm{C}$ higher than in batch melting experiments (Fig. 3). The bulk CIR2 composition corresponds to the residue immediately following the disappearance of plagioclase ( $\mathrm{F}=15.5$ wt.\%; Collinet and Grove 2020a) and produces pigeonite with a high wollastonite content (Wo) at the highest temperature $\left(1280{ }^{\circ} \mathrm{C}\right)$. LLR1-2 charges contain a pigeonite with lower Wo content and pigeonite disappears at $\sim 1220^{\circ} \mathrm{C}$ (as opposed to $1170{ }^{\circ} \mathrm{C}$ in batch melting experiments of $\mathrm{H}$ and LL compositions).

The pigeonite in LLR1-2 charges has a lower Wo content because $p y$ is significantly larger than in CIR1-3 charges (Fig. 4). The larger proportion of pyroxene relative to olivine in experimental charges with LLR1-2 compositions results from their lower bulk Mg/Si ratios (Table 2). In other words, in LLR1-2 charges, similar bulk $\mathrm{CaO}$ concentrations are "diluted" into a larger volume of pyroxene than in CIR1-3 charges. As melting progresses, pyroxene is consumed and $p y$ decreases along with the Wo content in the remaining pyroxene. However, at a given total extent of melting, there is $\sim 20 \mathrm{wt}$ \% less pyroxene in CI residues, with a higher Wo content, than in LL residues. The $\mathrm{Mg} \#$ of olivine and pyroxene increases with decreasing $f \mathrm{O}_{2}$ conditions from 75 at IW -1.3 to 95 at IW -2.5. In parallel, the fraction of Fe metal increases by 12 wt.\% (Fig. S1). 
213 Experimental charges with $\mathrm{CaO}$-rich bulk compositions that do not correspond to known 214 chondritic residues (DCa1 and DCa2) contain olivine, pigeonite, augite, glass and metal. No 215 attempt was made to estimate the melt fractions in those experiments. They are used in section 4.3 216 and 4.7, together with other experimental charges, to constrain the temperature of equilibration of 217 ureilites and the thermal history of the UPB. The detailed composition of experimental runs 218 products are reported in the supplementary material (Table S1-S5).

$219 \quad$ 3.2. Mineral composition and petrographic description of ureilites

220 Among the 12 ureilites analyzed for this study, eight are US Antarctic samples provided 221 by the Meteorite Working Group. Several of them have been described to various extents in the 222 literature: ALHA 82106 (Takeda et al. 1989), EET 96293 (Singletary and Grove 2003), LAP 22303721 (paired to LAP 03587; Warren and Rubin, 2010), EET 90019 (Warren 2012). Four 224 additional samples from Northwest Africa were acquired from private collectors and have not been 225 previously described in detail. The phase compositions and the phase proportions are reported in 226 Table 3 and the BSE images of six samples are shown in Fig. 5.

227 Three of the nine ureilites that we studied are orthopyroxene-augite-olivine ureilites (EET 228 96293, NWA 11754 and ALHA 82106), one is an orthopyroxene-pigeonite-olivine ureilite (NWA 229 5555) and the remaining eight are pigeonite-olivine ureilites. EET 90019 and NWA 4852 are some 230 of the most FeO-poor pigeonite-olivine ureilites (Fo $\mathrm{F}_{8.4}$ and $\mathrm{Fo}_{87.7}$, respectively). We observed a 231 single $80-\mu \mathrm{m}$ pigeonite in section $15\left(0.6 \mathrm{~cm}^{2}\right)$ of DOM 08012. Chromite was only found in MIL 23207447 as two 50- $\mu \mathrm{m}$ spherical crystals: one zoned and enclosed in olivine and the other relatively 233 homogenous and enclosed in pigeonite (Fig. S2). In addition to the grain boundary metal and 234 sulfide, spherules of variable size (1-20 $\mu \mathrm{m})$, made of C-rich metal (possibly cohenite), C-poor 235 metal, sulfides, and frequently all three, occur as inclusions in pigeonite and olivine (Fig. S2). 236 Most samples also display the typical 10-50 $\mu \mathrm{m}$ rims of MgO-rich olivine containing sub- $\mu \mathrm{m}$ metal 237 blebs and produced by reduction during the disruption of the UPB (i.e. "secondary smelting", see 238 section 4.8).

239 In four of the eight pigeonite-olivine ureilites (NWA 11755, LAP 03721, MIL 090076 and 240 EET96042), the pyroxene has been extensively smelted (Fig. 5e-f), probably due to a brief episode 241 of shock heating that followed the impact (Warren and Rubin 2010). In those samples, but not in 242 the other four, olivines contain sub- $\mu \mathrm{m}$ metal inclusions in their cores (Fig. S4). Unlike the metal243 sulfide spherules mentioned in the previous paragraph, they are homogenously distributed and 
244 exclusively sub- $\mu$ m. NWA 11755 (Fig. 5e) displays particularly clear evidence of this reduction 245 process, including the same bimodal porosity affecting "relic" pigeonite cores and reduced FeO246 poor pyroxene as in LAR 04315 (Warren and Rubin 2010). Because the pyroxene was almost 247 completely smelted and is porous, we did not attempt to estimate the pre-impact phase proportions 248 of NWA 11755. Unlike smelted rims, the core of olivine and pyroxenes are homogeneous in 249 composition.

250 NWA 11754 has a large fraction of pyroxene, including abundant augite, and a large 251 fraction of metal that fills fractures and silicate grain boundaries (Fig. 5d). NWA 11754 is in every 252 way identical to Hughes 009 and other members of the "Hughes cluster", a group of ureilites 253 interpreted as igneous cumulates rather than melting residues (Goodrich et al. 2001, 2009, 2016). 254 EET 96293 has the same Fo content in olivine as Hughes 009 and, while it contains less augite 255 than Hughes 009/NWA 11754, it contains a similar fraction of total pyroxene (Fig. 6).

256 ALHA 82106 is a unique orthopyroxene-augite-olivine ureilite that contains wavy 257 exsolution lamellae of augite in orthopyroxene (Fig. 5c). Because ALHA 82106 also contains 258 coarse-grained augite, its silicate phase assemblage at peak temperature is believed to have been 259 augite-pigeonite-olivine (Takeda et al. 1989).

260 The element maps used to calculate the modal composition of ten of the twelve ureilites 261 and eight of the ureilites analyzed by Singletary and Grove (2003) are available in the 262 supplementary material. All but three ureilites form an overall trend of increasing py with Fo in 263 olivine (Fig. 6; $\mathrm{R}^{2}=0.74$ ), similar to the py-Fo trends previously documented by Singletary and 264 Grove (2003) and Goodrich et al. (2007). Only the two anomalous "Hughes cluster" samples and 265 MET 01083, which displays a poikilitic texture (Fig. S11), were excluded. The trend formed by 266 ureilites in Fig. 6 has the same slope as residues with constant Mg/Si ratios, having lost the same 267 aggregate melt fraction at various $\mathrm{fO}_{2}$. It is also parallel to similar trends formed by ordinary 268 chondrites and other groups of primitive achondrites (Collinet and Grove 2020b).

269 4. Discussion

$270 \quad$ 4.1. The initial composition of the UPB

$271 \quad$ Ureilites have long been thought to be related to carbonaceous chondrites due to their high 272 graphite content. In support of this view, Clayton et al. (1976) and Clayton and Mayeda (1988) 273 showed that ureilites form a trend of mass-independent fractionation in three-isotope plots and are 274 coarsely aligned with CV chondrites (Greenwood et al., 2017). However, the discovery of 
275 nucleosynthetic anomalies in $\mathrm{Cr}, \mathrm{Ni}$ and $\mathrm{Ti}$ isotopes in bulk ureilites has questioned the connection 276 between ureilites and carbonaceous chondrites (Qin et al. 2010; Warren 2011). On a $\Delta^{17} \mathrm{O}-\varepsilon^{54} \mathrm{Cr}$ 277 diagram, ureilites, which have higher concentrations of neutron-rich isotopes (e.g. ${ }^{54} \mathrm{Cr}$ and ${ }^{50} \mathrm{Ti}$ ) 278 relative to carbonaceous chondrites, are part of the "non-carbonaceous" (NC) group along with 279 enstatite and ordinary chondrites. Goodrich et al. (2015) inferred that ureilites still formed in the 280 same region of the nebula as carbonaceous chondrites (greater heliocentric distance) but at a time 281 when nucleosynthetic anomalies were distinct ( $\sim .5 \mathrm{Ma}$ after CAIs). However, the NC and CC 282 reservoirs are thought to have been present and isolated from each other very early $(<1$ Ma after 283 CAIs), presumably by a proto-Jupiter, based on the Mo isotopes of NC and CC iron meteorites 284 (Kruijer et al. 2017). If this is true, and if the UPB accreted relatively late (1.4-1.7 Ma after CAIs) 285 as suggested by Budde et al. (2015), then the UPB would have accreted within the orbit of proto286 Jupiter together with the other NC parent bodies. However, the accretion time of the UPB is still 287 debated and van Kooten et al. (2017) and Zhu et al. (2020) argued that the UPB was partly 288 differentiated earlier than $1 \mathrm{Ma}$ after CAIs and (as early as $0.6 \mathrm{Ma} \Delta \mathrm{CAIs}$ ), an older age compatible 289 with the thermal evolution models of Wilson et al. (2008) and Goodrich et al. (2015). Based on a 290 presumed relationship between $\mathrm{Si}$ isotopes and the $\mathrm{Mg} / \mathrm{Si}$ ratio of parent bodies, Dauphas et al. 291 (2015) calculated a value of $1.00 \pm 0.08$ for the UPB, but the uncertainty overlaps with both 292 carbonaceous and ordinary chondrites. In summary, at present, isotopic systematics do not provide 293 strong constraints on the initial major element composition of the UPB.

294 Using MAGPOX (Longhi 1991), Goodrich (1999) and Goodrich et al. (2007) showed that 295 superchondric $\mathrm{CaO} / \mathrm{Al}_{2} \mathrm{O}_{3}$ ratios were required to stabilize pigeonite in ureilites. They extensively 296 discussed whether this could represent a primary feature of the UPB. Other workers have 297 commented this issue and the consensus that emerged is that the superchondritic $\mathrm{CaO} / \mathrm{Al}_{2} \mathrm{O}_{3}$ ratios 298 resulted from parent body processes rather than nebula processes (Kita et al. 2004; Warren 2012; 299 Goodrich et al. 2013c). In a recent experimental study (Collinet and Grove 2020b), we show that 300 the UPB was initially characterized by a chondritic $\mathrm{CaO} / \mathrm{Al}_{2} \mathrm{O}_{3}$ and only became depleted in $\mathrm{Al}_{2} \mathrm{O}_{3}$ 301 following the extraction of low-degree silicate melts. We also show that the initial composition of 302 the UPB was not depleted in alkali elements relative to the sun's photosphere ( $\mathrm{NaK} \#=50)$. All 303 high NaK\# chondritic compositions (H, LL, CI) produce pigeonite-olivine residues upon melting, 304 contrary to CM (33) and CV (25) compositions. Therefore, the assumption that the precursor 305 material of $\mathrm{FeO}$-poor ureilites contained more CAIs than the one of FeO-rich ureilites (Singletary 
306 and Grove, 2006; Goodrich et al. 2013a) appear to be no longer justified. Any significant addition 307 of CAIs to FeO-poor ureilites would drive down the NaK\# towards the value of CM (33) and CV 308 chondrites (25), which do not form pigeonite-olivine residues by partial melting.

309 The new incremental melting experiments and additional analyses of ureilites performed 310 for this study can be used to constrain the initial $\mathrm{Mg} / \mathrm{Si}$ ratio of the UPB in more detail. Warren 311 (2011) argued that, despite being carbon-rich, ureilites could derive from "non-carbonaceous" 312 chondritic materials with $\mathrm{Mg} / \mathrm{Si}$ ratios resembling ordinary chondrites (0.92-0.95) but lower $\mathrm{Fe} / \mathrm{Si}$ 313 ratios. Goodrich (1999) also concluded that the initial $\mathrm{Mg} / \mathrm{Si}$ ratio was close to the one of ordinary 314 chondrites and Goodrich and Wilson (2013) proposed that it was even lower, close to the $\mathrm{Mg} / \mathrm{Si}$ 315 ratio of enstatite chondrites (0.74-0.88).

316 The olivine and pigeonite of CIR2 experimental charges are identical, both in terms of 317 chemical composition and relative proportions (py), to the olivine and pigeonite in ureilites 318 (compare Fig. 4 to Fig. 6). On the other hand, LLR1-2 experimental charges contain an 319 overabundance of low-Ca pyroxene, with relatively lower Wo contents (4-6.5) compared to 320 ureilites (up to $\mathrm{Wo}_{12}$ ). Therefore, the $\mathrm{Mg} / \mathrm{Si}$ ratio of the LL starting composition (0.92) places a 321 firm lower limit on the initial Mg/Si ratio of the UPB. Any composition with a lower ratio would 322 contain no pigeonite at all $(\mathrm{Wo}<5)$. The $\mathrm{Mg} / \mathrm{Si}$ ratio of the $\mathrm{CI}$ composition (1.03) is likely much 323 closer to the average initial ratio of the UPB. The positive correlation between the Fo content in 324 olivine and the $p y$ of ureilites displays some scatter that allows for a certain degree of heterogeneity 325 in the initial $\mathrm{Mg} / \mathrm{Si}$ ratio (i.e. 0.98-1.05). However, the slope of the Fo-py trend, which is identical 326 to experimental trends of constant aggregate melt fraction, suggest that, if present, slight variations 327 in the $\mathrm{Mg} / \mathrm{Si}$ ratio were independent of the Fo content in olivine. Therefore, ureilites with $\mathrm{Fo}_{75}$ and $328 \mathrm{Fo}_{95}$ olivine were characterized by the same overall initial $\mathrm{Mg} / \mathrm{Si}$ ratio.

329 If the initial $\mathrm{Fe} / \mathrm{Mg}$ of the UPB had been homogenous, high-Fo ureilites, that formed under 330 more reducing conditions (IW -2 / -2.5) should also contain more metal, unless some of the metal 331 was extracted from the residues along with FeS (Barrat et al. 2015), in which case highly 332 siderophile element concentrations (HSE) would be expected to be lower (Warren and Huber 2006; 333 Warren et al. 2006). Ureilites with $\mathrm{Fo}_{85}$ and $\mathrm{Fo}_{95}$ olivine should contain 6 wt.\% and 12 wt.\% more $334 \mathrm{Fe}^{0}$ than ureilites with $\mathrm{Fo}_{75}$ olivine (Fig. S1). Because neither metal fractions nor siderophile 335 element concentrations correlate with Fo content in olivine, the UPB is often thought of as initially 336 heterogenous in $\mathrm{Fe} / \mathrm{Mg}$. However, the siderophile element concentrations of ureilites are still not 
337 well understood despite extensive studies. It remains possible that the UPB was heterogenous in 338 siderophile elements or that a fraction or exogenous metal overprinted siderophile element 339 concentrations (Goodrich et al. 2013a; Goodrich and Desch 2019).

\subsection{Literature estimates of ureilite equilibration temperatures}

Estimating the temperature of equilibration $\left(\mathrm{T}_{\mathrm{E}}\right)$ of individual ureilite samples has been a central issue in interpreting their petrogenesis. As most ureilites only contain pigeonite and olivine, 343 two-pyroxene (Lindsley 1983; Lindsley and Andersen 1983; Sack and Ghiorso 1994) and olivine344 chromite thermometry (Evans and Frost 1975; Wlotzka 2005) can only be applied to relatively 345 small sub-groups of ureilites. Most two-pyroxene temperatures that have been calculated for 346 orthopyroxene-augite or pigeonite-orthopyroxene ureilites are in the range $1200-1270{ }^{\circ} \mathrm{C}$ (Takeda 347 1989; Takeda et al. 1989; Sinha et al. 1997; Chikami et al. 1997; Weber et al. 2003) while olivine348 chromite temperatures are much lower $1040-1060^{\circ} \mathrm{C}$ (Goodrich et al. 2014).

349 Singletary and Grove (2003) made the first attempt at estimating the temperature of 350 pigeonite-olivine ureilites by calibrating an empirical thermometer based on the $\mathrm{MgO}$ and $\mathrm{CaO}$ 351 concentrations of pigeonite. Our batch and incremental melting experiments of chondritic 352 compositions can be used to evaluate its utility. Out of 22 experimental charges containing olivine, 353 pigeonite, metal and melt, only five have a calculated temperature within $\pm 20{ }^{\circ} \mathrm{C}$ of the 354 experimental temperature. Five experiments have a calculated temperature within $\pm 50^{\circ} \mathrm{C}$ and the 355 last ten experiments are within $\pm 100{ }^{\circ} \mathrm{C}$. The pigeonite thermometer of Singletary and Grove 356 (2003) overestimates the actual temperatures of most of our experiments (Fig. S8). Pyroxene phase 357 diagrams (Lindsley and Andersen 1983; Sack and Ghiorso 1994), previous experiments on basaltic 358 compositions (Grove and Juster 1989) and the experiments of this study show that the minimum 359 temperature at which pigeonite is stable increases with the Mg\#. The maximum temperature of 360 pigeonite stability (i.e. melting temperature in simple systems) is also a function of the $\mathrm{Mg \#}: 1409$ $361{ }^{\circ} \mathrm{C}$ for a pigeonite $\mathrm{En}_{90} \mathrm{Wo}_{10}$ but probably $\sim 1350{ }^{\circ} \mathrm{C}$ for the pigeonite of $\mathrm{FeO}$-rich ureilites $362\left(\mathrm{En}_{74} \mathrm{Wo}_{10}\right.$; Presnall 1995; Warren and Rubin 2010). Therefore, if permitted by the bulk 363 composition of the system, pigeonite with given $\mathrm{MgO}$ and $\mathrm{CaO}$ concentrations (or En and Wo 364 contents) can be stable over a temperature interval of $150-250{ }^{\circ} \mathrm{C}$. The apparent temperature 365 dependence of $\mathrm{MgO}$ and $\mathrm{CaO}$ concentrations in pigeonite used by Singletary and Grove (2003) 366 reflected the restricted temperature and compositional range of the melts produced in earlier 367 experiments. The UPB was initially rich in alkalis (Kita et al. 2004; Bischoff et al. 2014; Collinet 
368 and Grove 2020b) but the absence of $\mathrm{Na}_{2} \mathrm{O}$ in ureilite pyroxenes did not allow Singletary and 369 Grove (2003) to include this important element in the calibration of their single-pyroxene 370 thermometer. Therefore, the thermometer of Singletary and Grove (2003) should be replaced by 371 the thermometer described in the next section.

4.3. New thermometer based on the partitioning of $\mathrm{Cr}$ between olivine and low-Ca pyroxene

374 The compatibility of $\mathrm{Cr}$ in olivine and LCP strongly decreases with increasing temperature 375 in batch melting experiments of chondrites (Fig. 7 a-b). At $1100{ }^{\circ} \mathrm{C}$, the $\mathrm{Cr}_{2} \mathrm{O}_{3}$ content of olivine 376 is less than half of the $\mathrm{Cr}_{2} \mathrm{O}_{3}$ content of coexisting $\mathrm{LCP}$. However, the $\mathrm{D}_{\mathrm{Cr}}^{\mathrm{LCP}}-\mathrm{liq}\left(\mathrm{Cr}_{2} \mathrm{O}_{3}{ }^{\mathrm{LCP}} / \mathrm{Cr}_{2} \mathrm{O}_{3}{ }^{\text {liq }}\right.$ 377 in wt.\%) decreases faster with increasing temperature than the $\mathrm{D}_{\mathrm{Cr}}^{\text {oliv }}$ - liq and the $\mathrm{Cr}_{2} \mathrm{O}_{3}$ content of 378 olivine becomes nearly identical to that of the coexisting LCP at $1300{ }^{\circ} \mathrm{C}$. Therefore, with 379 increasing temperature, the ratio of $\mathrm{D}_{\mathrm{Cr}}^{\text {oliv }}-$ liq and $\mathrm{D}_{\mathrm{Cr}}^{\mathrm{LCP}}-$ liq (i.e. $\mathrm{D}_{\mathrm{Cr}}^{\text {oliv }}-\mathrm{LCP}$ ) increases with 380 increasing temperature and follows a linear relationship (Fig. $7 \mathrm{c}-\mathrm{d}$ ). The $\mathrm{D}_{\mathrm{Cr}}^{\text {oliv }}-\mathrm{liq}, \mathrm{D}_{\mathrm{Cr}}^{\mathrm{LCP}}-\mathrm{liq}$ and $381 \mathrm{D}_{\mathrm{Cr}}^{\text {oliv }-\mathrm{LCP}}$ do not seem to be influenced by the $f \mathrm{O}_{2}$ over the range of IW -1.3 and IW -2.5 (Fig. $7 \mathrm{c}$ ). 382 Because the melt does not have to be analyzed to calculate the $\mathrm{D}_{\mathrm{Cr}}^{\text {oliv }}-\mathrm{LCP}$, we can use all of 383 our experimental charges, including residues with only a few percent of melt, to calibrate a $384 \mathrm{D}_{\mathrm{Cr}}^{\text {oliv }}-\mathrm{LCP}$ thermometer. In practice, we use a subset of 60 charges for which $\mathrm{Cr}_{2} \mathrm{O}_{3}$ contents were 385 the most accurately determined (Table S6). The 60 experimental charges include all ten starting 386 compositions (Table 1): H, LL and CI (31), LLR1-2 and CIR1-3 (23) and RCa1-2 (6). All 387 experimental charges, whether they contain one LCP (orthopyroxene or pigeonite) or one LCP and 388 augite, visible traces of chromite, and regardless of the experimental $f_{2}$ fall on the same linear 389 trend with an accuracy of $\pm 15^{\circ} \mathrm{C}$ (Fig. $7 \mathrm{c}$-d). The $\mathrm{D}_{\mathrm{Cr}}^{\text {oliv }}$ - LCP also appears to be largely independent 390 of the wollastonite content in LCP (Fig. 7d). Nonetheless, a few experiments with very low Wo 391 content in pyroxene $(<3)$, not observed in ureilites, could be characterized by slightly higher $392 \mathrm{D}_{\mathrm{Cr}}^{\text {oliv }}-\mathrm{LCP}$ and were not included in the linear regression.

393 The independence of the $\mathrm{D}_{\mathrm{Cr}}^{\text {oliv }}-\mathrm{LCP}$ to $f \mathrm{O}_{2}$ is not intuitive because the average valence state 394 of $\mathrm{Cr}$ decreases with decreasing $f \mathrm{O}_{2}$. Most $\mathrm{Cr}$ is present as $\mathrm{Cr}^{3+}$ at $\mathrm{QFM}+1(\sim \mathrm{IW}+4.5)$ but $\mathrm{Cr}^{2+}$ 395 predominates at conditions more reducing than IW -1 (Hanson and Jones 1998; Papike et al. 2005) 396 and $\mathrm{Cr}^{0}$ becomes the dominant oxidation state under IW -5/-6 (Holzheid and O'Neill 1995). 397 Cations with contrasting charge and size such as $\mathrm{Cr}^{2+}$ and $\mathrm{Cr}^{3+}$ would be expected to partition 
398 differently in the M1 and M2 octahedral sites of the olivine and pyroxene crystal structures. 399 Presumably, this is not the case in olivine, for which the partition coefficients $\mathrm{D}_{\mathrm{Cr}}{ }^{3+}$ and $\mathrm{D}_{\mathrm{Cr}}{ }^{2+}$ 400 appear to be identical and largely independent of the $f \mathrm{O}_{2}$ (Papike et al. 2005), as suggested by our 401 experimental results. In pyroxene, $\mathrm{Cr}^{3+}$ should fit easily in the smaller M1 site and can be charged 402 balanced by $\mathrm{Al}^{3+}$ in the tetrahedral site (Tschermak substitution) while $\mathrm{Cr}^{2+}$ would only fit in the 403 larger M2 site. Therefore, $\mathrm{D}_{\mathrm{Cr}}^{\text {oliv }}-\mathrm{LCP}$ could be expected to decrease with $f \mathrm{O}_{2}$, a behavior that has 404 been shown experimental between IW +1 and IW -1 (Karner et al. 2007) but that should become 405 negligible under IW -1 as most $\mathrm{Cr}$ is already in the $\mathrm{Cr}^{2+}$ state, as suggested by our experiments 406 (Fig. S6). The predominance of $\mathrm{Cr}^{2+}$ in ureilites is also indicated by XANES analyses (calculated 407 valence of 2.0-2.2; Goodrich et al., 2013b; Sutton et al., 2017). In summary, the $\mathrm{D}_{\mathrm{Cr}}^{\text {oliv }-\mathrm{LCP}}$ 408 thermometer can be used at conditions more reducing than IW -1 without any $f \mathrm{O}_{2}$ dependent term, 409 as the influence of $f \mathrm{O}_{2}$ is undetectable. The $\mathrm{D}_{\mathrm{Cr}}^{\text {oliv }}-\mathrm{LCP}$ thermometer is specifically designed for 410 ureilites and is likely not directly applicable to more oxidizing systems in its current form.

411 The $\mathrm{D}_{\mathrm{Cr}}^{\text {oliv }}$ - LCP thermometer can be used to calculate the temperature of equilibration $\left(\mathrm{T}_{\mathrm{E}}\right)$ 412 of all ureilites, regardless of their mineral assemblage, as long as they contain olivine and at least 413 one LCP. It can be directly applied to 76 samples with detailed EPMA analyses of both olivine 414 and LCP (Table S8). Their $\mathrm{T}_{\mathrm{E}}$ cover a large range of temperature, $1054-1276^{\circ} \mathrm{C}$, which is identical 415 to the range of previous $T_{E}$ estimates (section 4.2). However, the $D_{C r}^{\text {oliv }}-L C P$ 416 reliable representation of the temperature distribution in the UPB and provide important new 417 constraints on the petrogenesis of ureilites.

418 Ureilites with low Fo content in olivine $\left(\mathrm{Fo}_{75-80}\right)$ have the most contrasting $\mathrm{T}_{\mathrm{E}}(1054-1276$ $\left.419{ }^{\circ} \mathrm{C}\right)$ while ureilites with high Fo content in olivine $\left(\mathrm{Fo}_{90-95}\right)$ have more restricted and higher $\mathrm{T}_{\mathrm{E}}$ of $4201180-1250^{\circ} \mathrm{C}$ (Fig. 8). Histograms of the $\mathrm{T}_{\mathrm{E}}$ of ureilites with either $\mathrm{Fo}_{74-85}$ or $\mathrm{Fo}_{87-96}$ olivine display 421 overlapping modes at $1180-1220{ }^{\circ} \mathrm{C}$. In other words, $\mathrm{FeO}$-poor and $\mathrm{FeO}$-rich ureilites are 422 characterized by identical average $T_{E}$ and eight of the nine samples with $T_{E}$ higher than $1240{ }^{\circ} \mathrm{C}$ 423 are FeO-rich. This result is in stark contrast with the positive correlation between $\mathrm{T}_{\mathrm{E}}$ and olivine 424 Fo contents (i.e. $\mathrm{Mg \#}$ ) that was predicted by the pigeonite thermometer of Singletary and Grove 425 (2003). Because the new $\mathrm{T}_{\mathrm{E}}$ no longer correlate with the Mg\# of ureilite samples, a strict separation 426 between $\mathrm{FeO}$-poor and $\mathrm{FeO}$-rich ureilites appears arbitrary. In the remainder of the discussion, 427 these two groups should be thought of as the end members of a continuum. 
All ureilites with two pyroxenes show a $\mathrm{D}_{\mathrm{Cr}}^{\text {oliv }-\mathrm{LCP}}$ equilibration temperature that is lower than the minimum temperature of pigeonite stability of Sack and Ghiorso (1994). The few ureilite 430 samples containing euhedral chromite, such as NWA 766, LEW 88774, and NWA 3109, display 431 low olivine-chromite temperatures (1037, 1042 and $1058{ }^{\circ} \mathrm{C}$; Goodrich et al. 2014) and low $432 \mathrm{D}_{\mathrm{Cr}}^{\text {oliv }}-\mathrm{LCP}$ temperatures $\left(1054,1085\right.$ and $\left.1141^{\circ} \mathrm{C}\right)$ that correlate with the $\mathrm{Cr} \#($ i.e. $\mathrm{Cr} /(\mathrm{Cr}+\mathrm{Al})$ in 433 mol.\%) of chromites: 0.65, 0.71 and 0.76 , respectively.

\subsection{Anomalous low-temperature ureilites}

$435 \quad$ Ureilites containing orthopyroxene and augite, characterized by low $\mathrm{T}_{\mathrm{E}}$ (open symbols in 436 Fig. 8), display poikilitic textures with large (up to $15 \mathrm{~mm}$ ) orthopyroxene oikocrysts enclosing 437 rounded olivine and augite crystals: LEW 88774 (Chikami et al. 1997), MET 78008 and Y 74130 438 (Takeda et al. 1989), RaS 517 (Rosén et al. 2019) and HaH 064 (Weber et al. 2003). Many such 439 samples contain unusually large fractions of pyroxene (e.g. LEW 88774, the "Hughes cluster" 440 samples, RaS 517) or, more rarely, unusually little pyroxene (MET 01083). Those anomalous low441 temperature ureilites are the only ones that do not plot on the trend of increasing $p y$ with increasing 442 Fo content in olivine (Fig. 6b). In addition, the $\mathrm{Al}_{2} \mathrm{O}_{3}$ concentrations of their LCP are significantly 443 higher (1.3-2.2 wt.\%) than in other ureilites (0.3-1.0 wt.\%; Fig 9a). The "Hughes cluster" samples 444 traditionally contain a large fraction of augite (>30 vol.\%) and their bulk $\mathrm{Ca} / \mathrm{Mg}$ ratios are super445 chondritic (Goodrich et al. 2001, 2009).

446 Due to their large pyroxene fractions and poikilitic textures, some anomalous ureilites have 447 been interpreted as cumulates or older residues that reacted with silicate melts (Downes et al. 2008; 448 Goodrich et al. 2009). All of the aforementioned samples are characterized by lower $\mathrm{T}_{\mathrm{E}}$ than the 449 temperature of plagioclase disappearance in chondritic materials (Fig. 8). If they represented 450 simple melting residues quenched at peak temperature following the destruction of the UPB, they 451 would be expected to contain plagioclase. Yet, only one sample contain plagioclase (Goodrich et 452 al. 2016). This sample, equilibrated at $1144^{\circ} \mathrm{C}$, is part of the Hughes cluster. It contains a 453 plagioclase much more calcic $\left(\mathrm{An}_{68.4}\right)$ than the plagioclase of the melting residues of high NaK\# 454 chondrites $\left(\mathrm{An}_{20-40}\right.$; Collinet and Grove 2020a).

455 Collectively, those observations are consistent with the idea that all anomalous low456 temperature samples do not represent melting residues but cumulates or products of melt-rock 457 reactions during melt migration. RaS 517 was recently described as containing primary melts and 458 recording the ureilite anatexis (Rosén et al. 2019). Due to its very low $\mathrm{T}_{\mathrm{E}}\left(1072{ }^{\circ} \mathrm{C}\right)$ and high augite 
459 fraction, this scenario does not seem viable. Instead, the silicate melt could represent a residual 460 liquid crystallizing in a superficial intrusion or magma conduit. Some brachinite-like meteorites 461 display similar coarse poikilitic textures and are inferred to form by partial crystallization of the 462 melt during melt migration (Goodrich et al. 2017a).

\subsection{Temperatures and extents of melting recorded by pigeonite-olivine ureilites}

The anomalous samples described in the previous section are in part responsible for the 465 once popular view that ureilites were igneous cumulates (Berkley et al. 1980; Goodrich et al. 466 1987). However, since the 1990s, pigeonite-olivine ureilites have largely been regarded as melting 467 residues (Warren and Kallemeyn 1992; Scott et al. 1993). If FeO-rich pigeonite-olivine ureilites 468 ( $\left.\mathrm{Fo}_{76-82}\right)$, which represent $70-80 \%$ of all ureilites, are melting residues from a relatively 469 homogeneous chondritic material, the samples that equilibrated at high temperature should have 470 experienced larger extents of melting than the samples that equilibrated at lower temperature. The 471 chemical composition and petrologic features of pigeonite-olivine ureilites should correlate with $472 \mathrm{~T}_{\mathrm{E}}$. Several such correlations are indeed observed. In ureilites with $\mathrm{Fo}_{76-82}$ olivine, the $\mathrm{Al}_{2} \mathrm{O}_{3}$ 473 content of LCP decreases linearly with increasing $\mathrm{T}_{\mathrm{E}}$ from $1 \mathrm{wt} . \%$ at $1150{ }^{\circ} \mathrm{C}$ to $0.35 \mathrm{wt} \%$ at 1276 $474{ }^{\circ} \mathrm{C}$ (Fig. 9b). The Wo content in LCP decreases in parallel, albeit with more scatter, from $\mathrm{Wo}_{10.5-}$ 47512 to $\mathrm{Wo}_{4.5-5}$ (Fig. 9c). The variability of Wo contents at a given temperature could result from the 476 interaction of migrating CaO-rich "late stage melts" with melting residues (see next section). 477 Finally, Barrat et al. (2016) have recently analyzed the rare earth element (REE) concentrations of 478 a large number of ureilites. They identified two main patterns: (1) "group B” with steeper LREE 479 profiles and high HREE concentrations, representing MgO-rich ureilites (Fo89-95), and (2) "group 480 A" with less steep LREE profiles and more variable bulk REE depletions, representing FeO-rich 481 ureilites. The REE concentrations, as well as the $\mathrm{Zr}$ concentrations of the ureilites of "group A" 482 (bulk leachates) correlate negatively with $\mathrm{T}_{\mathrm{E}}$ (Fig. 10).

483 The ureilites of "group B" (Fo Fo-95 $_{85}$ olivine) could represent the melting residues, produced 484 under more reducing conditions, of a chondritic material with initial $\mathrm{NaK \#}$ and $\mathrm{Mg} / \mathrm{Si}$ ratios similar 485 to the chondritic material that produced $\mathrm{FeO}$-rich ureilites (section 4.1). In addition, FeO-poor 486 ureilites were equilibrated over the same range of temperature as FeO-rich ureilites (1180-1220 $487{ }^{\circ} \mathrm{C}$; Fig. 8). Because the melting temperature of ferro-magnesian silicates increases with the $\mathrm{Mg \# ,}$ 488 FeO-poor ureilites should represent residues that melted to a lower extent than the FeO-rich 
489 ureilites equilibrated at the same temperature. A lower bulk degree of melting could explain in part 490 the higher REE concentrations of group B ureilites (Fig. 10).

\subsection{Incremental melting and composition of "late-stage" silicate melts}

492

As discussed in section 4.1, a chondritic composition with a high NaK\# (50) and a relatively homogenous $\mathrm{Mg} / \mathrm{Si}$ ratio (0.98-1.05) can produce ureilite-like residues by partial melting $494\left(\mathrm{~F}=15-24\right.$ wt.\%) under variable $f \mathrm{O}_{2}$ conditions. In batch melting experiments, pigeonite melts out 495 at $1170-1200{ }^{\circ} \mathrm{C}$ while it persists up to $1280{ }^{\circ} \mathrm{C}$ in incremental melting experiments. The ureilite 496 samples with the highest $\mathrm{T}_{\mathrm{E}}$ (Goalpara, $1276^{\circ} \mathrm{C}$, and Dingo Pup Donga, $1267^{\circ} \mathrm{C}$ ) have a LCP with 497 low Wo content (4.7-4.6, i.e. orthopyroxene). However, many FeO-rich samples with $\mathrm{T}_{\mathrm{E}}$ between 4981240 and $1260^{\circ} \mathrm{C}$ contain $\mathrm{Wo}_{6.5-10}$ pigeonite: RC 027, Y 74123, NWA 11755, Y 82100 and GRO 49995575 (Table S8). Residues containing pigeonite $\left(\mathrm{Wo}_{6.5-10}\right)$ at $1250{ }^{\circ} \mathrm{C}$ cannot form by batch 500 melting of any chondritic material (Fig. 3) and, instead, suggest that silicate melts were extracted 501 in several steps (i.e. incremental melting).

502 The composition of the first silicate melts produced in ureilites have been constrained by 503 batch melting experiments of high NaK\# chondritic materials (Collinet and Grove 2020a). Low504 degree partial melts $\left(<15\right.$ wt.\%), rich in alkali elements, $\mathrm{Al}_{2} \mathrm{O}_{3}$ and $\mathrm{SiO}_{2}$ were likely extracted 505 from their source and formed the ALM-A trachyandesite (Bischoff et al. 2014) and the 506 albite/oligoclase-rich clasts of polymict ureilites (Ikeda and Prinz 2001; Cohen et al. 2004; Kita et 507 al. 2004). If pigeonite-ureilites melted incrementally, the melts that were produced in later melting 508 stages would have been radically different in composition from the melts of batch melting 509 experiments. Because the melt productivity drops significantly following the extraction of alkali510 rich melts ( $\sim 5$ wt.\% between 1120 and $1250 / 1280{ }^{\circ} \mathrm{C}$; Fig. 2 ), ureilites would have contained very 511 little melt at the time of the destruction of the parent body. Similarly, LLR2 and CIR2-3 512 experimental charges contain very little melt (2-5 wt.\%) that could not be analyzed successfully. 513 These "late-stage" melts are expected to be depleted in alkali elements relative to batch melts. 514 Following the disappearance of plagioclase, $\mathrm{Na}_{2} \mathrm{O}$ concentrations decrease rapidly with successive 515 increments of melting (see pMELTS simulations in supplementary material).

516 Pigeonite-olivine ureilites with $\mathrm{Fo}_{75-82}$ olivine and high $\mathrm{T}_{\mathrm{E}}\left(1200-1260{ }^{\circ} \mathrm{C}\right)$ have the highest 517 concentrations of $\mathrm{CaO}$ in olivine (0.36-0.44; Fig. 11b). The partition coefficient of $\mathrm{CaO}$ between 518 olivine and liquid $\left(\mathrm{D}_{\mathrm{Ca}}^{\text {oliv }}-\mathrm{liq}=\mathrm{CaO}_{\text {oliv }} / \mathrm{CaO}_{\text {liq }}\right)$ decreases with increasing temperature $($ Fig $11 \mathrm{a})$, and 519 can be parametrized to calculate the $\mathrm{CaO}$ content of the late-stage melts that were in equilibrium 
520 with specific samples (Fig. 11c). At low temperature $\left(<1170{ }^{\circ} \mathrm{C}\right)$, the $\mathrm{CaO}$ content of the melts in 521 equilibrium with ureilites were identical to batch melts of high NaK\# chondrites (H, LL and CI). 522 However, at higher temperature, the late-stage melts were increasingly CaO-rich (8-12 wt.\%; Fig. 523 11d) while the $\mathrm{CaO}$ content of batch melts plateaus at $7-8 \mathrm{wt} . \%$ and then decreases from $1220{ }^{\circ} \mathrm{C}$. 524 The high $\mathrm{CaO}$ content of late-stage melts cannot result from batch melting and supports an origin 525 of ureilites as residues of incremental melting.

$526 \quad \mathrm{The}_{2} \mathrm{Al}_{2} \mathrm{O}_{3}$ content of late-stage melts could be estimated based on the $\mathrm{D}_{\mathrm{Al}}^{\mathrm{LCP}}-$ liq . In practice, 527 due to the low $\mathrm{Al}_{2} \mathrm{O}_{3}$ content of pyroxene in experiments, the $\mathrm{D}_{\mathrm{Al}}^{\mathrm{LCP}}-$ liq is difficult to calculate 528 precisely. In batch melting experiments Collinet and Grove (2020a), and the experiments of 529 Singletary and Grove (2006), the $\mathrm{D}_{\mathrm{Al}}^{\mathrm{LCP}}$ - liq varies between 0.04 and 0.07 at 2-13 MPa for a 530 pigeonite with $\mathrm{Wo}_{6-10}$ but we could not identify systematic variations. In Collinet et al. (2015), the $531 \mathrm{D}_{\mathrm{Al}}^{\mathrm{LCP}}-$ liq strongly increases with pressure but is constant over a $150{ }^{\circ} \mathrm{C}$ temperature interval (i.e. 5320.11 at $0.5 \mathrm{GPa}, 0.2$ at $1.0 \mathrm{GPa}$ and 0.3 at $2.0 \mathrm{GPa}$ ). Therefore, we estimate the $\mathrm{Al}_{2} \mathrm{O}_{3}$ 533 concentrations of late-stage melts with a constant $\mathrm{D}_{\mathrm{Al}}^{\mathrm{LCP}-\text { liq }}$ of 0.055 and find that, within the \pm 20 534 wt.\% relative uncertainty, they are indistinguishable from the $\mathrm{Al}_{2} \mathrm{O}_{3}$ concentrations of batch melts. 535 Our best estimate of the composition of a late-stage melt, produced at $1240{ }^{\circ} \mathrm{C}$ by incremental 536 melting and in equilibrium with olivine $\mathrm{Fo}_{79}$, is reported in Table 4. The $\mathrm{MgO}$ content is estimated 537 as a function of the temperature and is used to constrain the $\mathrm{FeO}$ content, assuming a $\mathrm{K}_{\mathrm{D}}^{\mathrm{oliv}} \mathrm{Fe}-\mathrm{liq} \mathrm{Mg}$ 538 of 0.31 , from batch melting experiments.

539 The $\mathrm{Na}_{2} \mathrm{O}$ content of late stage melts is more difficult to constrain. Following the 540 disappearance of plagioclase, $\mathrm{Na}$ behaves as an incompatible element and is rapidly exhausted 541 from the residue. Therefore, the $\mathrm{Na}_{2} \mathrm{O}$ content of the melts produced at this stage was likely 542 variable and decreased rapidly (from $\sim 2$ to $0 \mathrm{wt} . \% \mathrm{Na}_{2} \mathrm{O}$ ). Late-stage melts such as the one reported 543 in Table 4 could easily have crystallized the labradorite-rich clasts observed in polymict ureilites 544 (Cohen et al. 2004; Kita et al. 2004; Goodrich et al. 2017b). With the algorithm MELTS (Ghiorso 545 and Sack 1995), equilibrium and fractional crystallization of a late-stage melt containing $1 \mathrm{wt} . \%$ $546 \mathrm{Na}_{2} \mathrm{O}$ produce $\sim 20-30$ wt.\% labradorite plagioclase $\left(\mathrm{An}_{50-70}\right)$. This is also consistent with the 547 composition of plagioclase $\left(\mathrm{An}_{68}\right)$ in one Hughes cluster sample and with the idea that this sample 548 represents an olivine-rich residue in which a silicate melt migrated and partly re-crystallized 549 (Goodrich et al. 2016). Cumulate-residue hybrids have occasionally been advocated to explain the 550 origin of ureilites under the term "paracumulates" (Warren and Kallemeyn 1989; Goodrich et al. 
551 2004). The Hughes cluster samples and other anomalous low-T ureilites rich in augite could 552 represent such lithologies and derive from the crystallization of $\mathrm{CaO}$-rich and alkali-poor late stage 553 melts.

554 The behavior of melting of the UPB has been disputed based on differing interpretations 555 of REE patterns (Warren and Kallemeyn 1992; Goodrich et al. 2007, 2013c; Warren and Huber 556 2006; Warren 2012). Most recently, Barrat et al. (2016) used REE melting models to argue that 557 ureilites formed by continuous/dynamic melting, a specific case of incremental melting during 558 which a fixed melt fraction, referred to as the critical melt fraction, is retained in the residue. We 559 reproduced their calculations using the modal proportions and melting coefficients of Collinet and 560 Grove (2020a) and find that the REE patterns of FeO-rich ureilites can be explained by 15-24 wt.\% 561 of continuous melting with a 2 wt.\% critical melt fraction (Fig. 12a), a range that is identical to the 562 aggregate melt fractions of experimental charges containing ureilite-like residues (section 4.1, Fig. 563 4). In agreement with their more restricted $\mathrm{T}_{\mathrm{E}}$, FeO-poor ureilites can be explained by 16-18 wt.\% 564 of continuous melting. In detail, REE melting models are non-unique and the REE patterns can be 565 reproduced by different incremental melting processes, such as the complete removal of larger 566 melt increments (e.g. 5-10 wt.\%; Fig. S10). On the other hand, near-fractional melting would 567 produce stronger depletions in LREE (Fig. 11c), unless melting was faster than LREE diffusion in 568 pyroxene (Goodrich et al. 2007). Because all ureilites represent melting residues that melted 569 enough to exhaust plagioclase ( $\mathrm{F}>15.5 \mathrm{wt} . \%)$, and because REE melting models produce model570 dependent results (Fig. S10), it is impossible to constrain uniquely the size of the melt increments. 571 We infer that they were in the range $2-5 \mathrm{wt} . \%$.

\section{$572 \quad$ 4.7. Peak temperatures of ureilites and thermal history of the UPB}

573 Ureilites are sometimes described as having a two-stage cooling history: an initial episode 574 of slow-cooling followed by an episode of rapid-cooling simultaneous with the destruction of the 575 UPB (e.g. Goodrich 1992). It could be argued that the $\mathrm{T}_{\mathrm{E}}$ of ureilites, estimated with the $\mathrm{D}_{\mathrm{Cr}}^{\mathrm{oliv}}-\mathrm{LCP}$ 576 thermometer, does not represent the peak temperature. $\mathrm{Cr}$ diffuses relatively fast in olivine and in 577 orthopyroxene. Diffusion coefficients are only one order of magnitude slower than the ones of Fe578 Mg interdiffusion (Ito and Ganguly 2006; Dohmen et al. 2007; Ganguly et al. 2007). If main group 579 ureilites had stopped melting and started cooling following the extinction of ${ }^{26} \mathrm{Al}$, the $\mathrm{D}_{\mathrm{Cr}}^{\text {oliv }}-\mathrm{LCP}$ 580 thermometer would have recorded a lower final temperature rather than the peak melting 581 temperature. However, the cores of olivine and pyroxene display homogeneous $\mathrm{Cr}_{2} \mathrm{O}_{3}$ contents. 
582 Either slow cooling did not occur or ureilites systematically and completely re-equilibrated at an 583 intermediate temperature. Because olivine and pyroxene cores are also homogenous in $\mathrm{Fe}, \mathrm{Mg}$ and 584 Ca, two-pyroxene thermometers should record the same final temperature of equilibration. Only a 585 handful of samples have actually been suggested to record two distinct temperatures of 586 equilibration and, therefore, a slow-cooling event. In the next paragraphs, we use our experiments, 587 the new $\mathrm{D}_{\mathrm{Cr}}^{\text {oliv }}-\mathrm{LCP}$ thermometer and the phase diagrams and two-pyroxene temperatures of Sack 588 and Ghiorso (1994) to re-evaluate whether some ureilites, and more generally the UPB, went 589 through a stage of slow cooling.

590 As long as pigeonite-olivine ureilites remained in the field of pigeonite stability, a stage of 591 slow-cooling could be undetectable. However, many pigeonite-olivine ureilites with $\mathrm{Wo}_{6.5-10}$ were 592 last equilibrated at $1240-1260^{\circ} \mathrm{C}$, a temperature which is close to the highest temperature at which 593 we observe pigeonite $\left(\mathrm{Wo}_{5.5-7}\right)$ in incremental melting experiments $\left(1274{ }^{\circ} \mathrm{C}\right)$. At higher 594 temperature $\left(1300^{\circ} \mathrm{C}\right)$, melting residues become extremely $\mathrm{CaO}$-poor and pigeonite is replaced by 595 orthopyroxene. If ureilites had cooled slowly over a significant interval of temperature (from 1300 596 to $1240{ }^{\circ} \mathrm{C}$ ), they would have contained less $\mathrm{CaO}$ and orthopyroxene would have replaced 597 pigeonite. In addition, if the final $\mathrm{T}_{\mathrm{E}}$ had been significantly lower than the peak temperatures, the 598 correlation of $\mathrm{T}_{\mathrm{E}}$ with bulk REE concentrations and $\mathrm{Al}_{2} \mathrm{O}_{3}$ contents in pyroxene might have been 599 erased. This is not the case.

600 Only one ureilite displays inverted pigeonite with augite lamellae in a orthopyroxene host: 601 ALH 82106 (Takeda et al. 1989; Fig. 5c). This unique sample has a high $\mathrm{T}_{\mathrm{E}}$ of $1245 \pm 15^{\circ} \mathrm{C}$, just 602 under the minimum temperature of pigeonite stability (see symbol 22 in Fig. 8). One of our 603 experiments (CHS 66; RCa1) performed at $1250{ }^{\circ} \mathrm{C}$ contains olivine ( $\mathrm{Fo}_{95.3}$ vs. Fo95.5 in ALH 604 82106), augite and a pigeonite that is almost identical to the bulk unmixed pyroxene of ALH 82106 605 (opx+augite lamellae; $\mathrm{Wo}_{10.5}$, Table S7). This experiment suggests that ALH 82106 reached its 606 peak temperature at $1250 \pm 10^{\circ} \mathrm{C}$ and only had to cool by a few to $20^{\circ} \mathrm{C}$ to form inverted pigeonite. 607 The large majority of ureilites that equilibrated below the minimum temperature of pigeonite 608 stability contain distinct, randomly orientated, orthopyroxene and augite crystals. We posit that if 609 those ureilites had cooled slowly by more than $0-20^{\circ} \mathrm{C}$ below their peak temperatures many more 610 samples should instead contain inverted pigeonite.

611 To our knowledge, only one other ureilite displays clear signs of slow cooling: the highly 612 anomalous sample LEW 88774 (Chikami et al. 1997), which contains coarse $\sim 50 \mu \mathrm{m}$ intergrown 
613 lamellae of orthopyroxene and augite. Based on the bulk composition of the pyroxene $\left(\mathrm{Wo}_{15-20}\right.$; 614 sub-calcic augite), Chikami et al. (1997) argued that the pyroxene progressively recrystallized 615 during slow cooling, starting at $1280{ }^{\circ} \mathrm{C}$. The model of Sack and Ghiorso (1994), which agrees 616 closely with our experimental results (Fig. S5), suggests that a bulk pyroxene with a composition 617 of $\mathrm{En}_{66} \mathrm{Wo}_{15}$ is stable at $1180-1200{ }^{\circ} \mathrm{C}$ as opposed to $1280{ }^{\circ} \mathrm{C}$ (Chikami et al. 1997). LEW 88774 618 might have cooled slowly from $1200{ }^{\circ} \mathrm{C}$ to $1100{ }^{\circ} \mathrm{C}$, the $\mathrm{D}_{\mathrm{Cr}}^{\text {oliv }}-\mathrm{LCP}$ temperature. Because LEW 61988774 is a highly unusual pyroxenite $(p y=76)$ it could represent a cumulate formed within an 620 outer layer of the UPB and its thermal history is likely not representative of the conditions recorded 621 by most ureilites in the deeper interior of the UPB.

622 Several other "anomalous low-temperature ureilites" (section 4.4), are thought to have 623 equilibrated at two distinct temperatures. For example, Goodrich et al. (2001) suggest that Hughes 624009 , containing orthopyroxene and augite (Mg\# of 88-89), cooled from $1250^{\circ} \mathrm{C}$ to $1050^{\circ} \mathrm{C}$. One 625 of our experiments places an upper limit to the peak temperature of Hughes 009. CIR1-CHS 48 626 contain pigeonite $(\mathrm{Mg} \# 88)$ at $1194{ }^{\circ} \mathrm{C}$, which is close to the minimum temperature of pigeonite 627 stability at that $\mathrm{Mg} \#\left(1190^{\circ} \mathrm{C}\right.$; Sack and Ghiorso 1994). Because Hughes 009 contain no exsolution 628 lamellae but "standard" anhedral crystals of orthopyroxene and augite, it probably reached a peak 629 temperature lower than the temperature of pigeonite stability $\left(1190^{\circ} \mathrm{C}\right)$, while the final temperature 630 recorded by the $\mathrm{D}_{\mathrm{Cr}}^{\text {oliv }}-\mathrm{LCP}$ thermometer is $1167 \pm 15^{\circ} \mathrm{C}$. Those two temperatures suggest that 631 Hughes 009 cooled, at most, over $30{ }^{\circ} \mathrm{C}$ instead of $200{ }^{\circ} \mathrm{C}$. Using a similar reasoning, and 632 comparing the ureilite $\mathrm{HaH} 064$ to experiment CI-CHS 54 performed at $1129{ }^{\circ} \mathrm{C}$ (Collinet and 633 Grove 2020a), we infer that its peak temperature was in the range $1125^{\circ} \mathrm{C}$ (Sack and Ghiorso 634 1994) $-1089^{\circ} \mathrm{C}\left(\mathrm{D}_{\mathrm{Cr}}^{\text {oliv }}-\mathrm{LCP} \mathrm{T}_{\mathrm{E}}\right)$ rather than $1200^{\circ} \mathrm{C}$ (Weber et al. 2003) and that, therefore, it did 635 not cool significantly.

636 In summary, ALH 82106 is the only sample that has recorded an episode of slow cooling 637 at high temperature and in the region of the UPB representing the residual mantle. It cooled by 638 only $\sim 20^{\circ} \mathrm{C}$. The bulk of evidence suggests that the ureilites that represent melting residues were 639 maintained very close to their peak temperature, and might have been actively melting, at the time 640 of the disruption of the UPB. 
641

642

643

644

645

646

647

648

649

650

651

652

653

654

655

656

657

658

659

660

661

662

663

664

665

666

667

668

669

670

671

\subsection{Variable $f \mathrm{O}_{2}$ during melting and mantle heterogeneity of the UPB}

The metal and carbon polymorphs present along silicate grain boundaries have occasionally been interpreted as being added by the impactor that disrupted the UPB (Boynton et al. 1976; Wasson et al. 1976; Day et al. 2017). However, the weakly shocked ureilite ALHA 78019 (Berkley and Jones 1982) contains euhedral crystals of graphite intergrown with metal and sulfide. In addition, mixed cohenite-metal-sulfide inclusions occur in the silicates of many ureilites (Goodrich et al. 2013a; Fig. S2) and strongly suggest that graphite and metal were in equilibrium with silicates during partial melting. The presence of metal in equilibrium with olivine places strict constraints on the $f \mathrm{O}_{2}$ of the system (OSI equilibrium; Nitsan, 1974). A composition of $\mathrm{Fo}_{75-95}$ in olivine and $\mathrm{Fe}_{90-95} \mathrm{Ni}_{10-5}$ in the metal at $1100-1300{ }^{\circ} \mathrm{C}$ correspond to $\Delta \mathrm{IW}-1.3$ to -2.5 , which is identical to our experimental range of $f \mathrm{O}_{2}$. In experiments, the $f \mathrm{O}_{2}$ relevant to the formation of ureilites is imposed by the $\mathrm{C}$-CO buffer. Its position relative to the IW buffer is strongly dependent on both the temperature and the pressure. If the temperature is increased or the pressure is decreased, $\mathrm{Fe}^{2+}$ is progressively reduced to $\mathrm{Fe}^{0}$.

Because ureilites contain abundant graphite, it has long been assumed that the $\mathrm{C}-\mathrm{CO}$ buffer imposed the $f \mathrm{O}_{2}$ of equilibration of ureilites, like in our experiments, and was responsible for the variable Fo content of olivine cores $\left(\mathrm{Fo}_{75-95}\right)$ between samples (e.g. Berkley et al. 1980; Berkley and Jones 1982). In metallurgy, the process by which $\mathrm{Fe}$ metal is produced by heating $\mathrm{FeO}$ ores in the presence of $\mathrm{C}$ is called "smelting". By analogy, a primary control of the C-CO buffer on the composition of silicate cores (i.e. $\mathrm{Mg} \#$ ) in ureilites has been called smelting by Walker and Grove (1993). It is now called "primary smelting" or "equilibrium smelting" in the recent ureilite literature, by opposition to "secondary smelting" or "disequilibrium smelting", which refer to the reduction event associated with the disruption of the parent body. Despite minor semantic disagreement (Warren and Huber 2006), disequilibrium smelting has not been a source of contention. It is widely recognized as having produced the ubiquitous $10-50 \mu \mathrm{m}$ wide rims of olivine that are increasingly $\mathrm{FeO}$-poor outward and contain small metal blebs and free $\mathrm{SiO}_{2}$ (Fig. 5a), following the pressure drop and rapid cooling at $2-20{ }^{\circ} \mathrm{C} / \mathrm{h}$ caused by the destruction of the UPB (Miyamoto 1985; Takeda et al. 1989; Herrin et al. 2010). In most cases, the pyroxene is less affected by this process, probably due to the slower rate of Fe-Mg interdiffusion. However, a few samples display pyroxene smelted to different extents (Fig. 5e-f and Fig. S3) associated with olivine crystals containing homogenously distributed sub- $\mu$ m metal inclusions (Fig. S4). Such 
672 samples are interpreted as briefly shock-heated by the impact before being rapidly cooled (Warren 673 and Rubin 2010).

674 Equilibrium smelting, which would control the composition of olivine cores, has been more 675 controversial. It has been invoked in the context of cumulate and residue models alike and 676 encompasses different processes (Walker and Grove 1993; Goodrich et al. 1987, 2007; Sinha et 677 al. 1997; Singletary and Grove 2006). In Goodrich et al. (1987), equilibrium smelting is envisioned 678 as affecting the parental melts of ureilites as they migrate upwards and decompress before pooling 679 at various depths. In the model of Singletary and Grove (2006), smelting affects partly molten 680 diapirs heated more rapidly than the surrounding mantle due to their higher CAIs contents, and 681 higher ${ }^{26} \mathrm{Al}$ concentrations. In the model of Goodrich et al. (2007), primary smelting is driven by 682 an increase in temperature at constant pressure and happens simultaneously with partial melting. In detail, those simple primary smelting models appear to be inconsistent with the new $684 \mathrm{D}_{\mathrm{Cr}}^{\text {oliv }}$ - LCP thermometer. For example, the model of Goodrich et al. (2007) assumed that ureilites,

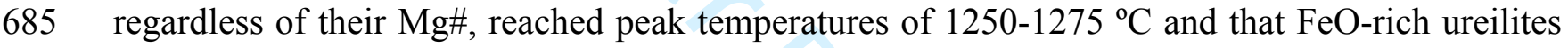
$686\left(\mathrm{Fo}_{75-80}\right)$ melted deeper in the parent body than $\mathrm{FeO}$-poor ureilites, as a consequence of the pressure 687 sensitivity of the C-CO buffer (Warren 2012; Goodrich et al. 2013c). However, it is now clear that 688 the equilibration temperatures of $\mathrm{FeO}$-rich pigeonite-olivine ureilites span a $150{ }^{\circ} \mathrm{C}$ interval (1130$6891280^{\circ} \mathrm{C}$ ). The Fo content of olivine in our experiments, which is a function of the temperature and 690 of the CO pressure, is used to calculate the pressure of equilibration of ureilites, assuming that the $691 \mathrm{fO}_{2}$ is primarily controlled by the C-CO buffer (Fig. 13a and Fig. S9). Because FeO-rich ureilites 692 formed over a large range of temperature, they would also have melted over a large range of 693 pressure (4-14 MPa), which would overlap with the pressure of equilibration of FeO-poor ureilites 694 (2-8 MPa; Fig 13a).

695 If melting occurred at higher pressure $(>15 \mathrm{MPa})$, where graphite can be stable with olivine 696 of various compositions $\left(\mathrm{Fo}_{74-95}\right)$ over the same temperature interval $\left(1130-1280{ }^{\circ} \mathrm{C}\right)$, the Fo 697 content in olivine and the $\mathrm{T}_{\mathrm{E}}$ based on the $\mathrm{D}_{\mathrm{Cr}}^{\text {oliv }-\mathrm{LCP}}$ would not be sufficient to constrain the 698 pressure of ureilite equilibration (Warren and Kallemeyn 1992; Walker and Grove 1993; Warren 699 and Huber 2006). Nevertheless, the temperature interval over which pigeonite-olivine ureilites 700 equilibrated $\left(1130-1280{ }^{\circ} \mathrm{C}\right)$ could represent a radial temperature gradient within the UPB. The 701 slope of such a temperature profile is unconstrained as it would be influenced by many parameters 
702 (e.g. Neumann et al. 2012). In any case, the identical equilibration temperatures of FeO-poor and 703 FeO-rich ureilites could indicate that they melted at the same depth (Fig. 13b).

704 There is little doubt that the UPB accreted from isotopically heterogeneous materials. The 705 fact that C (Barrat et al. 2017), Cr (Zhu et al. 2020) and O isotopes (Clayton and Mayeda 1988) 706 all correlate with the $\mathrm{Mg} \#$ of silicates suggests that the intrinsic $f \mathrm{O}_{2}$ of ureilites was at least partly 707 inherited from the precursor chondritic materials. The origin of the intrinsic $f \mathrm{O}_{2}$ of meteorite parent 708 bodies is an active area of research. The formation of $\mathrm{FeO}$ in the nebula setting is non-trivial and 709 could require high dust-to-gas ratios and dust rich in $\mathrm{H}_{2} \mathrm{O}$ (e.g. Fedkin and Grossman, 2016). 710 Similar correlations between the $\mathrm{Mg} \#$ of silicates (i.e. the intrinsic $f \mathrm{O}_{2}$ ) and the $\Delta^{17} \mathrm{O}$ are observed 711 in various meteorite groups other than ureilites. Such trends could be connected to the distribution 712 of ice and/or water vapor, either in the accretion disk or within parent bodies (e.g. Tenner et al. 713 2015; Sanders et al. 2017). Regardless of their origin, the initial heterogeneities in intrinsic $f \mathrm{O}_{2}$ of 714 ureilites do not preclude that reduction processes involving $\mathrm{C}$ and various gas species occurred 715 during melting and melt migration. Such "equilibrium smelting" reactions could have partly 716 overprinted the initial heterogeneities in intrinsic $f \mathrm{O}_{2}$. The presence of a gas phase could explain 717 the incremental nature of the melting process (Wilson et al. 2008) but it is no longer seen as a 718 requirement to drive rapid melt extraction from the residues (Goodrich et al. 2015). New models 719 for the origin of ureilites should evaluate which primary/equilibrium smelting processes are 720 compatible with the presence of initial heterogeneities in $f \mathrm{O}_{2}$ and the T-P conditions of 721 equilibration of ureilites (Fig. 13a). The large span in $\mathrm{T}_{\mathrm{E}}$ and extent of melting recorded in ureilites 722 suggests a UPB that was heterogeneous in intrinsic $f \mathrm{O}_{2}, \mathrm{Mg} \#$ and isotopic compositions, resulting 723 in a residual mantle where both $\mathrm{FeO}$-rich and $\mathrm{FeO}-$ poor ureilites were generated over a range of 724 depths (Fig. 14).

\section{5. Acknowledgements}

726 This research project was funded by a NASA Emerging Worlds grant (NNX16AD29J). US

727 Antarctic meteorite samples are recovered by the Antarctic Search for Meteorites (ANSMET)

728 program which has been funded by NSF and NASA, and characterized and curated by the

729 Department of Mineral Sciences of the Smithsonian Institution and the Astromaterials Curation

730 Office at NASA Johnson Space Center. We thank Kevin Righter for his editorial handling as 731 well as Cyrena Goodrich and Akira Yamaguchi for their thorough and constructive reviews. 


\section{References}

733

734

735

736

737

738

739

740

741

742

743

744

745

746

747

748

749

750

751

752

753

754

755

756

757

758

759

760

761

762

763

764

765

766

767

768

769

770

771

772

773

774

775

776

777

778

779

780

781

782

783

784

785

786

Barrat J. A., Rouxel O., Wang K., Moynier F., Yamaguchi A., et al. 2015. Early stages of core segregation recorded by Fe isotopes in an asteroidal mantle. Earth and Planetary Science Letters 419:93-100.

Barrat J.-A., Jambon A., Yamaguchi A., Bischoff A., Rouget M.-L., and Liorzou C. 2016. Partial melting of a C-rich asteroid: Lithophile trace elements in ureilites. Geochimica et Cosmochimica Acta 194:163-178.

Barrat J.-A., Sansjofre P., Yamaguchi A., Greenwood R. C., and Gillet P. 2017. Carbon isotopic variation in ureilites: Evidence for an early, volatile-rich Inner Solar System. Earth and Planetary Science Letters 478:143-149.

Berkley J. L., Taylor G. J., Keil K., Harlow G. E., and Prinz M. 1980. The nature and origin of ureilites. Geochimica et Cosmochimica Acta 44:1579-1597.

Berkley J. L., and Jones J. H. 1982. Primary igneous carbon in ureilites: Petrological implications. Journal of Geophysical Research: Solid Earth 87:A353-A364.

Bischoff A., Horstmann M., Barrat J.-A., Chaussidon M., Pack A., et al. 2014. Trachyandesitic volcanism in the early Solar System. Proceedings of the National Academy of Sciences of the United States of America 111:12689-92.

Boynton W. V, Starzyk P. M., and Schmitt R. A. 1976. Chemical evidence for the genesis of the ureilites, the achondrite Chassigny and the nakhlites. Geochimica et Cosmochimica Acta 40:1439-1447.

Broadley M. W., Bekaert D. V., Marty B., Yamaguchi A., and Barrat J. A. 2020. Noble gas variations in ureilites and their implications for ureilite parent body formation. Geochimica et Cosmochimica Acta 270:325-337.

Budde G., Kruijer T. S., Fischer-Gödde M., Irving A. J., and Kleine T. 2015. Planetesimal differentiation revealed by the Hf-W systematics of ureilites. Earth and Planetary Science Letters 430:316-325.

Chikami J., Mikouchi T., Takeda H., and Miyamoto M. 1997. Mineralogy and cooling history of the calciumaluminum-chromium enriched ureilite, Lewis Cliff 88774. Meteoritics \& Planetary Science 32:343-348.

Clayton R. N., Mayeda T. K., Onuma N., and Shearer J. 1976. Oxygen isotopic composition of minerals in the Kenna ureilite. Geochimica et Cosmochimica Acta 40:1475-1476.

Clayton R. N., and Mayeda T. K. 1988. Formation of ureilites by nebular processes. Geochimica et Cosmochimica Acta 52:1313-1318.

Cohen B. A., Goodrich C. A., and Keil K. 2004. Feldspathic clast populations in polymict ureilites: Stalking the missing basalts from the ureilite parent body. Geochimica et Cosmochimica Acta 68:4249-4266.

Collinet M., Médard E., Charlier B., Vander Auwera J., and Grove T. L. 2015. Melting of the primitive martian mantle at 0.5-2.2 GPa and the origin of basalts and alkaline rocks on Mars. Earth and Planetary Science Letters 427:8394.

Collinet M., and Grove T. L. 2020a. Widespread production of silica- and alkali-rich melts at the onset of planetesimal melting. Geochimica et Cosmochimica Acta (revisions submitted).

Collinet M., and Grove T. L. 2020b. Formation of primitive achondrites by partial melting of alkali-undepleted planetesimals in the inner solar system. Geochimica et Cosmochimica Acta (revisions submitted).

Dauphas N., Poitrasson F., Burkhardt C., Kobayashi H., and Kurosawa K. 2015. Planetary and meteoritic Mg/Si and variations inherited from solar nebula chemistry. Earth and Planetary Science Letters 427:236-248.

Day J. M. D., Corder C. A., Cartigny P., Steele A., Assayag N., et al. 2017. A carbon-rich region in Miller Range 091004 and implications for ureilite petrogenesis. Geochimica et Cosmochimica Acta 198:379-395.

Dohmen R., Becker H.-W., and Chakraborty S. 2007. Fe-Mg diffusion in olivine I: experimental determination between 700 and $1,200^{\circ} \mathrm{C}$ as a function of composition, crystal orientation and oxygen fugacity. Physics and Chemistry of Minerals 34:389-407.

Downes H., Mittlefehldt D. W., Kita N. T., and Valley J. W. 2008. Evidence from polymict ureilite meteorites for a disrupted and re-accreted single ureilite parent asteroid gardened by several distinct impactors. Geochimica et Cosmochimica Acta 72:4825-4844.

Evans B. W., and Frost B. R. 1975. Chrome-spinel in progressive metamorphism — a preliminary analysis. Geochimica et Cosmochimica Acta 39:959-972.

Fedkin A. V., and Grossman L. 2016. Effects of dust enrichment on oxygen fugacity of cosmic gases. Meteoritics \& Planetary Science 51:843-850.

French B. M., and Eugster H. P. 1965. Experimental control of oxygen fugacities by graphite-gas equilibriums. Journal of Geophysical Research 70:1529-1539.

Ganguly J., Ito M., and Zhang X. 2007. Cr diffusion in orthopyroxene: Experimental determination, 53Mn-53Cr thermochronology, and planetary applications. Geochimica et Cosmochimica Acta 71:3915-3925.

Ghiorso M. S., and Sack R. O. 1995. Chemical mass transfer in magmatic processes IV. A revised and internally consistent thermodynamic model for the interpolation and extrapolation of liquid-solid equilibria in magmatic systems at elevated temperatures and pressures. Contributions to Mineralogy and Petrology 119:197-212. 
Ghiorso M. S., Hirschmann M. M., and Reiners P. W. 2002. The pMELTS: A revision of MELTS for improved calculation of phase relations and major element partitioning related to partial melting of the mantle to $3 \mathrm{GPa}$. Geochem. Geophys. Geosyst. 3:1030.

Goodrich C. A. 1992. Ureilites: A critical review. Meteoritics 27:327-352.

Goodrich C. A. 1999. Are ureilites residues from partial melting of chondritic material? The answer from MAGPOX. Meteoritics \& Planetary Science 34:109-119.

Goodrich C. A., and Desch S. J. 2019. Exogenous Metal in Ureilites (abstract). MetSoc annual meeting 82:\#6094.

Goodrich C. A., and Wilson L. 2013. Non-Basaltic Magmatism On the Ureilite Parent Body (abtract). Workshop on Planetseimal Formation and Differentiation \#8018.

Goodrich C. A., Jones J. H., and Berkley J. L. 1987. Origin and evolution of the ureilite parent magmas: Multi-stage igneous activity on a large parent body. Geochimica et Cosmochimica Acta 51:2255-2273.

Goodrich C. A., Fioretti A. M., Tribaudino M., and Molin G. 2001. Primary trapped melt inclusions in olivine in the olivine-augite-orthopyroxene ureilite Hughes 009. Geochimica et Cosmochimica Acta 65:621-652.

Goodrich C. A., Scott E. R. D., and Fioretti A. M. 2004. Ureilitic breccias: clues to the petrologic structure and impact disruption of the ureilite parent asteroid. Chemie der Erde - Geochemistry 64:283-327.

Goodrich C. A., Van Orman J. A., and Wilson L. 2007. Fractional melting and smelting on the ureilite parent body. Geochimica et Cosmochimica Acta 71:2876-2895.

Goodrich C. A., Fioretti A. M., and Van Orman J. 2009. Petrogenesis of augite-bearing ureilites Hughes 009 and FRO 90054/93008 inferred from melt inclusions in olivine, augite and orthopyroxene. Geochimica et Cosmochimica Acta 73:3055-3076.

Goodrich C. A., Ash R. D., Van Orman J. A., Domanik K., and McDonough W. F. 2013a. Metallic phases and siderophile elements in main group ureilites: Implications for ureilite petrogenesis. Geochimica et Cosmochimica Acta 112:340-373.

Goodrich C. A., Sutton S. R., Wirick S., and Jercinovic M. J. 2013b. Chromium valences in ureilite olivine and implications for ureilite petrogenesis. Geochimica et Cosmochimica Acta 122:280-305.

Goodrich C. A., Wilson L., Van Orman J. A., and Michel P. 2013c. Comment on "Parent body depth-pressuretemperature relationships and the style of the ureilite anatexis" by P. H. Warren (MAPS 47:209-227). Meteoritics and Planetary Science 48:1096-1106.

Goodrich C. A., Harlow G. E., Van Orman J. A., Sutton S. R., Jercinovic M. J., and Mikouchi T. 2014. Petrology of chromite in ureilites: Deconvolution of primary oxidation states and secondary reduction processes. Geochimica et Cosmochimica Acta 135:126-169.

Goodrich C. A., Hartmann W. K., O’Brien D. P., Weidenschilling S. J., Wilson L., et al. 2015. Origin and history of ureilitic material in the solar system: The view from asteroid 2008 TC3 and the Almahata Sitta meteorite. Meteoritics \& Planetary Science 50:782-809.

Goodrich C. A., Ebert S., Bischoff A., Treiman A. H., Pack A., and Barrat J.-A. 2016. MS-MU-012: A primary plagioclase-bearing main group ureilite from Almahata sitta, with implications for the igneous evolution of the ureilite parent body (abstract). MetSoc annual meeting 79:\#6105.

Goodrich C. A., Kita N. T., Sutton S. R., Wirick S., and Gross J. 2017a. The Miller Range 090340 and 090206 meteorites: Identification of new brachinite-like achondrites with implications for the diversity and petrogenesis of the brachinite clan. Meteoritics \& Planetary Science 52:949-978.

Goodrich C. A., Treiman A. H., and Boyle S. 2017b. Melt formation and evolution on the ureilite parent body, as shown by feldspathic clasts in polymict ureilites (abstract). Lunar Planet. Sci. Conf. 48:\#1196.

Greenwood R. C., Burbine T. H., Miller M. F., and Franchi I. A. 2017. Melting and differentiation of early-formed asteroids: The perspective from high precision oxygen isotope studies. Chemie der Erde - Geochemistry 77:143.

Grove T. L., and Bence A. E. 1977. Experimental study of pyroxene-liquid interaction in quartz-normative basalt 15597. Proc. Lunar Planet. Sci. Conf. 8:1549-1579.

Grove T. L., and Juster T. C. 1989. Experimental investigations of low-Ca pyroxene stability and olivine-pyroxeneliquid equilibria at 1-atm in natural basaltic and andesitic liquids. Contributions to Mineralogy and Petrology 103:287-305.

Hanson B., and Jones J. H. 1998. The systematics of $\mathrm{Cr}^{3+}$ and $\mathrm{Cr}^{2+}$ partitioning between olivine and liquid in the presence of spinel. American Mineralogist 83:669-684.

Herrin J. S., Zolensky M. E., Ito M., Le L., Mittlefehldt D. W., et al. 2010. Thermal and fragmentation history of ureilitic asteroids: Insights from the Almahata Sitta fall. Meteoritics \& Planetary Science 45:1789-1803.

Holzheid A., and O'Neill H. S. C. 1995. The $\mathrm{Cr}_{2} \mathrm{O}_{3}$ oxygen buffer and the free energy of formation of $\mathrm{Cr}_{2} \mathrm{O}_{3}$ from high-temperature electrochemical measurements. Geochimica et Cosmochimica Acta 59:475-479. 
Huebner J. S. 1971. Buffering Techniques for Hydrostatic Systems at Elevated Pressures. In Research Techniques for pp. 123-177.

Ikeda Y., and Prinz M. 2001. Magmatic inclusions and felsic clasts in the Dar al Gani 319 polymict ureilite. Meteoritics and Planetary Science 36:481-499.

Ito M., and Ganguly J. 2006. Diffusion kinetics of Cr in olivine and ${ }^{53} \mathrm{Mn}-{ }^{53} \mathrm{Cr}$ thermochronology of early solar system objects. Geochimica et Cosmochimica Acta 70:799-809.

Karner J. M., Papike J. J., Sutton S. R., Shearer C. K., McKay G., et al. 2007. Valence state partitioning of Cr between pyroxene-melt: Effects of pyroxene and melt composition and direct determination of $\mathrm{Cr}$ valence states by XANES. Application to Martian basalt QUE 94201 composition. American Mineralogist 92:2002-2005.

Kita N. T., Ikeda Y., Togashi S., Liu Y., Morishita Y., and Weisberg M. K. 2004. Origin of ureilites inferred from a SIMS oxygen isotopic and trace element study of clasts in the Dar al Gani 319 polymict ureilite. Geochimica et Cosmochimica Acta 68:4213-4235.

van Kooten E. M. M. E., Schiller M., and Bizzarro M. 2017. Magnesium and chromium isotope evidence for initial melting by radioactive decay of ${ }^{26} \mathrm{Al}$ and late stage impact-melting of the ureilite parent body. Geochimica et Cosmochimica Acta 208:1-23.

Kruijer T. S., Burkhardt C., Budde G., and Kleine T. 2017. Age of Jupiter inferred from the distinct genetics and formation times of meteorites. Proc. Natl. Acad. Sci. U.S.A. 114:6712-6716.

Lindsley D. H. 1983. Pyroxene thermometry. American Mineralogist 68:477-493.

Lindsley D. H., and Andersen D. J. 1983. A two-pyroxene thermometer. Journal of Geophysical Research 88:A887.

Lodders K. and Fegley B. 1998. The planetary scientist's companion. New York: Oxford University Press.

Longhi J. 1991. Comparative liquidus equilibria of hypersthene-normative basalts at low pressure. American Mineralogist 76:785-800.

Miyamoto M. 1985. Cooling history of some antarctic ureilites (abstract). Proc. Lunar Planet. Sci. Conf. 90:D116D122.

Neumann W., Breuer D., and Spohn T. 2012. Differentiation and core formation in accreting planetesimals. Astronomy \& Astrophysics 543:A141.

Nitsan U. 1974. Stability field of olivine with respect to oxidation and reduction. Journal of Geophysical Research 79:706-711.

Papike J. J., Karner J. M., and Shearer C. K. 2005. Comparative planetary mineralogy: Valence state partitioning of $\mathrm{Cr}, \mathrm{Fe}, \mathrm{Ti}$, and $\mathrm{V}$ among crystallographic sites in olivine, pyroxene, and spinel from planetary basalts. American Mineralogist 90:277-290.

Presnall D. C. 1995. Phase Diagrams of Earth-Forming Minerals. American Geophysical Union (AGU). pp. 248-268

Qin L., Rumble D., Alexander C. M. O. D., Carlson R. W., Jenniskens P., and Shaddad M. H. 2010. The chromium isotopic composition of Almahata Sitta. Meteoritics and Planetary Science 45:1771-1777.

Rosén Å. V., Pape J., Hofmann B. A., Gnos E., and Guillong M. 2019. Quenched primary melt in Ramlat as Sahmah 517 - Snapshot of ureilite anatexis in the early solar system. Geochimica et Cosmochimica Acta 246:1-20.

Sack R., and Ghiorso M. 1994. Thermodynamics of multicomponent pyroxenes: II. Phase relations in the quadrilateral. Contributions to Mineralogy and Petrology 116:287-300.

Sanders I. S., Scott E. R. D., and Delaney J. S. 2017. Origin of mass-independent oxygen isotope variation among ureilites: Clues from chondrites and primitive achondrites. Meteoritics \& Planetary Science 52:690-708.

Scott E. R. D., Taylor G. J., and Keil K. 1993. Origin of ureilite meteorites and implications for planetary accretion. Geophysical Research Letters 20:415-418.

Singletary S. J., and Grove T. L. 2003. Early petrologic processes on the ureilite parent body. Meteoritics \& Planetary Science 38:95-108.

Singletary S., and Grove T. L. 2006. Experimental constraints on ureilite petrogenesis. Geochimica et Cosmochimica Acta 70:1291-1308.

Sinha S. K., Sack R. O., and Lipschutz M. E. 1997. Ureilite meteorites: Equilibration temperatures and smelting reactions. Geochimica et Cosmochimica Acta 61:4235-4242.

Sutton S. R., Goodrich C. A., and Wirick S. 2017. Titanium, vanadium and chromium valences in silicates of ungrouped achondrite NWA 7325 and ureilite Y-791538 record highly-reduced origins. Geochimica et Cosmochimica Acta 204:313-330.

Takeda. 1989. Mineralogy of coexisting pyroxenes in magnesian ureilites and their formation conditions. Earth and Planetary Science Letters 93:181-194.

Takeda H., Mori H., and Ogata H. 1989. Mineralogy of augite-bearing ureilites and the origin of their chemical trends. 


\section{Figure captions:}

Tenner T. J., Nakashima D., Ushikubo T., Kita N. T., and Weisberg M. K. 2015. Oxygen isotope ratios of FeO-poor chondrules in CR3 chondrites: Influence of dust enrichment and $\mathrm{H} 2 \mathrm{O}$ during chondrule formation. Geochimica et Cosmochimica Acta 148:228-250.

Walker D., and Grove T. 1993. Ureilite smelting. Meteoritics 28:629-636.

Warren P. H. 2011. Stable isotopes and the noncarbonaceous derivation of ureilites, in common with nearly all differentiated planetary materials. Geochimica et Cosmochimica Acta 75:6912-6926.

Warren P. H. 2012. Parent body depth-pressure-temperature relationships and the style of the ureilite anatexis. Meteoritics \& Planetary Science 47:209-227.

Warren P. H., and Huber H. 2006. Ureilite petrogenesis: A limited role for smelting during anatexis and catastrophic disruption. Meteoritics \& Planetary Science 41:835-849.

Warren P. H., and Kallemeyn G. W. 1989. Geochemistry of polymict ureilite EET83309, and a partially-disruptive impact model for ureilite origin. Meteoritics 24:233-246.

Warren P. H., and Kallemeyn G. W. 1992. Explosive volcanism and the graphite-oxygen fugacity buffer on the parent asteroid(s) of the ureilite meteorites. Icarus 100:110-126.

Warren P. H., and Rubin A. E. 2010. Pyroxene-selective impact smelting in ureilites. Geochimica et Cosmochimica Acta 74:5109-5133.

Warren P. H., Ulff-MøllerHuebner J. S. 1971. Buffering Techniques for Hydrostatic Systems at Elevated Pressures. In Research Techniques for High Pressure and High Temperature, edited by Ulmer G. C. Berlin, Heidelberg: Springer Berlin Heidelberg. pp. 123-177 http://dx.doi.org/10.1007/978-3-642-88097-1_5.

Wasson J. T., Chou C.-L., Bild R. W., and Baedecker P. A. 1976. Classification of and elemental fractionation among ureilites. Geochimica et Cosmochimica Acta 40:1449-1458.

Weber I., Bischoff A., and Weber D. 2003. TEM investigations on the monomict ureilites Jalanash and Hammadah al Hamra 064. Meteoritics \& Planetary Science 38:145-156.

Wilson L., Goodrich C. A., and Van Orman J. A. 2008. Thermal evolution and physics of melt extraction on the ureilite parent body. Geochimica et Cosmochimica Acta 72:6154-6176.

Wlotzka F. 2005. Cr spinel and chromite as petrogenetic indicators in ordinary chondrites: Equilibration temperatures of petrologic types 3.7 to 6. Meteoritics \& Planetary Science 40:1673-1702.

Zhu K., Moynier F., Schiller M., Wielandt D., Larsen K. K., et al. 2020. Chromium Isotopic Constraints on the Origin of the Ureilite Parent Body. The Astrophysical Journal 888:126.

Figure 1. Backscattered images of experimental charges containing ureilite-like residues (olivinepigeonite-metal). (a) CI residue with $p y$ of 21 . (b) LL residue with $p y$ of 39.5 . py= $\mathrm{px} /(\mathrm{px}+\mathrm{oliv}) * 100$ in wt.\%.

Figure 2. Aggregate melt fraction as a function of the experimental temperature in batch (Collinet and Grove, 2020a) and incremental melting experiments (this study; IW -1.4/-1.7). The melt productivity is low following the extraction of $15 \mathrm{wt} . \%$ melt (plag-out temperature).

Figure 3. Composition of low Ca pyroxene (LCP) as a function of the temperature in batch melting experiments (shaded areas; Collinet and Grove, 2020a) and incremental melting experiments (this study). (a) ordinary chondritic compositions. (b) CI chondritic compositions.

Figure 4. Composition (a-b) and fraction of pyroxene (c-d) as a function of the Fo content in olivine in batch and incremental melting experiments of ordinary (a-c) and CI (b-d) chondritic compositions. The Fo content in olivine and $p y$ increase with decreasing $f \mathrm{O}_{2}$. From $\mathrm{Fo}_{75}$ (IW -1.3) to $\mathrm{Fo}_{95}$ (IW -2.5), $\sim 12$ wt.\% Fe metal is produced (Figure S1). Wo content and $p y$ decrease with increasing aggregate melt fraction (colored bar). The lines represent the modal and chemical compositions of residues for a given degree of melting (Collinet and Grove, 2020b). 
Figure 5. Backscattered images of a subset of the ureilites analyzed for this study. See text for detail. All samples display reduction rims in olivine. Pyroxene is almost completely "smelted" in NWA 11755 (e). It displays a coarse porosity in the FeO-poor area and a fine porosity in the FeOrich area. MIL 090076 displays a similar texture but the pyroxene cores are homogeneous and free of porosity (f). NWA 11754 is characteristic of the "Hughes cluster" (d).

Figure 6. Composition (Wo content) and fraction of pyroxene ( $p y)$ as a function of the Fo content in olivine in ureilites. All X-ray maps used to calculate the modal compositions are available in the supplementary material. Leaving out the Hughes cluster samples and the anomalous sample MET 01083, ureilites form of similar trend of increasing py with Fo (dotted line, equation $\mathrm{R}^{2}=0.74$ ). The solid lines (b) and shaded areas (a) represent the experimental trends of Fig. 4: CI and CI residues (CIR1-3, light gray) and LL and LL residues (LLR1-2, dark gray).

Figure 7. Calibration of the $\mathrm{D}_{\mathrm{Cr}}^{\text {oliv }}$ - LCP thermometer. (a-b) different temperature dependence of the Cr partition coefficients between olivine (a) or low $\mathrm{Ca}$ pyroxene (b) and silicate melt in batch melting experiments of a CI composition $\left(f \mathrm{O}_{2}\right.$ : IW $-1.3 /-2.2$; Collinet and Grove, 2020a). (c-d) Linear relationship between the $\mathrm{D}_{\mathrm{Cr}}^{\mathrm{oliv}}-\mathrm{LCP}$ and the experimental temperature of 60 charges with various bulk compositions (supplementary material and see text for detail). The linear relationship is used as a simple mineral thermometer that is independent of the $f \mathrm{O}_{2}$ (within the experimental range) and the Wo content.

Figure 8. Equilibration temperature $\left(\mathrm{T}_{\mathrm{E}}\right)$ of 76 ureilites as a function of the Fo content in olivine. All pigeonite-olivine ureilites have a higher $\mathrm{T}_{\mathrm{E}}$ (within $\pm 15^{\circ} \mathrm{C}$ uncertainty) than the minimum temperature of pigeonite stability of Sack and Ghiorso (1994). Two-pyroxene ureilites have a lower $\mathrm{T}_{\mathrm{E}}$ than pigeonite-olivine ureilites at a given Fo content in olivine (or $\mathrm{Mg} \#$ in pyroxene, see supplementary material). FeO-rich ureilites (e.g. $\mathrm{Fo}_{77-80}$ ) cover a large range of temperature (210 ${ }^{\circ} \mathrm{C}$ ). The temperature at which plagioclase melts out during batch melting of CI, H, LL and CM chondrites is shown for reference (green lines). Ureilites with $\mathrm{Fo}_{74-85}$ and $\mathrm{Fo}_{87-96}$ olivine are equilibrated at similar temperatures (mode at 1180-1220 ${ }^{\circ} \mathrm{C}$ ). Open symbols are considered "anomalous" in the sense that they do not represent simple melting residues. Key samples: [1] NWA 766, [2] MET 78008, [3] Y 74130, [4] RaS 517, [5-6] LEW 88774, [7] HaH 064, [8] NWA 7349, [9] LAP 02382, [10] Havero, [11] EET 96293, [12] FRO 90054, [13] EET 96314, [14] NWA 11754, [15] Hughes 009, [16] MIL 091004, [17] MET01083, [18] NWA 5555, [19-20] ALHA 82130, [21]ALHA 84136, [22] ALHA 82106, [23] MS-MU-012. See text and supplementary material for references.

Figure 9. (a) Concentration of $\mathrm{Al}_{2} \mathrm{O}_{3}$ in low-Ca pyroxene (orthopyroxene or pigeonite) as a function of the $\mathrm{D}_{\mathrm{Cr}}^{\mathrm{oliv}}-\mathrm{LCP}$ temperature (ureilites) or the experimental temperature $(+)$. See caption of Fig. 8 for sample numbers. (b) Same as (a) but only keeping FeO-rich pigeonite-olivine ureilites.

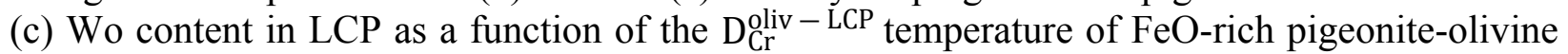
ureilites (same samples as in (b)). The $\mathrm{R}^{2}$ value in parentheses characterizes the linear regression 990 without the three open symbols. 
991 Figure 10. (a) Rare earth element concentrations of ureilites from Barrat et al. (2016). We excluded 992 one sample from group A (LAP 03587) and one from group B (LAR 04315) as their pyroxene is 993 thought to have been shock-melted (Warren and Rubin, 2010), a process that probably lowered the 994 bulk concentration of incompatible elements. (b-d) Bulk incompatible element concentrations 995 (leachates) as a function of the $\mathrm{D}_{\mathrm{Cr}}^{\mathrm{oliv}}-\mathrm{LCP}$ temperature. Incompatible element concentrations of 996 Group A samples correlate negatively with $\mathrm{T}_{\mathrm{E}}$. Yamato 790981 (open symbol) might represent an 997 anomalous low-temperature sample.

998

Figure 11. (a) Temperature dependence of Ca partition coefficients between olivine and liquid in 1001 CI, $\mathrm{H}$ and LL batch melting experiments (Collinet and Grove, 2020a). (b) Concentration of $\mathrm{CaO}$ in olivine as a function of the Fo content and the temperature (colored bar). (c) Estimated concentration of $\mathrm{CaO}$ in the "late-stage melts" that were last equilibrated with FeO-rich ureilites and comparison with batch melts (IW -1.3/-1.7) of H, LL, CI, CM and CV chondrites at the same temperature. The "late-stage melts" of ureilites show a CaO-enrichment trend that is characteristic of incremental melting. (d) pMELTS simulation (CI, IW -1.5) illustrating how instantaneous melts, produced by incremental melting (e.g. continuous melting, 1 and $3 \mathrm{wt} \%$ critical melt fraction) become $\mathrm{CaO}$-rich with increasing temperature relative to batch melts. Batch melt compositions and melting temperatures are not consistent with experiments in detail.

Figure 12. Rare earth element modeling using the data and the same overall approach as Barrat et al. (2016) but with the melting coefficients and phase proportions of Collinet and Grove (2020a). The blue field represents the "Group A" and the red field the "Group B" see Figure 10. Following Barrat et al. (2016), merrillite is stable in the residue and melts out simultaneously with plagioclase. (a) dynamic melting at IW -1.5 reproducing the REE patterns of FeO-rich ureilites, with a 0.02 critical melt fraction until the last increment, where either all the melt is removed (black lines) or 0.015 (75 wt.\% of the final melt fraction) is removed (blue lines). (b) same as (a) but with a pyroxene-rich starting composition (IW -2) and 0.001 of the final melt fraction (5 wt.\%) retained. (c) fractional melting. REE melting model results are non-unique, see supplementary material.

Figure 13. (a) Pressure of equilibration of ureilites assuming that the $f \mathrm{O}_{2}$ is primarily controlled by the $\mathrm{C}-\mathrm{CO}$ buffer. The pressure of equilibration $\left(\mathrm{P}_{\mathrm{C}-\mathrm{CO}}\right)$ is fixed by the Fo content of olivine of individual samples and their $\mathrm{D}_{\mathrm{Cr}}^{\text {oliv }}-\mathrm{LCP}$ temperature of equilibration ( $\mathrm{T}_{\mathrm{E}}$; Fig. S9). (b) If the actual pressure of equilibration of all ureilites is larger than $15 \mathrm{MPa}$, the $\mathrm{P}_{\mathrm{C}-\mathrm{CO}}$ of (a) is no longer relevant and the $f \mathrm{O}_{2}$ is not controlled by the C-CO buffer. The intrinsic $f \mathrm{O}_{2}$ of ureilites is variable (IW $1.3 /-2.5)$ and is higher than the $f \mathrm{O}_{2}$ of the C-CO buffer. Graphite is stable and there are no precise constraints on the pressure of equilibration $\left(\mathrm{P}_{\mathrm{E}}\right)$. The various $\mathrm{T}_{\mathrm{E}}$ of ureilites can still be interpreted as representing a "geotherm" (a temperature profile). Although the slope of the geotherm is unconstrained, ureilites with different Fo content in olivine but identical $\mathrm{T}_{\mathrm{E}}$ could be assumed to have equilibrated at the same pressure. 
1030 Figure 14. Summary: origin of ureilites and possible internal structure of the UPB. The large 1031 majority of ureilites, equilibrated at $1150-1280{ }^{\circ} \mathrm{C}$, represent the residual mantle of a chondritic 1032 planetesimal (green) from which $15-24 \mathrm{wt} . \%$ of silicate melt was incrementally extracted (pink). 1033 The diversity of ureilites in terms of $\mathrm{T}_{\mathrm{E}}$ and extent of melting suggests a vertical temperature 1034 gradient in the mantle. Ureilites equilibrated at higher temperature could have originated from 1035 deeper in the UPB. Because the $\mathrm{T}_{\mathrm{E}}$ of more oxidized ureilites (light green) and more reduced 1036 ureilites (dark green) overlap, the residual mantle of the UPB was heterogenous in terms of Mg\# 1037 (and intrinsic $f \mathrm{O}_{2}$, isotopic composition) but not stratified. The UPB melted incrementally. Alkali1038 rich melts (Collinet and Grove 2020a), and late-stage melts rich in $\mathrm{CaO}$ but poor in alkali were 1039 successively extracted from the melting residues. Late stage melts produced the anomalous low- $T$ 1040 ureilites $\left(1060-1170{ }^{\circ} \mathrm{C}\right)$ rich in augite, which represent cumulates or derive from melt-rock 1041 reactions in magma conduits (i.e. Hughes cluster samples). They were likely emplaced in a shallow 1042 region of the UPB. 


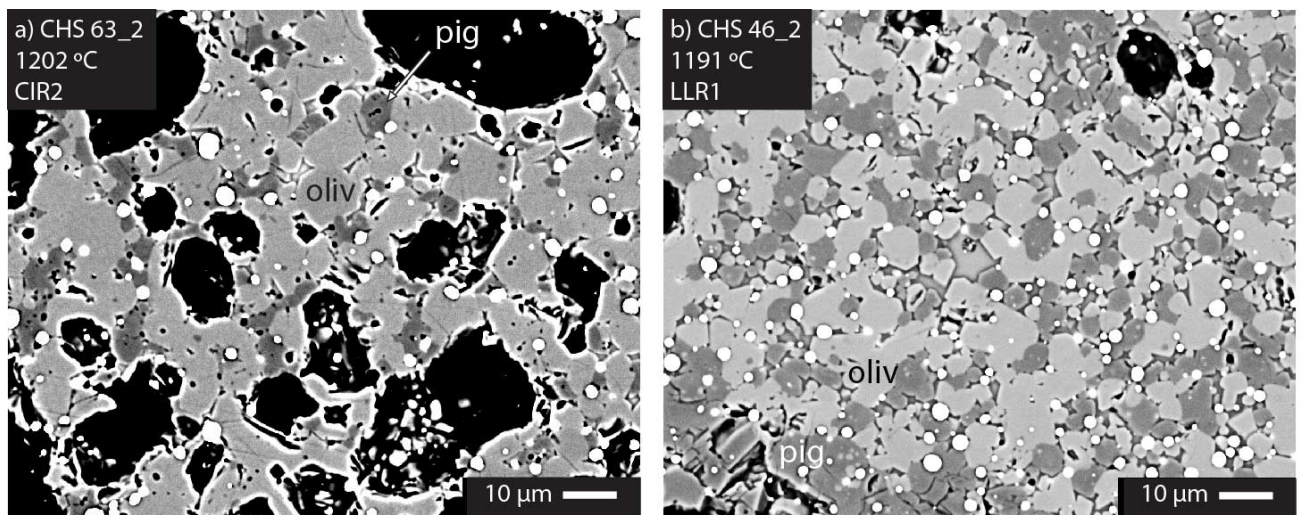

Figure 1. Backscattered images of experimental charges containing ureilite-like residues (olivine-pigeonitemetal). (a) CI residue with py of 21. (b) LL residue with py of 39.5. py $=p x /(p x+o l i v) * 100$ in wt.\%.

$247 \times 96 \mathrm{~mm}(150 \times 150 \mathrm{DPI})$ 


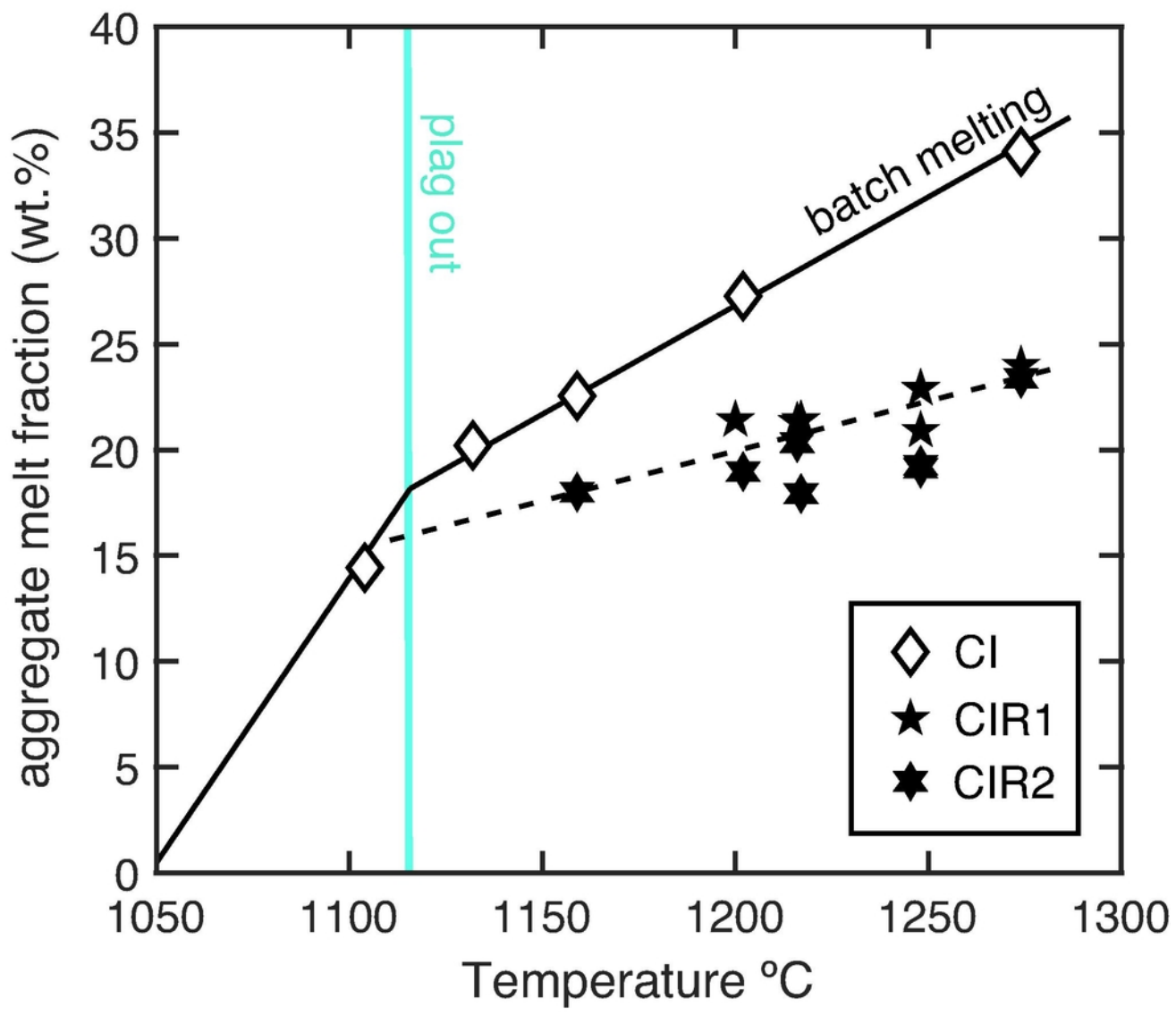

Figure 2. Aggregate melt fraction as a function of the experimental temperature in batch (Collinet and Grove, 2020a) and incremental melting experiments (this study; IW -1.4/-1.7). The melt productivity is low following the extraction of $15 \mathrm{wt} . \%$ melt (plag-out temperature).

$86 \times 75 \mathrm{~mm}(300 \times 300$ DPI $)$ 

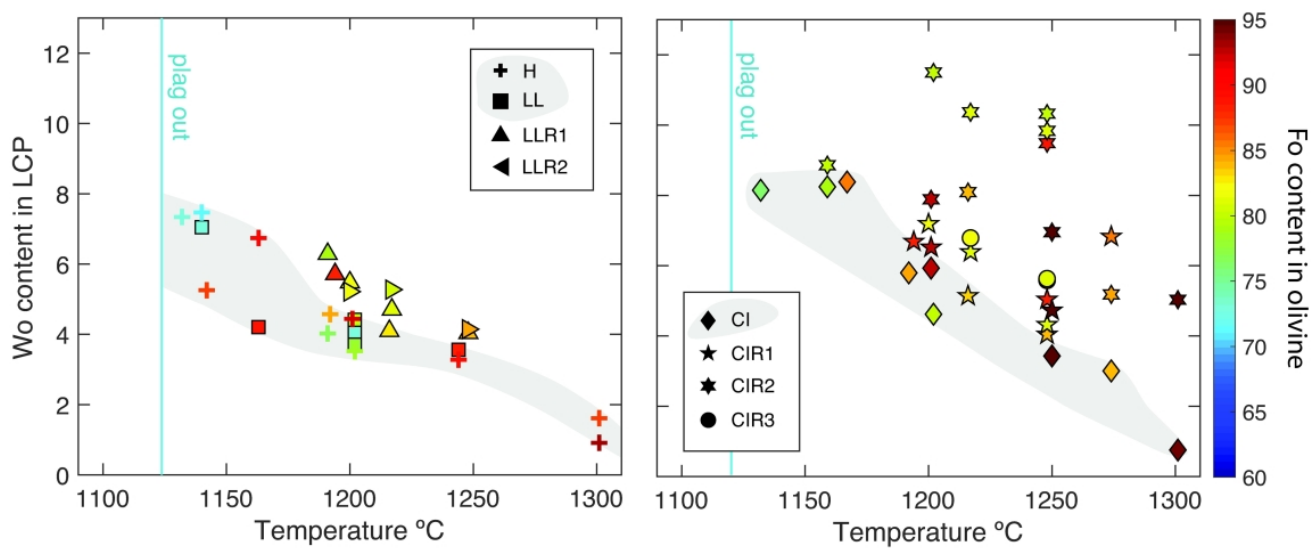

Figure 3. Composition of low Ca pyroxene (LCP) as a function of the temperature in batch melting experiments (shaded areas; Collinet and Grove, 2020a) and incremental melting experiments (this study). (a) ordinary chondritic compositions. (b) CI chondritic compositions.

$338 \times 141 \mathrm{~mm}(300 \times 300 \mathrm{DPI})$ 
Figure 4. Composition (a-b) and fraction of pyroxene (c-d) as a function of the Fo content in olivine in batch and incremental melting experiments of ordinary $(a-c)$ and $C I(b-d)$ chondritic compositions. The Fo content in olivine and py increase with decreasing fO2. From Fo75 (IW -1.3) to Fo95 (IW -2.5), 12 wt.\% Fe metal is produced (Figure S1). Wo content and py decrease with increasing aggregate melt fraction (colored bar). The lines represent the modal and chemical compositions of residues for a given degree of melting (Collinet and Grove, 2020b).

$$
311 \times 307 \mathrm{~mm} \text { ( } 300 \times 300 \text { DPI) }
$$



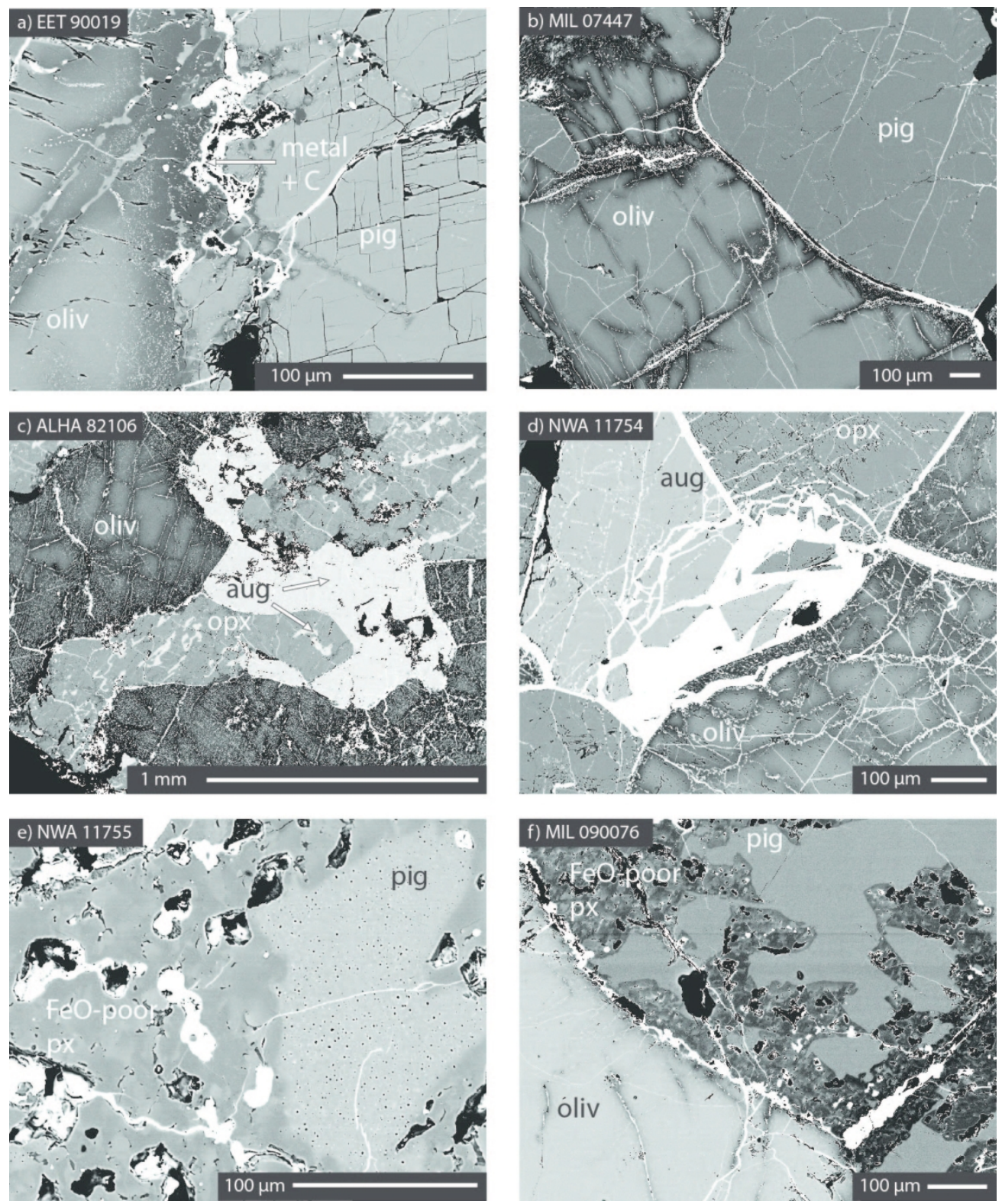

Figure 5. Backscattered images of a subset of the ureilites analyzed for this study. See text for detail. All samples display reduction rims in olivine. Pyroxene is almost completely "smelted" in NWA 11755 (e). It displays a coarse porosity in the FeO-poor area and a fine porosity in the FeO-rich area. MIL 090076 displays a similar texture but the pyroxene cores are homogeneous and free of porosity (f). NWA 11754 is characteristic of the "Hughes cluster" (d).

$248 \times 300 \mathrm{~mm}(150 \times 150 \mathrm{DPI})$ 


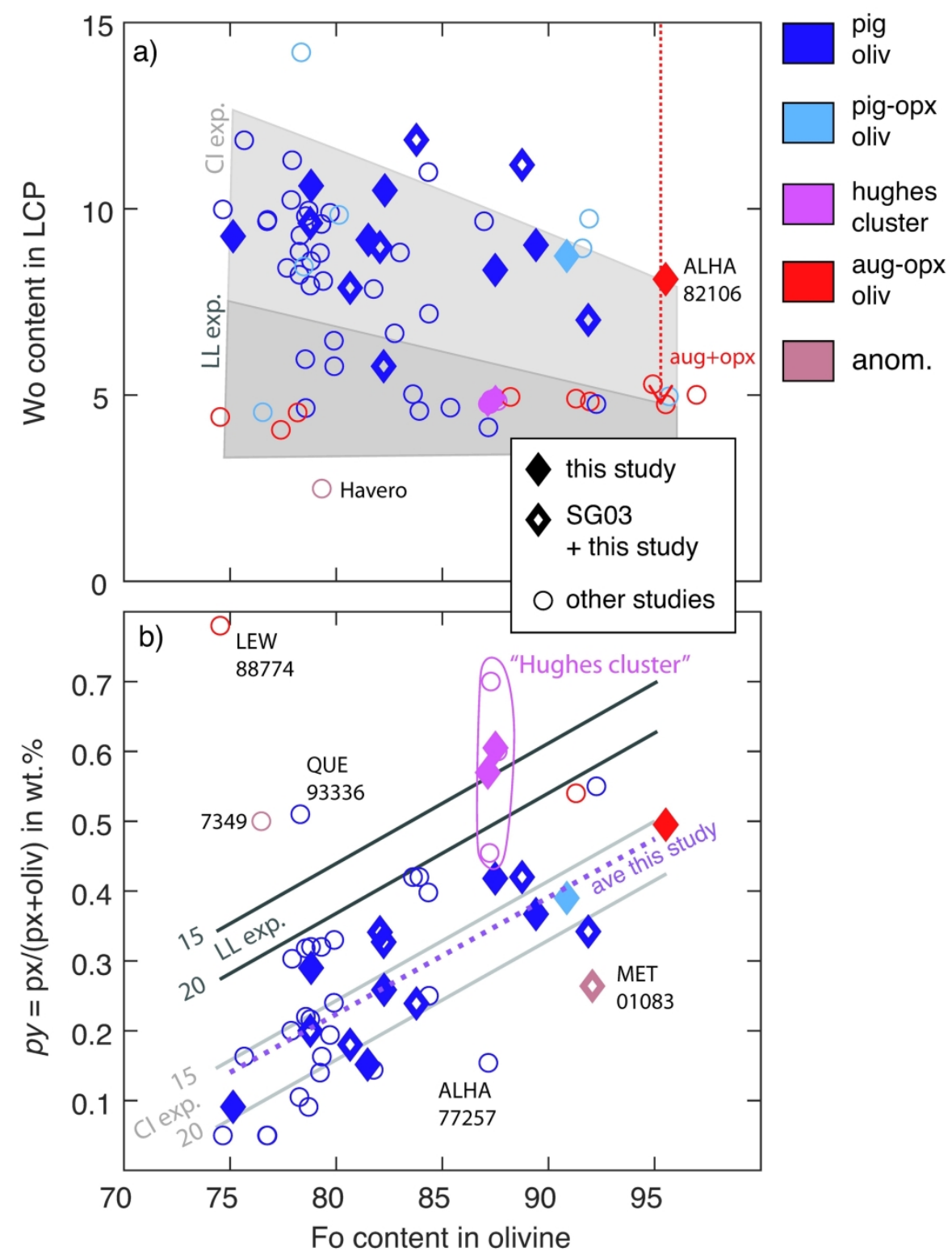

Figure 6. Composition (Wo content) and fraction of pyroxene (py) as a function of the Fo content in olivine in ureilites. All X-ray maps used to calculate the modal compositions are available in the supplementary material. Leaving out the Hughes cluster samples and the anomalous sample MET 01083, ureilites form of similar trend of increasing py with Fo (dotted line, equation R2 $=0.74$ ). The solid lines (b) and shaded areas (a) represent the experimental trends of Fig. 4: CI and CI residues (CIR1-3, light gray) and LL and LL residues (LLR1-2, dark gray).

$206 \times 272 \mathrm{~mm}(300 \times 300 \mathrm{DPI})$ 

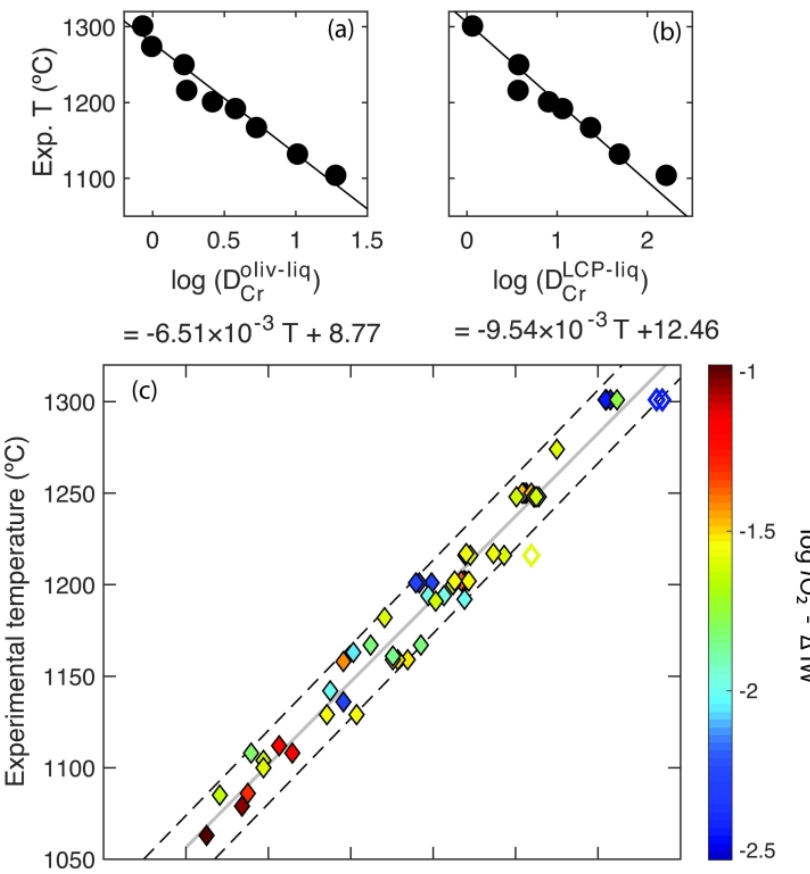

$\overline{0}$
0
0
1
0
$\vdots$

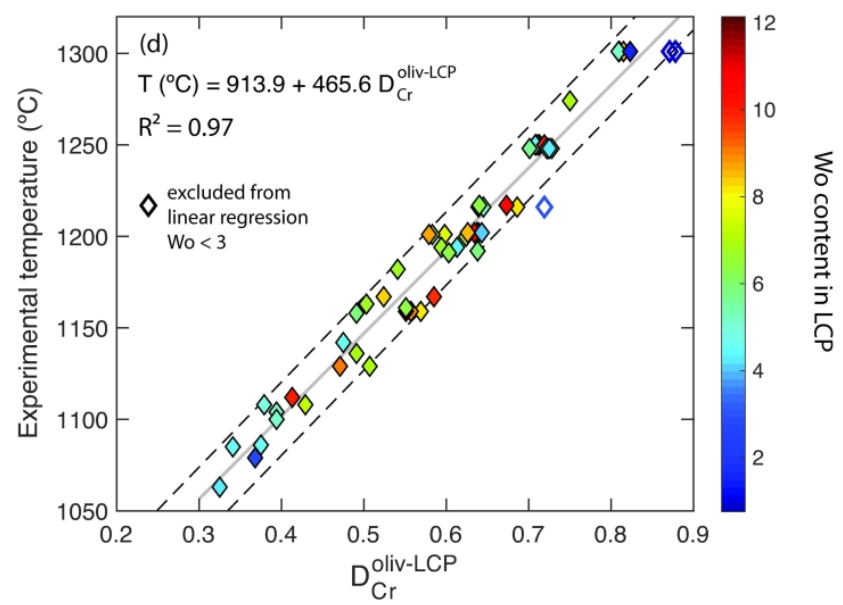

Figure 7. Calibration of the $\mathrm{D}_{-\mathrm{Cr}^{\wedge}}$ (oliv-LCP) thermometer. (a-b) different temperature dependence of the $\mathrm{Cr}$ partition coefficients between olivine (a) or low Ca pyroxene (b) and silicate melt in batch melting experiments of a CI composition (fO2: IW -1.3/-2.2; Collinet and Grove, 2020a). (c-d) Linear relationship between the $\mathrm{D}_{-} \mathrm{Cr}^{\wedge}$ (oliv-LCP) and the experimental temperature of 60 charges with various bulk compositions (supplementary material and see text for detail). The linear relationship is used as a simple mineral thermometer that is independent of the $\mathrm{fO} 2$ (within the experimental range) and the Wo content.

$202 \times 373 \mathrm{~mm}(300 \times 300 \mathrm{DPI})$ 


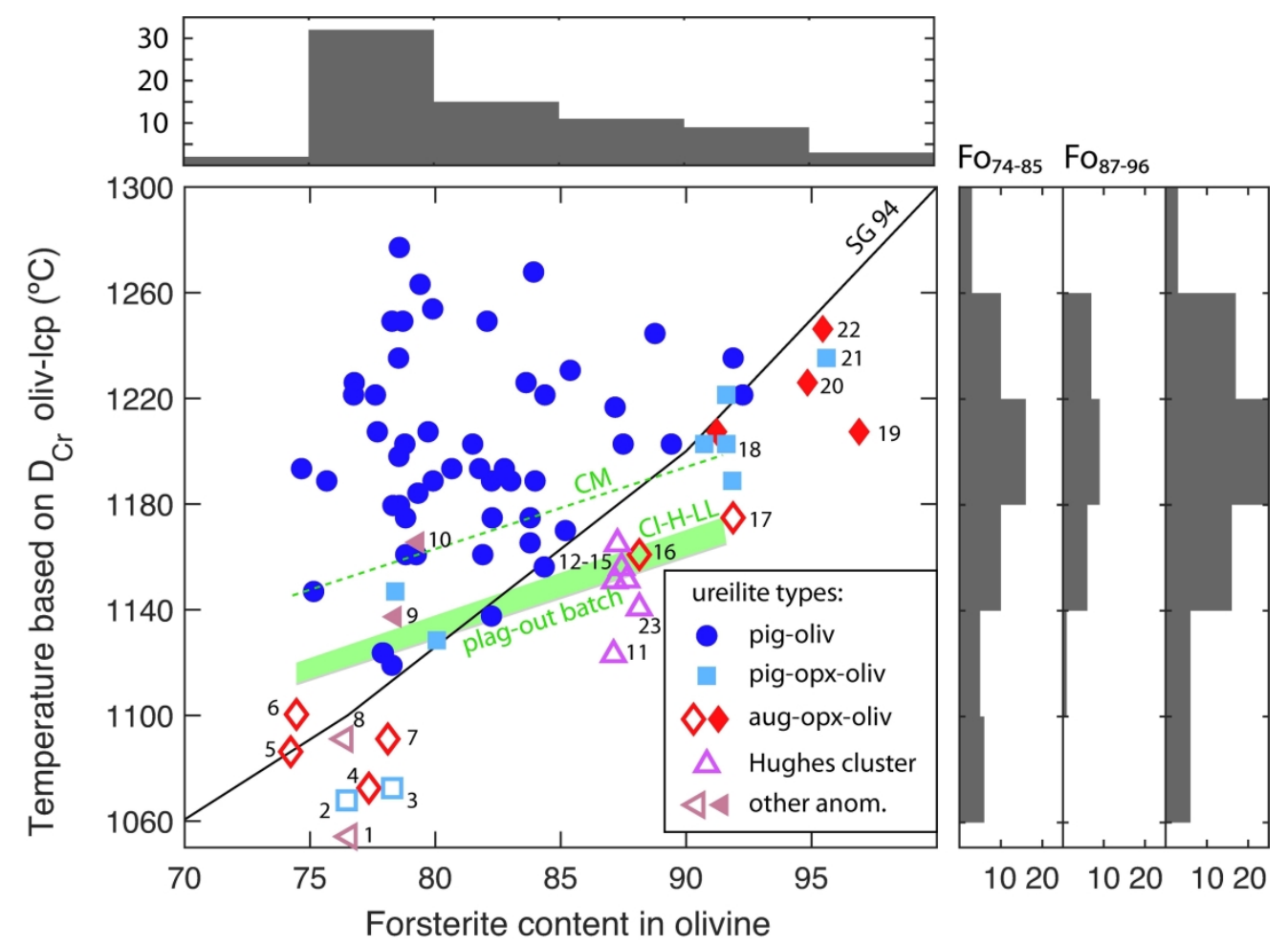

Figure 8. Equilibration temperature (TE) of 76 ureilites as a function of the Fo content in olivine. All pigeonite-olivine ureilites have a higher TE (within $\pm 15^{\circ} \mathrm{C}$ uncertainty) than the minimum temperature of pigeonite stability of Sack and Ghiorso (1994). Two-pyroxene ureilites have a lower TE than pigeoniteolivine ureilites at a given Fo content in olivine (or $\mathrm{Mg} \#$ in pyroxene, see supplementary material). FeO-rich ureilites (e.g. Fo $77-80$ ) cover a large range of temperature $\left(210^{\circ} \mathrm{C}\right.$ ). The temperature at which plagioclase melts out during batch melting of CI, H, LL and CM chondrites is shown for reference (green lines). Ureilites with Fo74-85 and Fo87-96 olivine are equilibrated at similar temperatures (mode at 1180-1220 ${ }^{\circ} \mathrm{C}$ ). Open symbols are considered "anomalous" in the sense that they do not represent simple melting residues. Key samples: [1] NWA 766, [2] MET 78008, [3] Y 74130, [4] RaS 517, [5-6] LEW 88774, [7] HaH 064, [8] NWA 7349, [9] LAP 02382, [10] Havero, [11] EET 96293, [12] FRO 90054, [13] EET 96314, [14] NWA 11754, [15] Hughes 009, [16] MIL 091004, [17] MET01083, [18] NWA 5555, [19-20] ALHA 82130, [21] ALHA 84136, [22] ALHA 82106, [23] MS-MU-012. See text and supplementary material for references. 

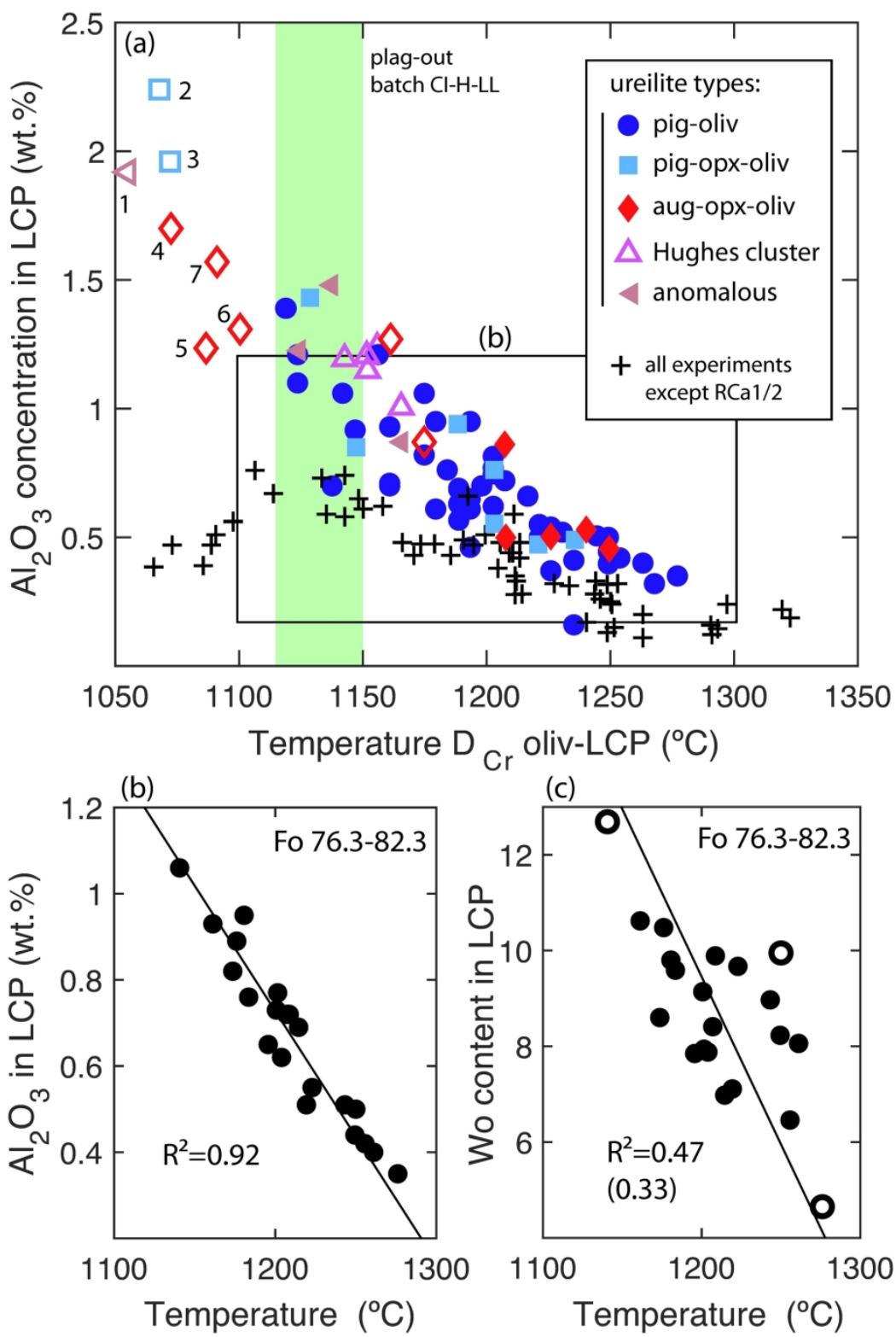

Figure 9. (a) Concentration of Al2O3 in low-Ca pyroxene (orthopyroxene or pigeonite) as a function of the D_ $\mathrm{Cr}^{\wedge}$ (oliv-LCP) temperature (ureilites) or the experimental temperature $(+)$. See caption of Fig. 8 for sample numbers. (b) Same as (a) but only keeping FeO-rich pigeonite-olivine ureilites. (c) Wo content in LCP as a function of the $D_{-} \mathrm{Cr}^{\wedge}$ (oliv-LCP) temperature of FeO-rich pigeonite-olivine ureilites (same samples as in (b)). The R2 value in parentheses characterizes the linear regression without the three open symbols.

$$
164 \times 244 \mathrm{~mm}(300 \times 300 \mathrm{DPI})
$$



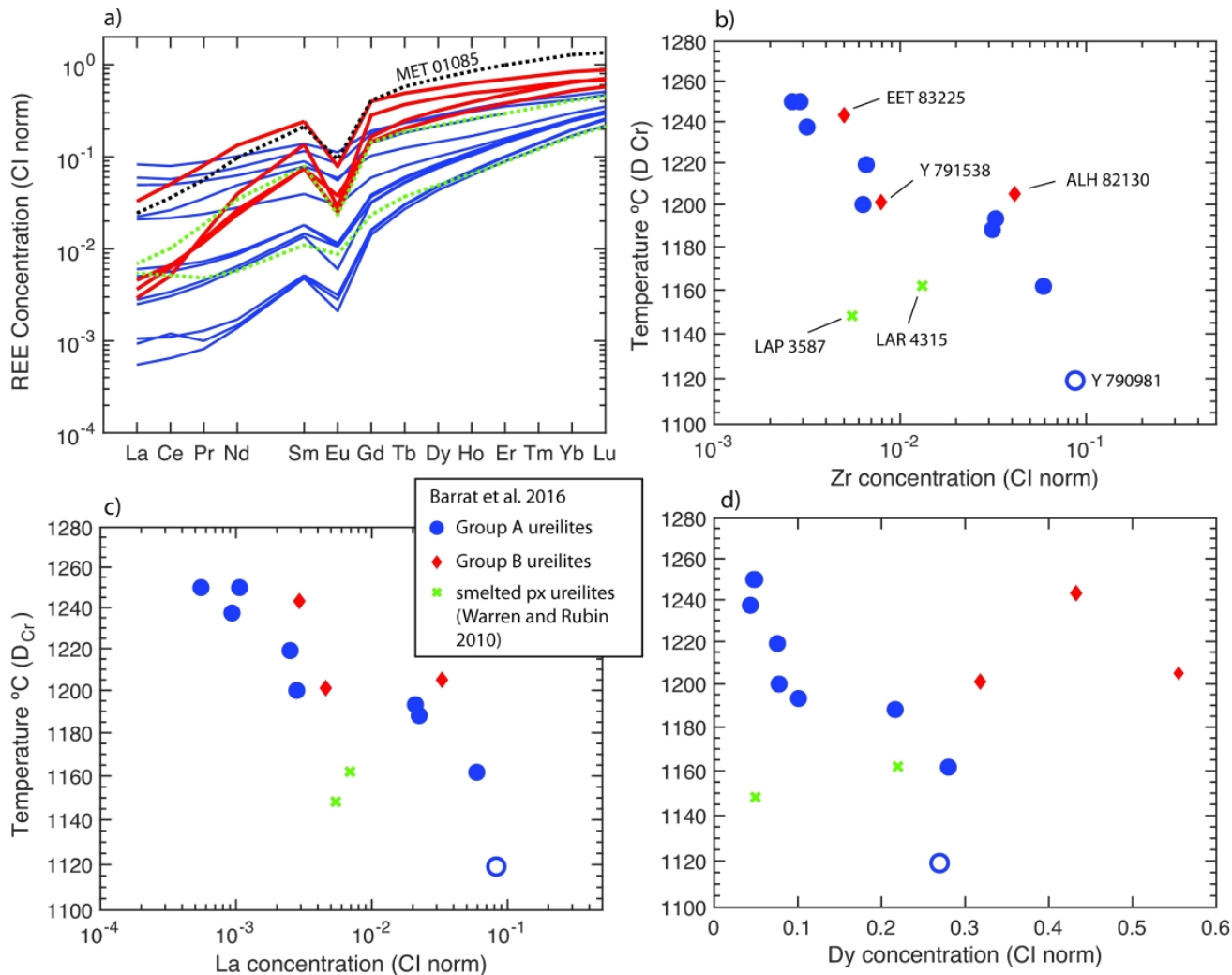

Figure 10. (a) Rare earth element concentrations of ureilites from Barrat et al. (2016). We excluded one sample from group A (LAP 03587) and one from group B (LAR 04315) as their pyroxene is thought to have been shock-melted (Warren and Rubin, 2010), a process that probably lowered the bulk concentration of incompatible elements. (b-d) Bulk incompatible element concentrations (leachates) as a function of the D_ $\mathrm{Cr}^{\wedge}$ (oliv-LCP) temperature. Incompatible element concentrations of Group A samples correlate negatively with TE. Yamato 790981 (open symbol) might represent an anomalous low-temperature sample.

$372 \times 298 \mathrm{~mm}(300 \times 300 \mathrm{DPI})$ 
(a)

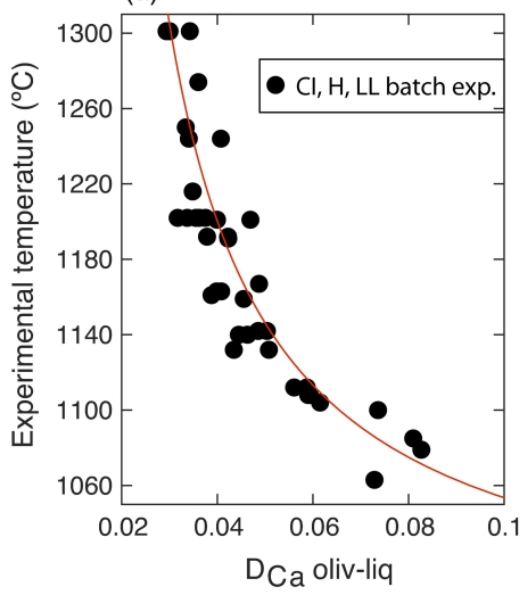

$\mathrm{CaO}$ concentration in oliv (wt.\%)

(b)

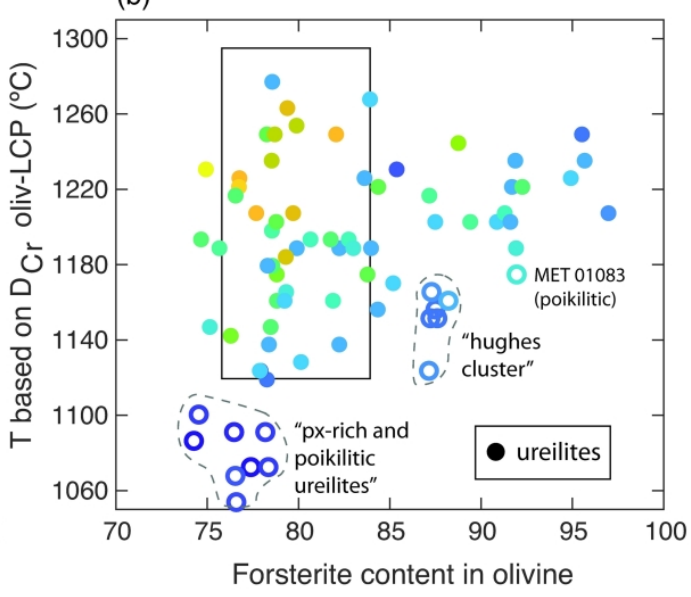

(c)
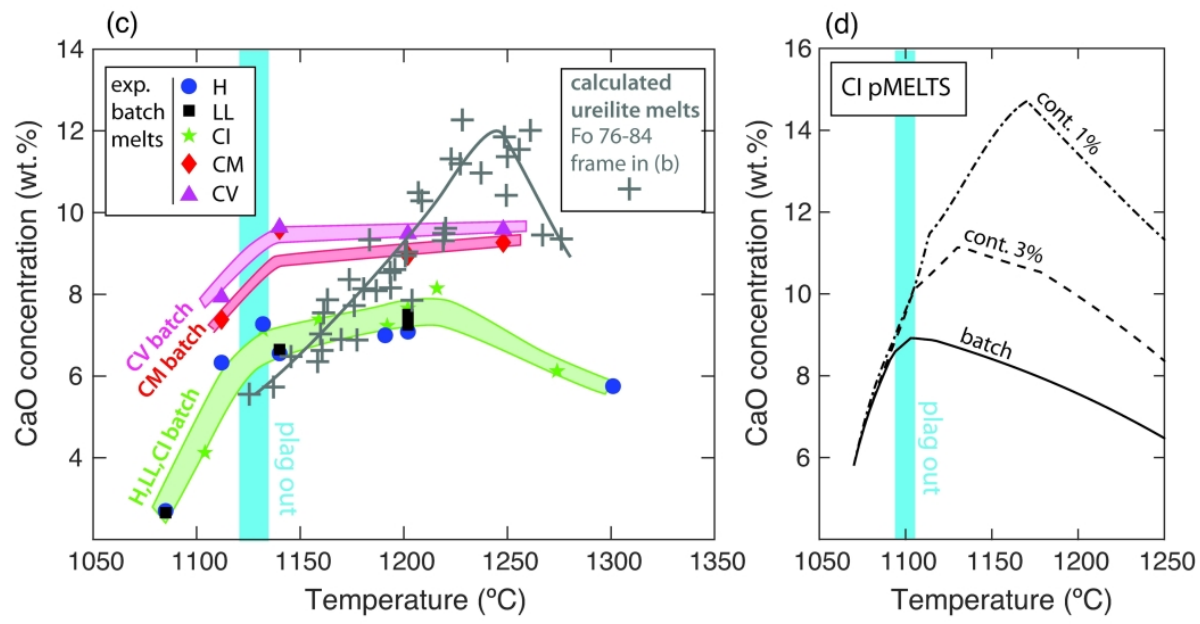

Figure 11. (a) Temperature dependence of Ca partition coefficients between olivine and liquid in $\mathrm{CI}, \mathrm{H}$ and LL batch melting experiments (Collinet and Grove, 2020a). (b) Concentration of $\mathrm{CaO}$ in olivine as a function of the Fo content and the temperature (colored bar). (c) Estimated concentration of $\mathrm{CaO}$ in the "late-stage melts" that were last equilibrated with FeO-rich ureilites and comparison with batch melts (IW -1.3/-1.7) of $\mathrm{H}, \mathrm{LL}, \mathrm{CI}, \mathrm{CM}$ and CV chondrites at the same temperature. The "late-stage melts" of ureilites show a CaOenrichment trend that is characteristic of incremental melting. (d) pMELTS simulation (CI, IW -1.5)

illustrating how instantaneous melts, produced by incremental melting (e.g. continuous melting, 1 and 3 wt.\% critical melt fraction) become CaO-rich with increasing temperature relative to batch melts. Batch melt compositions and melting temperatures are not consistent with experiments in detail.

$$
320 \times 340 \mathrm{~mm}(300 \times 300 \text { DPI })
$$




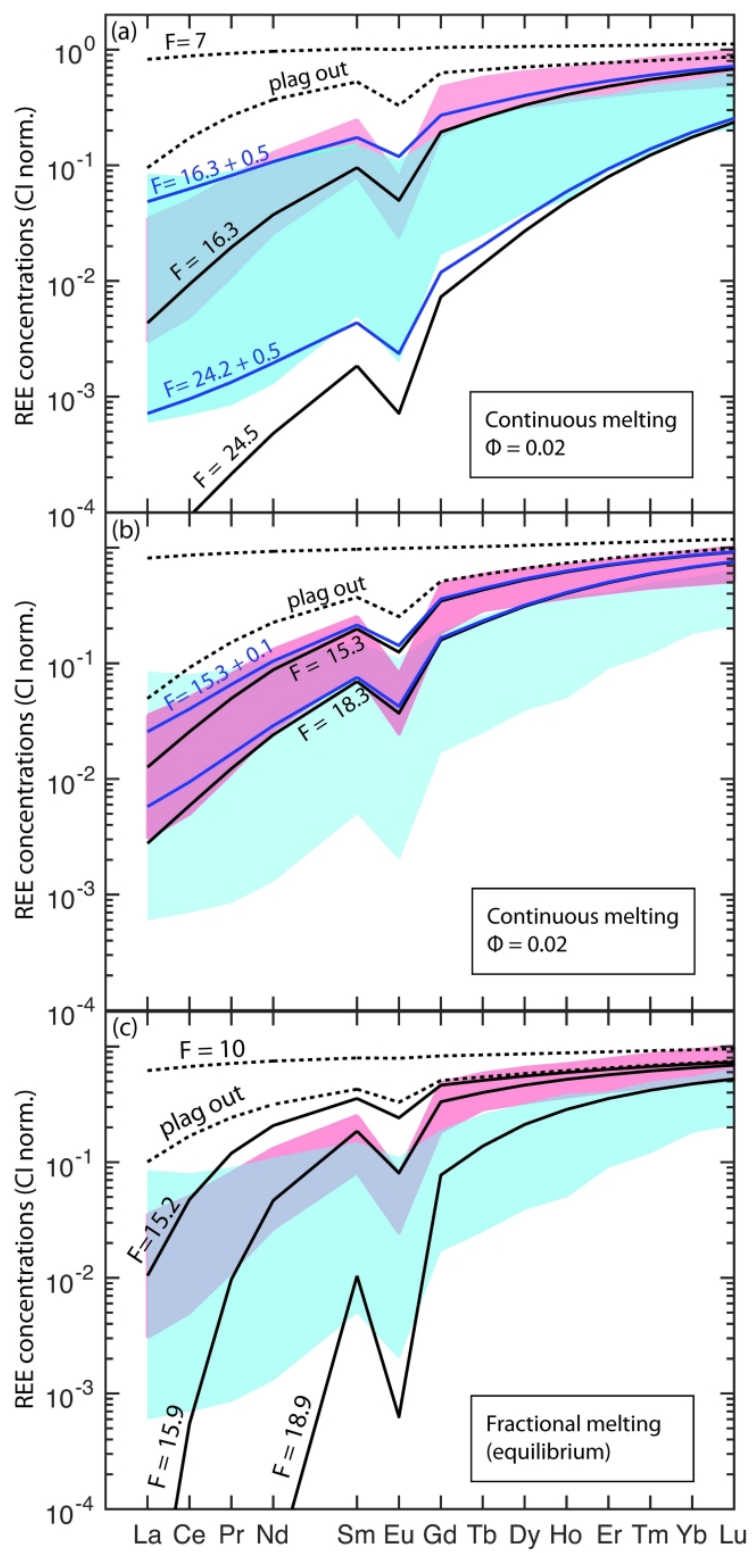

Figure 12. Rare earth element modeling using the data and the same overall approach as Barrat et al. (2016) but with the melting coefficients and phase proportions of Collinet and Grove (2020a). The blue field represents the "Group A" and the red field the "Group B" see Figure 10. Following Barrat et al. (2016), merrillite is stable in the residue and melts out simultaneously with plagioclase. (a) dynamic melting at IW 1.5 reproducing the REE patterns of FeO-rich ureilites, with a 0.02 critical melt fraction until the last increment, where either all the melt is removed (black lines) or 0.015 (75 wt.\% of the final melt fraction) is removed (blue lines). (b) same as (a) but with a pyroxene-rich starting composition (IW -2) and 0.001 of the final melt fraction ( $5 \mathrm{wt} . \%$ ) retained. (c) fractional melting. REE melting model results are non-unique, see supplementary material.

$179 \times 379 \mathrm{~mm}(300 \times 300 \mathrm{DPI})$ 
Figure 13. (a) Pressure of equilibration of ureilites assuming that the $\mathrm{fO} 2$ is primarily controlled by the C-CO buffer. The pressure of equilibration (PC-CO) is fixed by the Fo content of olivine of individual samples and their D_Cr^(oliv-LCP) temperature of equilibration (TE; Fig. S9). (b) If the actual pressure of equilibration of all ureilites is larger than $15 \mathrm{MPa}$, the PC-CO of (a) is no longer relevant and the fO2 is not controlled by the C-CO buffer. The intrinsic fO2 of ureilites is variable (IW -1.3/-2.5) and is higher than the fO2 of the C-CO buffer. Graphite is stable and there are no precise constraints on the pressure of equilibration (PE). The various TE of ureilites can still be interpreted as representing a "geotherm" (a temperature profile). Although the slope of the geotherm is unconstrained, ureilites with different Fo content in olivine but identical TE could be assumed to have equilibrated at the same pressure.

$167 \times 315 \mathrm{~mm}(300 \times 300$ DPI) 

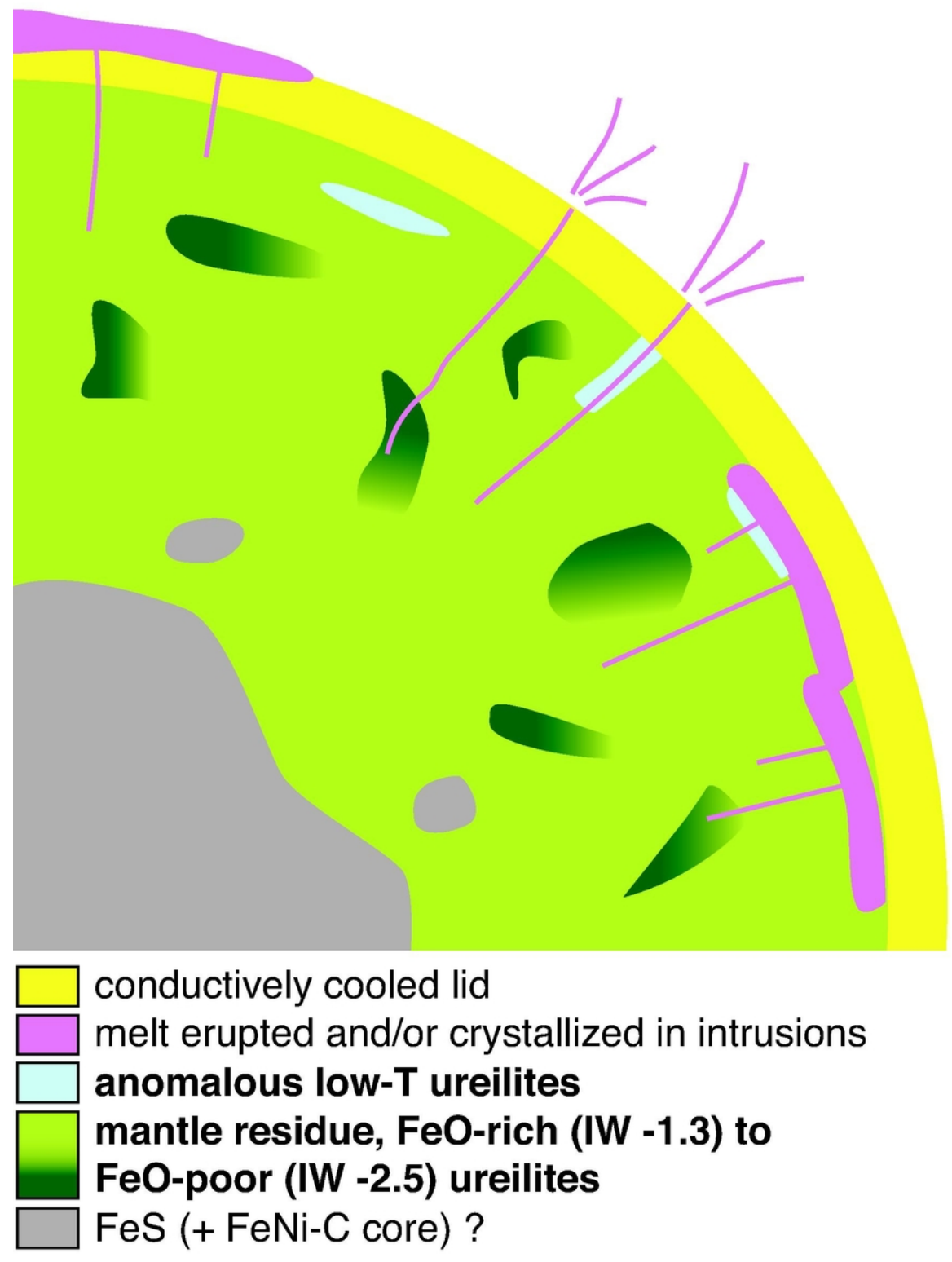

Figure 14. Summary: origin of ureilites and possible internal structure of the UPB. The large majority of ureilites, equilibrated at $1150-1280^{\circ} \mathrm{C}$, represent the residual mantle of a chondritic planetesimal (green) from which 15-24 wt.\% of silicate melt was incrementally extracted (pink). The diversity of ureilites in terms of TE and extent of melting suggests a vertical temperature gradient in the mantle. Ureilites equilibrated at higher temperature could have originated from deeper in the UPB. Because the TE of more oxidized ureilites

(light green) and more reduced ureilites (dark green) overlap, the residual mantle of the UPB was heterogenous in terms of $\mathrm{Mg} \#$ (and intrinsic fO2, isotopic composition) but not stratified. The UPB melted incrementally. Alkali-rich melts (Collinet and Grove 2020a), and late-stage melts rich in CaO but poor in alkali were successively extracted from the melting residues. Late stage melts produced the anomalous low$\mathrm{T}$ ureilites $\left(1060-1170^{\circ} \mathrm{C}\right)$ rich in augite, which represent cumulates or derive from melt-rock reactions in magma conduits (i.e. Hughes cluster samples). They were likely emplaced in a shallow region of the UPB. 
Table 1: summary of experimental conditions

\begin{tabular}{|c|c|c|c|c|c|c|c|c|c|c|c|}
\hline \multirow[t]{2}{*}{$\exp \#$} & \multirow{2}{*}{$\begin{array}{l}\mathrm{P}(\mathrm{CO}) \\
\mathrm{MPa}\end{array}$} & \multirow{2}{*}{$\begin{array}{l}\text { T int } \\
\text { oc } C\end{array}$} & \multirow{2}{*}{$\begin{array}{l}\log f O_{2} \\
\text { (CCO) }\end{array}$} & \multirow[t]{2}{*}{$\Delta \mathrm{IW}$} & \multirow[t]{2}{*}{$t(h)$} & \multirow{2}{*}{$\begin{array}{l}\Delta T^{*} \\
\text { oc }\end{array}$} & \multicolumn{5}{|c|}{ starting compositions per experiment } \\
\hline & & & & & & & 1 & 2 & 3 & 4 & 5 \\
\hline CHS 46 & 6.2 & 1191 & -13.7 & -1.61 & 72 & 20 & LLR1 & $H$ & & & \\
\hline CHS 47 & 6.6 & 1200 & -13.6 & -1.63 & 72 & 0 & CIR1 & LLR1 & LLR2 & & \\
\hline CHS 48 & 4.1 & 1194 & -14.0 & -1.98 & 72 & 0 & CIR1 & LLR1 & $H$ & & \\
\hline CHS 49 & 10.0 & 1248 & -13.0 & -1.62 & 24 & 0 & CIR1 & CIR3 & LLR1 & LLR2 & \\
\hline CHS 50 & 7.2 & 1248 & -13.3 & -1.89 & 27 & 0 & CIR1 & CIR2a & CIR3 & & \\
\hline CHS 51 & 8.1 & 1217 & -13.3 & -1.58 & 68 & 0 & CIR2a & CIR1 & CIR3 & LLR1 & LLR2 \\
\hline CHS 53 & 12.1 & 1248 & -12.8 & -1.47 & 46 & 0 & CIR2a & CIR1 & CIR3 & & \\
\hline CHS 63 & 9.1 & 1202 & -13.3 & -1.38 & 72 & 0 & $\mathrm{CIR} 2 \mathrm{~b}$ & $\mathrm{Cl}$ & $H$ & & \\
\hline CHS 65 & 3.1 & 1201 & -14.2 & -2.27 & 52 & 0 & $\mathrm{CIR} 2 \mathrm{~b}$ & CIR1 & $\mathrm{RCa}$ & $\mathrm{Cl}$ & $H$ \\
\hline CHS 66 & 3.4 & 1250 & -13.9 & -2.53 & 42 & 0 & CIR1 & $\mathrm{CIR} 2 \mathrm{~b}$ & $\mathrm{RCa}$ & $\mathrm{Cl}$ & \\
\hline CHS 67 & 13.3 & 1274 & -12.6 & -1.59 & 20 & 0 & $\mathrm{CIR} 2 \mathrm{~b}$ & CIR1 & $\mathrm{Cl}$ & & \\
\hline CHS 68 & 5.2 & 1159 & -12.5 & -1.53 & 100 & 0 & $\mathrm{CIR} 2 \mathrm{~b}$ & $\mathrm{RCa} 2$ & $\mathrm{RCa}$ & $\mathrm{Cl}$ & \\
\hline CHS 69 & 5.9 & 1301 & -13.2 & -2.44 & 9 & 0 & $\mathrm{RCa}$ & $\mathrm{RCa} 2$ & $\mathrm{CIR} 2 \mathrm{~b}$ & $H$ & $\mathrm{Cl}$ \\
\hline CHS 70 & 3.8 & 1205 & -14.2 & -1.84 & 96 & 0 & $\mathrm{RCa} 2$ & $\mathrm{RCa}$ & $\mathrm{Cl}$ & & \\
\hline CHS 71 & 7.9 & 1216 & -13.3 & -1.59 & 90 & 58 & LLR1 & CIR1 & $\mathrm{CIR} 2 \mathrm{~b}$ & $\mathrm{Cl}$ & \\
\hline
\end{tabular}

$\mathrm{fO}_{2}$ calculated based on the $\mathrm{CCO}$ buffer (extended formulation, French and Eugter, 1965) and expressed relative to

the IW buffer (Huebner 1971)

*T $($ o C) of initial $2 \mathrm{~h}$ step - final $\mathrm{T}(\mathrm{o}$ C); 0 = isothermal

Experimental charges with starting chondric compositions (italic) are described in Collinet and Grove (2020a) 
Table 2. Experimental starting compositions and bulk ureilite compositions

\begin{tabular}{|c|c|c|c|c|c|c|c|c|c|c|c|c|c|c|}
\hline & $\mathrm{Cl} *$ & CIR1 & CIR2a & CIR2b & CIR3 & PCA 82506 & North Haig & $\mathrm{H}^{*}$ & $\mathrm{LL}^{*}$ & LLR1 & LLR2 & DPD & RCa1 & $\mathrm{RCa} 2$ \\
\hline$F=$ & & 11 & 15.5 & 15.5 & 19.5 & mmict & (pmict) & & & 8.5 & 16 & mmict & n.a. & n.a. \\
\hline $\mathrm{SiO}_{2}$ & 40.8 & 39.7 & 37.1 & 38.1 & 38.3 & 42.0 & 40.3 & 37.6 & 43.5 & 41.6 & 40.3 & 41.8 & 37.8 & 41.5 \\
\hline $\mathrm{TiO}_{2}$ & 0.13 & 0.09 & 0.07 & 0.05 & 0.05 & 0.04 & 0.09 & 0.12 & 0.12 & 0.09 & 0.05 & 0.09 & 0.07 & 0.06 \\
\hline $\mathrm{Al}_{2} \mathrm{O}_{3}$ & 2.86 & 1.15 & 0.65 & 0.37 & 0.38 & 0.10 & 0.20 & 2.22 & 2.44 & 1.20 & 0.39 & 0.37 & 0.85 & 1.26 \\
\hline $\mathrm{Cr}_{2} \mathrm{O}_{3}$ & 0.69 & 0.60 & 0.79 & 0.60 & 0.62 & 0.82 & 0.73 & 0.51 & 0.59 & 0.63 & 0.65 & 0.81 & 0.65 & 0.88 \\
\hline $\mathrm{FeO}$ & 21.8 & 22.4 & 24.6 & 22.7 & 23.3 & 19.2 & 18.4 & 30.8 & 21.9 & 23.5 & 24.5 & 21.2 & 21.5 & 19.3 \\
\hline $\mathrm{MnO}$ & 0.44 & 0.36 & 0.36 & 0.36 & 0.37 & 0.41 & 0.44 & 0.31 & 0.36 & 0.38 & 0.39 & 0.36 & 0.34 & 0.30 \\
\hline $\mathrm{MgO}$ & 28.2 & 32.1 & 32.4 & 34.2 & 34.1 & 36.3 & 37.9 & 23.8 & 26.8 & 28.8 & 30.7 & 33.2 & 33.9 & 30.4 \\
\hline $\mathrm{CaO}$ & 2.30 & 1.87 & 1.99 & 2.00 & 1.34 & 1.00 & 1.38 & 1.78 & 2.11 & 1.96 & 1.41 & 1.54 & 3.58 & 5.14 \\
\hline $\mathrm{Na}_{2} \mathrm{O}$ & 1.20 & 0.54 & 0.26 & 0.24 & 0.25 & 0.03 & 0.09 & 0.89 & 0.99 & 0.56 & 0.26 & 0.07 & 0.23 & 0.21 \\
\hline $\mathrm{K}_{2} \mathrm{O}$ & 0.12 & 0.03 & 0.00 & 0.01 & 0.01 & 0.01 & 0.03 & 0.10 & 0.10 & 0.03 & 0.01 & 0.03 & 0.05 & 0.08 \\
\hline $\mathrm{P}_{2} \mathrm{O}_{5}$ & 0.39 & 0.20 & 0.32 & 0.19 & 0.19 & 0.04 & 0.23 & 0.26 & 0.22 & 0.21 & 0.20 & 0.21 & 0.18 & 0.16 \\
\hline $\mathrm{NiO}$ & 1.13 & 1.04 & 1.31 & 1.10 & 1.12 & 0.10 & 0.15 & 1.48 & 1.01 & 1.09 & 1.18 & 0.32 & 1.04 & 0.93 \\
\hline $\mathrm{Mg} / \mathrm{Si}$ & 1.03 & 1.21 & 1.30 & 1.34 & 1.33 & 1.29 & 1.40 & 0.94 & 0.92 & 1.03 & 1.14 & 1.18 & 1.33 & 1.09 \\
\hline$(\mathrm{Ca} / \mathrm{Mg})_{\mathrm{cl}}$ & 1.01 & 0.72 & 0.76 & 0.73 & 0.49 & 0.34 & 0.45 & 0.93 & 0.98 & 0.84 & 0.57 & 0.58 & 1.31 & 2.10 \\
\hline$(\mathrm{Al} / \mathrm{Mg})_{\mathrm{Cl}}$ & 1.00 & 0.35 & 0.20 & 0.11 & 0.11 & 0.03 & 0.05 & 0.92 & 0.90 & 0.41 & 0.13 & 0.11 & 0.25 & 0.41 \\
\hline Mg\# & 69.7 & 71.9 & 70.1 & 72.9 & 72.3 & 77.1 & 78.6 & 57.9 & 68.6 & 68.7 & 69.1 & 73.6 & 73.8 & 73.8 \\
\hline
\end{tabular}

*Average chondritic starting compositions of Lodders and Fegley (1998), renormalized without FeS or volatile elements;

starting compositions of batch melting experiments (Collinet and Grove, 2020a)

$\mathrm{F}=$ estimated melt fraction extracted from residues relative to chondritic composition $\mathrm{Cl}$ and $\mathrm{LL}$, respectively

mmict and pmcit = bulk composition of monomict and polymict ureilites from Jarosewich (2006), DPD: Dingo Pup Donga 
Table 3. Mineralogy of ureilites analyzed for this study

\begin{tabular}{|c|c|c|c|c|c|c|c|c|c|c|c|c|c|}
\hline & \multirow[t]{2}{*}{ py } & \multirow[t]{2}{*}{$\mathrm{px}_{2} / \mathrm{px}_{\text {tot }}$} & \multicolumn{3}{|l|}{ oliv } & \multicolumn{3}{|c|}{$\mathrm{px}_{1}(\mathrm{LCP})$} & \multicolumn{3}{|c|}{$\mathrm{px}_{2}$ (aug or opx) } & \multicolumn{2}{|c|}{ chromite } \\
\hline & & & Fo & $\mathrm{Cr}_{2} \mathrm{O}_{3}$ & $\mathrm{CaO}$ & Wo & $\mathrm{Cr}_{2} \mathrm{O}_{3}$ & $\mathrm{Al}_{2} \mathrm{O}_{3}$ & Wo & $\mathrm{Cr}_{2} \mathrm{O}_{3}$ & $\mathrm{Al}_{2} \mathrm{O}_{3}$ & Fe\# & $\mathrm{Cr} \#$ \\
\hline \multicolumn{14}{|l|}{ Antartic } \\
\hline LAP 03721 & 9.1 & & 75.1 & 0.61 & 0.32 & 9.3 & 1.22 & 0.92 & & & & & \\
\hline EET 90019 & 36.7 & & 89.4 & 0.64 & 0.34 & 9.0 & 1.04 & 0.81 & & & & & \\
\hline ALHA 82106 & 49.5 & 19.0 & 95.5 & 0.57 & 0.28 & 4.8 & 0.80 & 0.46 & 36.1 & 0.87 & 0.83 & & \\
\hline MIL 090076 & 29.0 & & 78.8 & 0.72 & 0.35 & 10.6 & 1.36 & 0.93 & & & & & \\
\hline EET 96293 & 57.0 & 3.5 & 87.1 & 0.48 & 0.29 & 4.8 & 1.07 & 1.22 & 37.2 & 1.33 & 1.87 & & \\
\hline DOM 08012 & & & 77.6 & 0.71 & 0.36 & 7.1 & 1.08 & 0.51 & & & & & \\
\hline EET 96042 & 15.1 & & 81.5 & 0.84 & 0.36 & 9.1 & 1.37 & 0.73 & & & & & \\
\hline MIL 07447 & 25.6 & & 82.2 & 0.71 & 0.34 & 10.5 & 1.25 & 0.89 & & & & 0.48 & 0.77 \\
\hline \multicolumn{14}{|c|}{ Northwest Africa } \\
\hline NWA 5555 & 39.0 & 21.1 & 90.9 & 0.64 & 0.31 & 8.7 & 1.03 & 0.55 & 4.8 & 0.95 & 0.57 & & \\
\hline NWA 4852 & 41.8 & & 87.5 & 0.64 & 0.31 & 8.4 & 1.04 & 0.75 & & & & & \\
\hline NWA 11754 & 60.5 & 33.6 & 87.5 & 0.51 & 0.28 & 4.9 & 0.98 & 1.23 & 36.5 & 1.19 & 1.91 & & \\
\hline NWA 11755 & & & 78.3 & 0.73 & 0.36 & 8.2 & 1.01 & 0.44 & & & & & \\
\hline
\end{tabular}

py is the ratio (pyroxene total)/(pyroxene total + olivine)*100, wt.\% percent pyroxene relative to olivine;

calculated from modal composition (X-ray maps) and phase densities

$\mathrm{px}_{2} / \mathrm{px}_{\text {tot }}$ is the ratio $\mathrm{px}_{2} /\left(\mathrm{px}_{1}+\mathrm{px}_{2}\right)$

for full EPMA analyses and analytical uncertainties, see Table S2 
Table 4. Average composition of melt extracted

\begin{tabular}{|c|c|c|c|}
\hline & 1 & 2 & \\
\hline & 1104 o C & 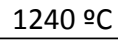 & \\
\hline $\mathrm{SiO}_{2}$ & 62.44 & 55.7 & by diff \\
\hline $\mathrm{TiO}_{2}$ & 0.52 & 0.3 & \pm 0.1 \\
\hline $\mathrm{Al}_{2} \mathrm{O}_{3}$ & 15.99 & 10 & \pm 2 \\
\hline $\mathrm{Cr}_{2} \mathrm{O}_{3}$ & 0.09 & 0.65 & \pm 0.15 \\
\hline $\mathrm{FeO}$ & 5.05 & 12.1 & \pm 1.5 \\
\hline $\mathrm{MnO}$ & 0.17 & 0.55 & \pm 0.10 \\
\hline MgO & 3.09 & 8 & \pm 1 \\
\hline $\mathrm{CaO}$ & 4.13 & 11.5 & \pm 1.0 \\
\hline $\mathrm{Na}_{2} \mathrm{O}$ & 6.78 & 1 & \pm 1 \\
\hline $\mathrm{K}_{2} \mathrm{O}$ & 0.82 & 0.05 & \pm 0.05 \\
\hline $\mathrm{P}_{2} \mathrm{O}_{5}$ & 0.86 & 0.1 & \pm 0.1 \\
\hline
\end{tabular}

1 Aggregate melt extracted immediately

prior to plagioclase exhaustion (Collinet and Grove, 2020a)

2 Average composition of "late-stage" melt. $\mathrm{SiO}_{2}$ calculated by

difference; see text for detail. 


\title{
Incremental melting in the ureilite parent body: initial composition, melting temperatures and melt compositions
}

\author{
Max Collinet* and Timothy L. Grove \\ Massachusetts Institute of Technology \\ Department of Earth, Atmospheric and Planetary Sciences \\ 77 Massachusetts avenue, 02139, MA, USA
}

\section{Supplementary material}

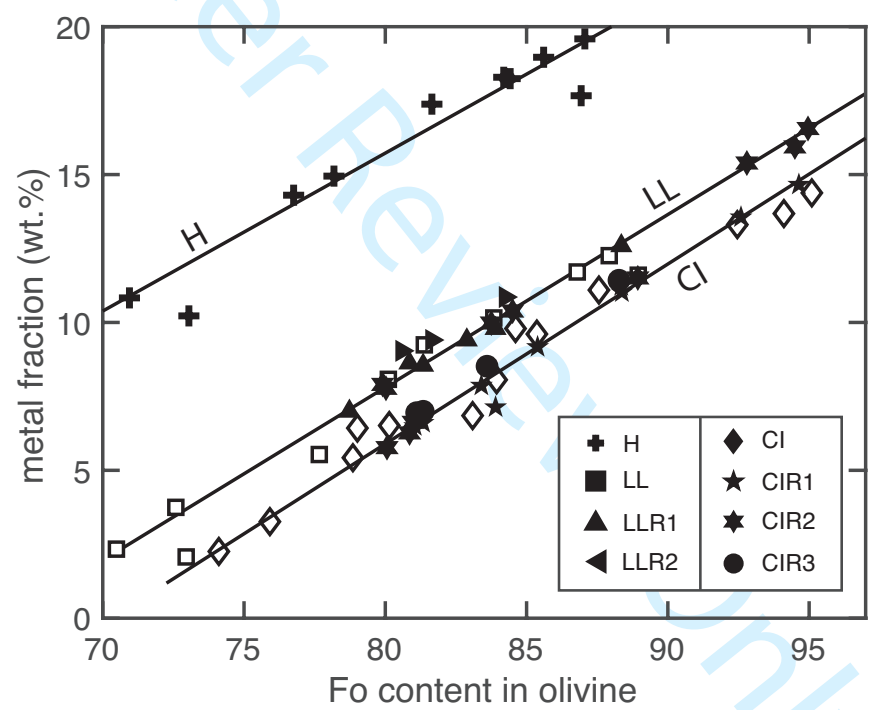

Figure S1. Metal fraction in experiments as a function of the forsterite content in olivine. 

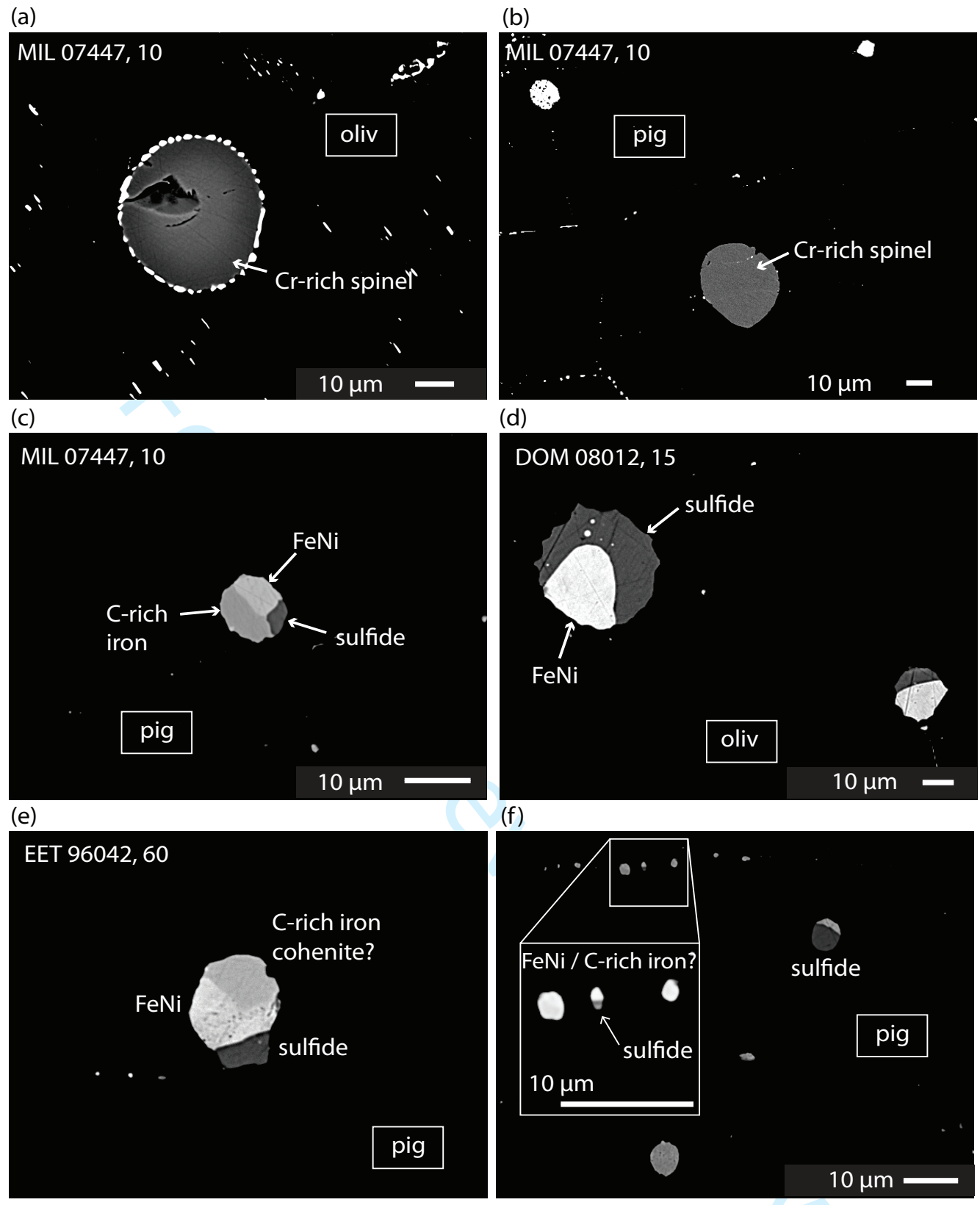

Figure S2. (a) zoned chromite inclusion in olivine with metal blebs surrounding the outer Mg-rich rims, indicative of "disequilibrium smelting". (b) a nearly identical chromite inclusion but in pigeonite instead of olivine is not zoned/smelted. The compositions at the centers of both chromite inclusions are identical. (c and e) Composite C-rich metal (cohenite?), FeNi C-poor metal and sulfide spherules (see (Goodrich et al., 2013)). (d) inclusions of immiscible sulfide and metal. Presumably both phases were liquid, which is consistent with $\mathrm{T}_{\mathrm{E}}$ of DOM $08012\left(1220^{\circ} \mathrm{C}, 70^{\circ} \mathrm{C}\right.$ above the FeC eutectic). (f) smaller inclusions in MIL 07447. Even the trails of $\mu \mathrm{m}$ to sub- $\mu \mathrm{m}$ inclusions in pigeonite can contain FeNi metal and sulfide. 

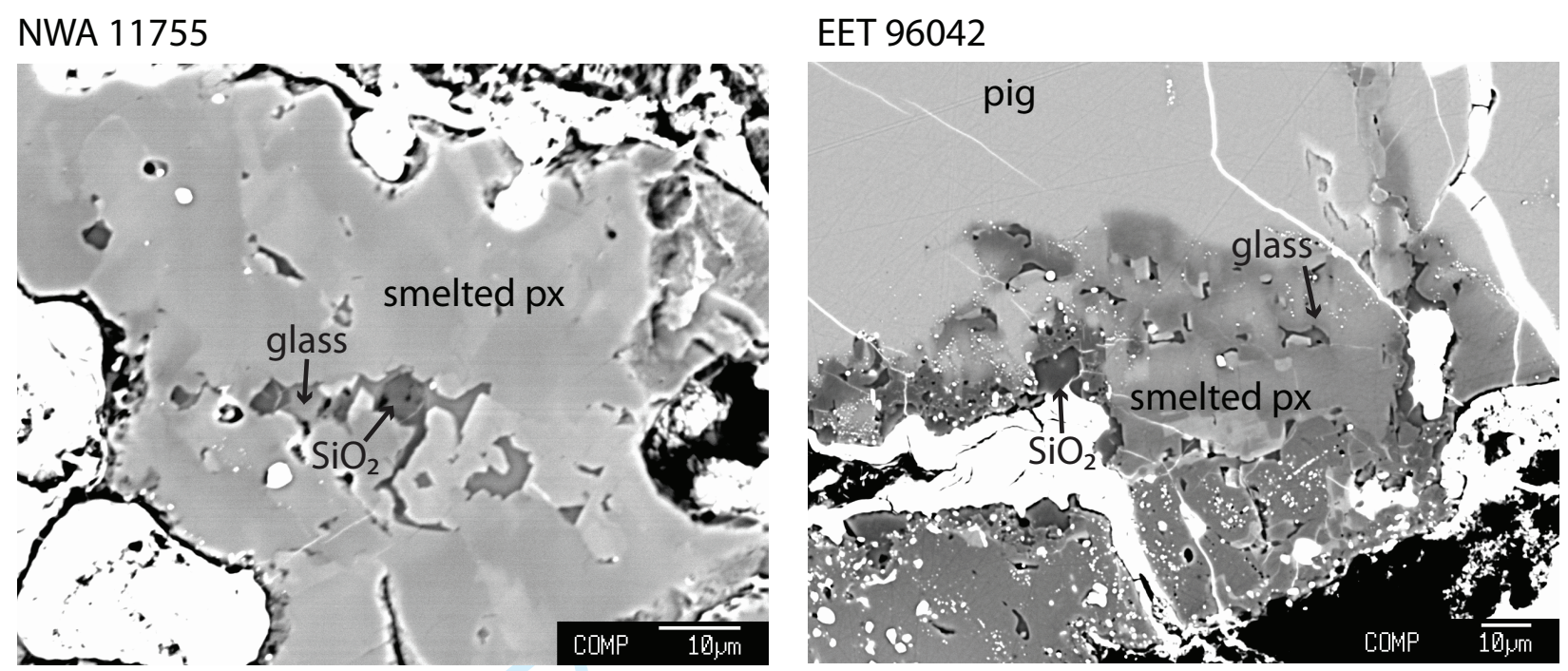

Figure S3. Additional BSE images of disequilibrium pyroxene smelting. Similar textures affecting the rims of homogenous pyroxene crystals can be observed in MIL 090076 and LAP 03721. Also see (Warren and Rubin, 2010).

Figure S4. (next page) sub- $\mu \mathrm{m}$ metal inclusions in the olivine cores of ureilites that suffered pyroxene smelting (EET 96042, LAP 03721, MIL 090076, NWA 11755), whether pyroxene smelting is limited to the rims or is extensive (NWA 11755). The last two pictures represent the homogeneous cores of two samples that do not display pyroxene smelting (MIL 07447 and DOM 08012). Also see Figure 5 of the main manuscript. 


\section{EET 96042}

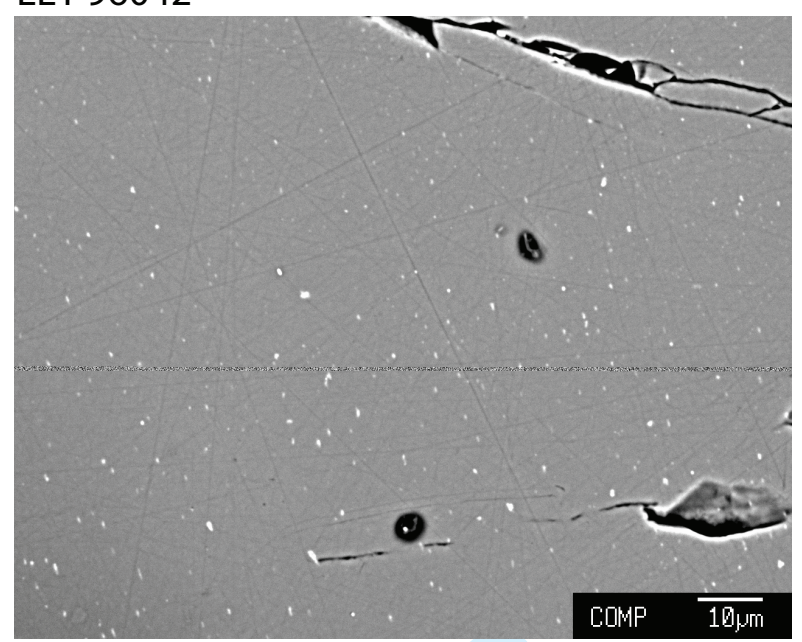

\section{LAP 03721}

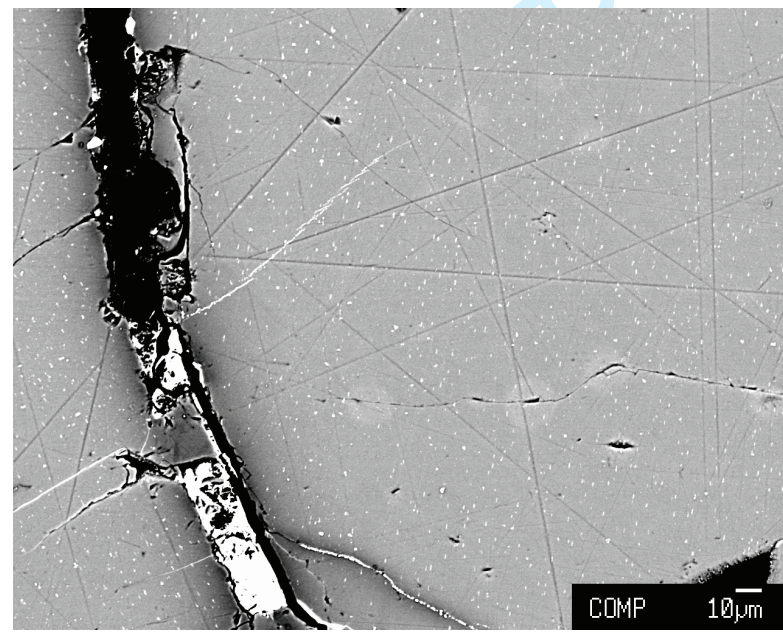

MIL 07447

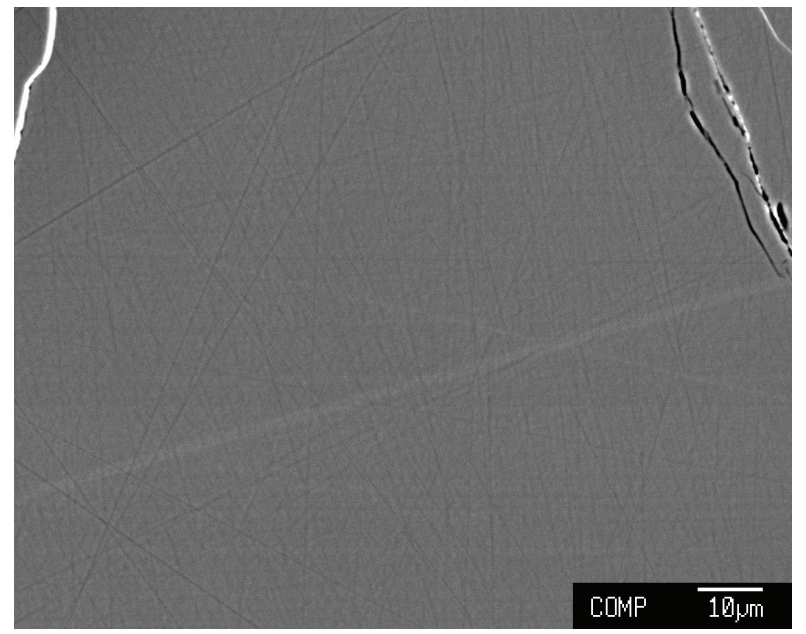

NWA 11755

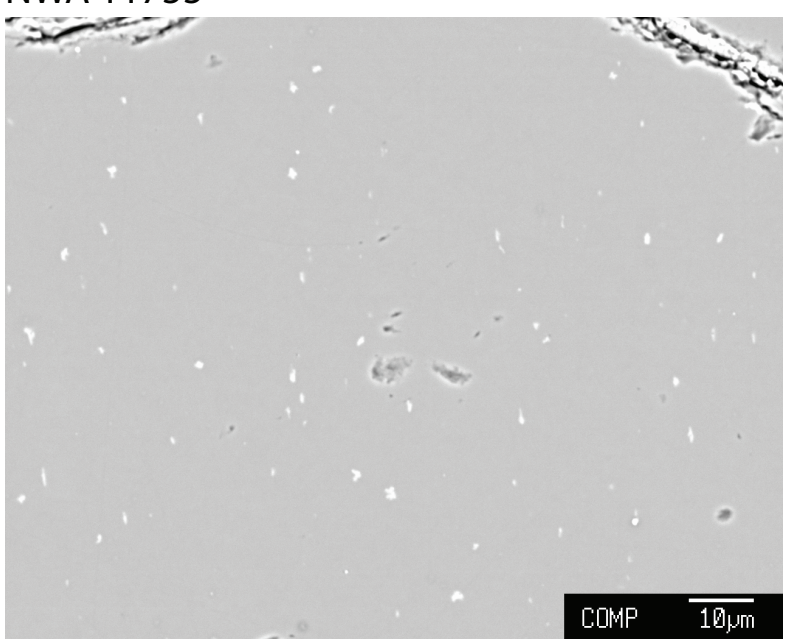

MIL 090076

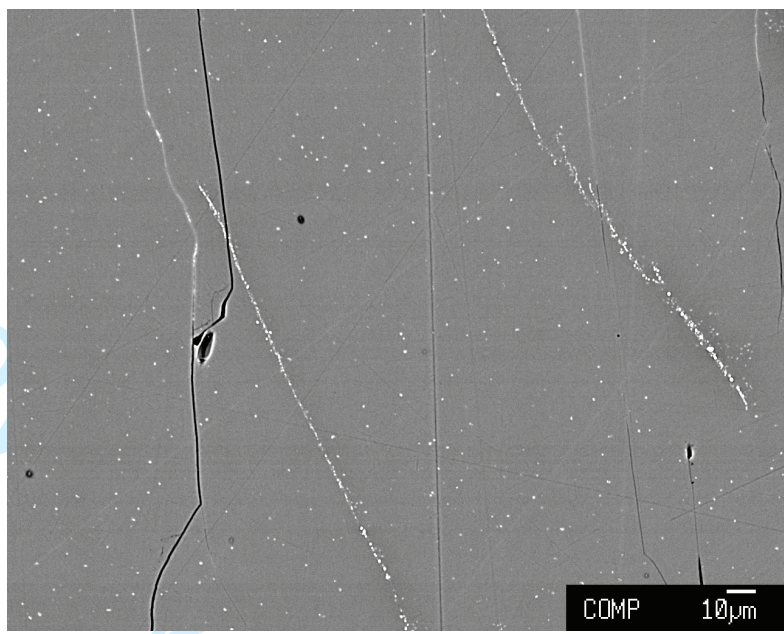

DOM 08012

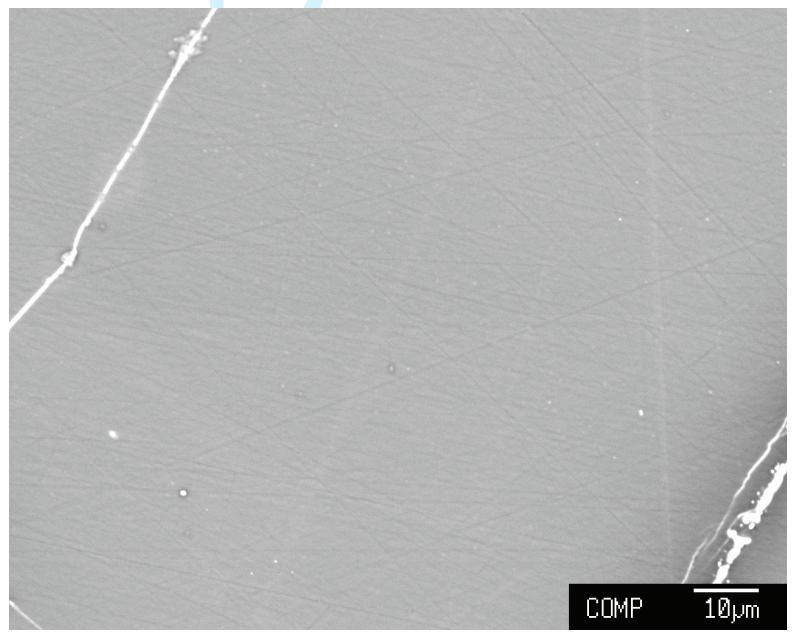

Figure S4. (caption on previous page) 


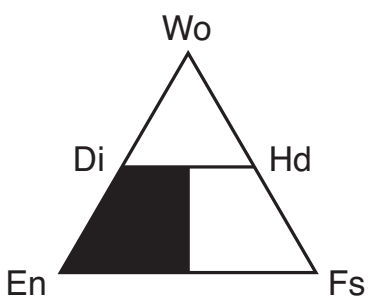

\section{2-px experiments} (aug-opx / aug-pig)

pig-oliv experiments

aug-opx-oliv ureilites $\diamond$ pig-oliv ureilites
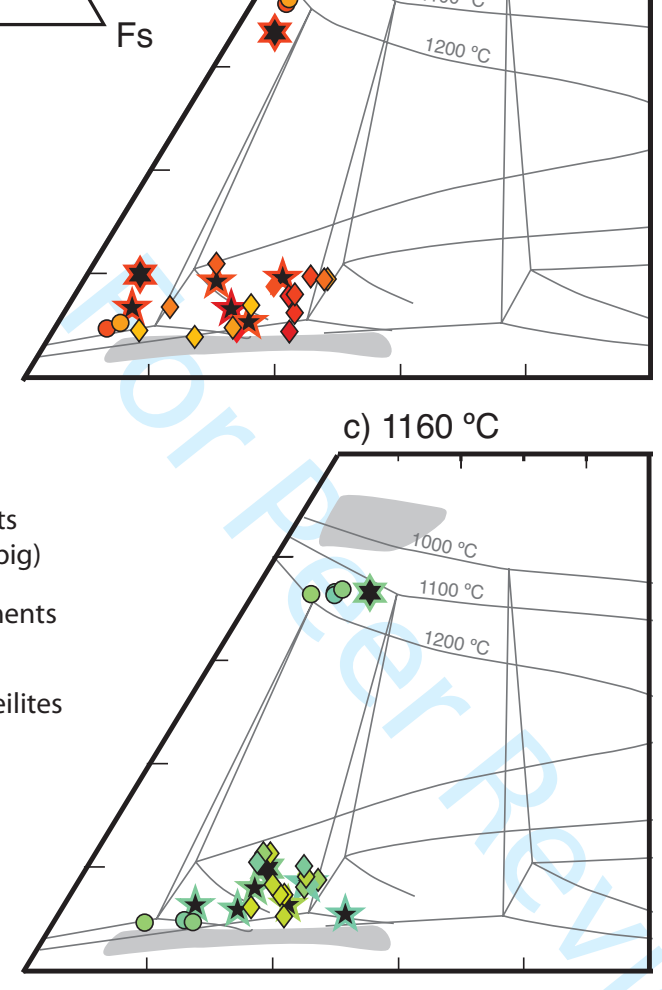

c) $1160^{\circ} \mathrm{C}$

a) $1250^{\circ} \mathrm{C}$

c 1

Temperature $\left({ }^{\circ} \mathrm{C}\right)$ b) $1200{ }^{\circ} \mathrm{C}$

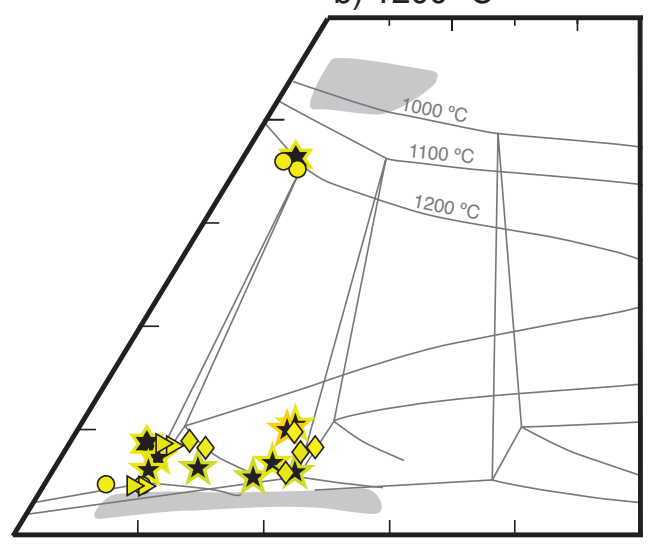

d) $1130-1070{ }^{\circ} \mathrm{C}$

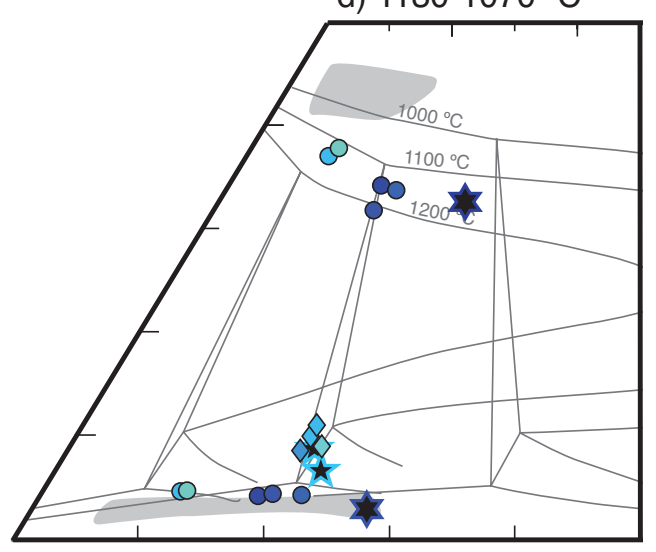

1050

Figure S5. Composition of pyroxene in experiments and ureilites compared to the phase diagram of (Sack and Ghiorso, 1994). The shaded areas represent the pyroxene assemblage in all other primitive achondrites (lodranites, brachinites, acapulcoites), which, contrary to ureilites cooled slowly. The color code represents the experimental temperature or the $\mathrm{D}_{\mathrm{Cr}}{ }^{\text {oliv-LCP }}$ temperature of equilibration (for ureilites). 


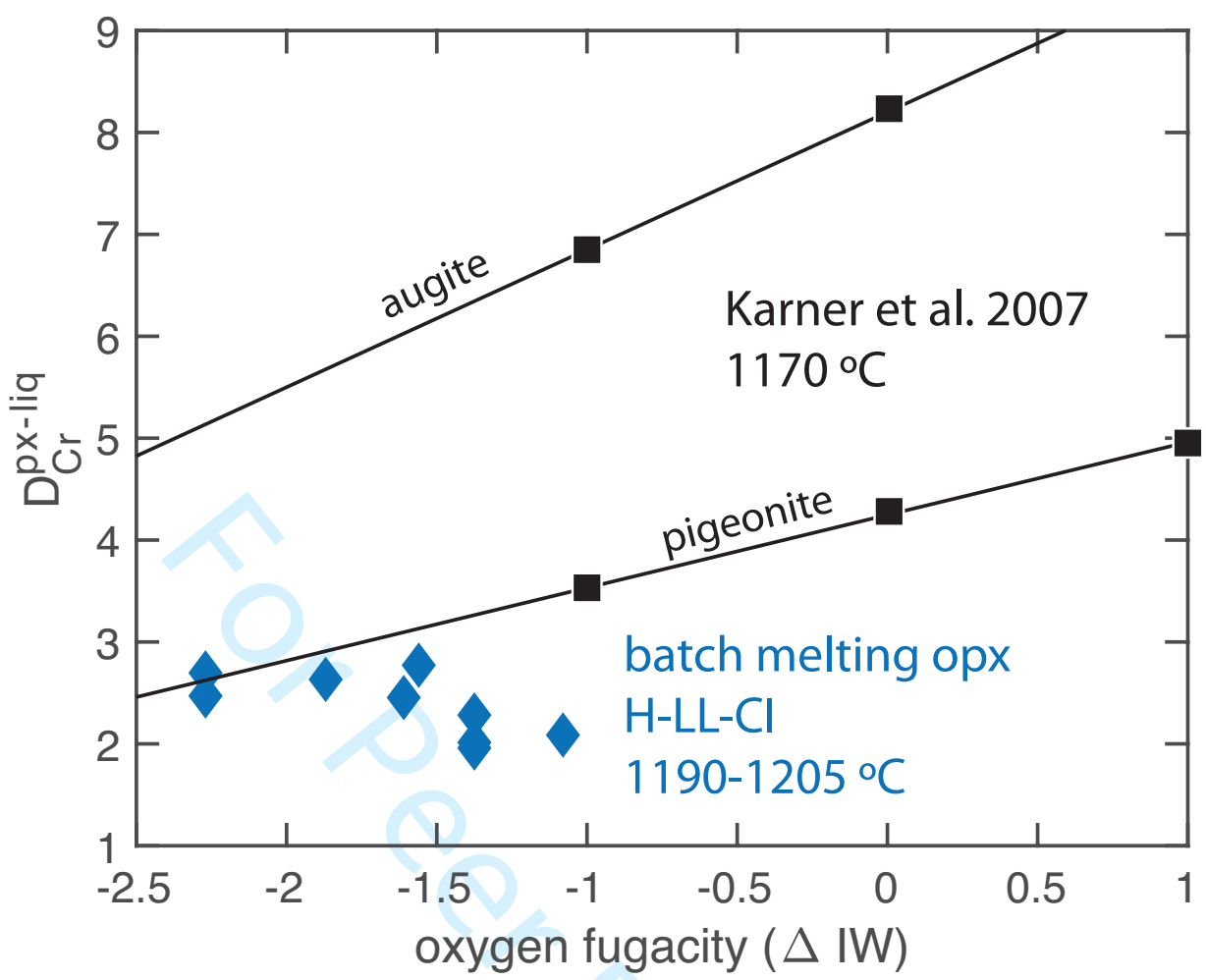

Figure S6. Oxygen fugacity dependence of the partitioning coefficients of $\mathrm{Cr}$ between pyroxene and silicate melt extrapolated from Karner et al. (2007) experiments at $1170^{\circ} \mathrm{C}$. Our experiments (Collinet and Grove, submitted), do not show a clear $\mathrm{fO}_{2}$ dependence at more reducing conditions. 


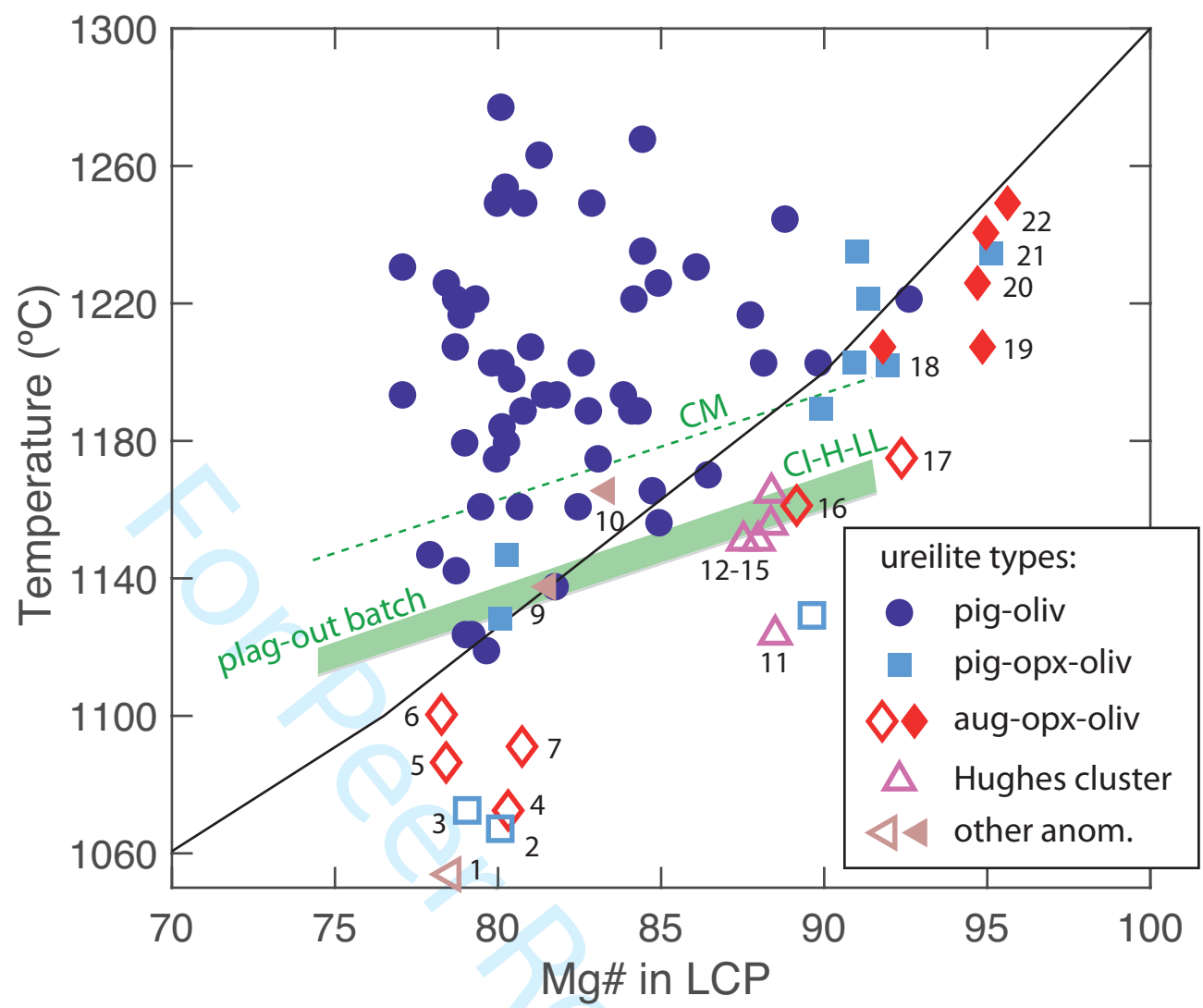

Figure S7. Equilibration temperature $\left(\mathrm{T}_{\mathrm{E}}\right.$; based on the partitioning of $\mathrm{Cr}$ ) of 75 ureilites as a function of the $\mathrm{Mg \#}$ in low-Ca pyroxene. The black line represents the minimum temperature of pigeonite stability from (Sack and Ghiorso, 1994). Compare with Figure 8 in the main manuscript. Key samples: [1]NWA 766 [2]MET 78008 [3]Y 74130 [4]RaS 517 [5-6]LEW 88774 [7]HaH 064 [8]NWA 7349 [9]LAP 02382 [10]Havero [11]EET 96293 [12]FRO 90054 [13]EET 96314 [14]NWA 11754 [15] Hughes 009 [16]MIL 091004 [17]MET01083 [18]NWA 5555 [1920]ALHA 82130 [21]ALHA 84136 [22]ALHA 82106. 


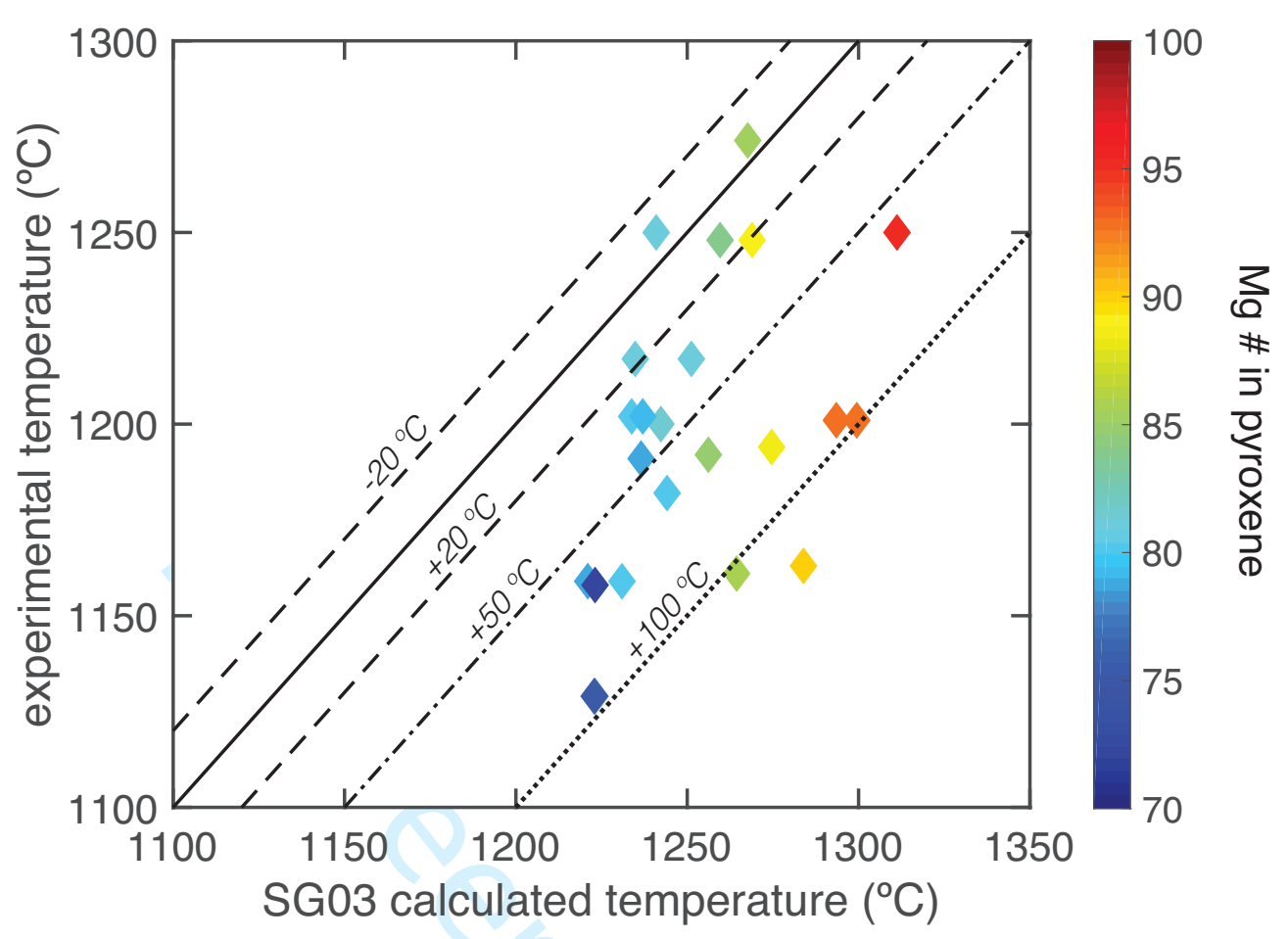

Figure S8. Offset between calculated temperature, using the thermometer of (Singletary and Grove, 2003), and the experimental temperature of pigeonite-olivine-liquid-metal experiments of this study. Offsets are large and generally overestimate the temperature (by up to $100{ }^{\circ} \mathrm{C}$ ) with no systematics. The pigeonite temperature of (Singletary and Grove, 2003) was calibrated in $\mathrm{Na}_{2} \mathrm{O}$ free melts, unlike the partial melts shown to be in equilibrium with ureilites. This thermometer should be replaced with the $\mathrm{D}_{\mathrm{Cr}}^{\text {oliv-LCP }}$ thermometer calibrated in this study (see main manuscript). 

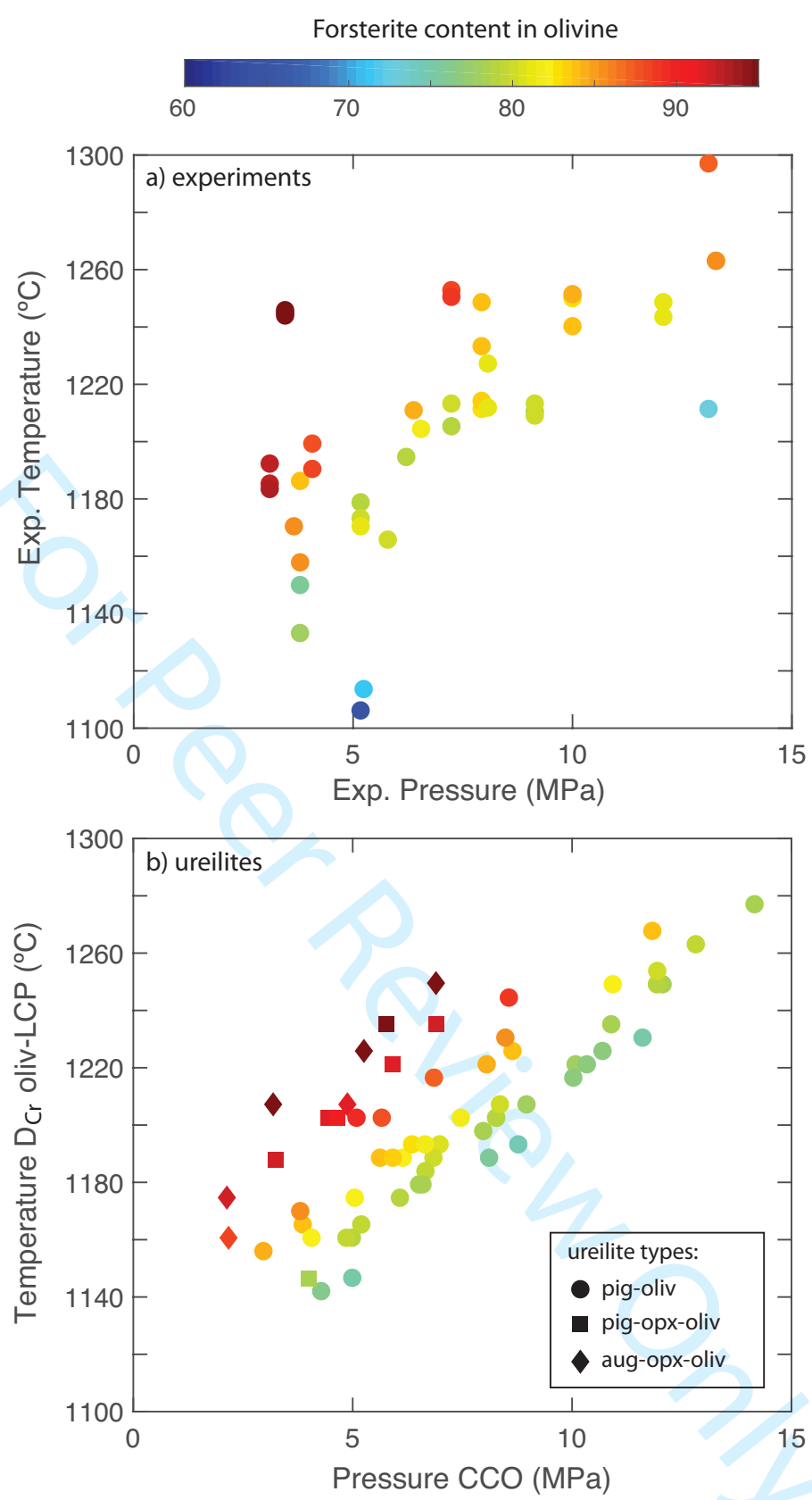

Figure S9. (a) Relationship between experimental pressure and temperature and the forsterite content in olivine of experiments. A subset of the experiments (CI composition) are used to calculate a linear regression of the pressure as a function of the temperature and Fo content in olivine: $\mathrm{P}(\mathrm{MPa})=-62.3-0.02993 \mathrm{Fo}+0.07828 \mathrm{~T}\left({ }^{\circ} \mathrm{C}\right)$. (b) Pressure of equilibration of ureilites assuming that the $f \mathrm{O}_{2}$ is controlled by the $\mathrm{CCO}$ buffer (primary smelting). The pressure is calculated from the temperature of equilibration $\left(\mathrm{D}_{\mathrm{Cr}}^{\text {oliv-LCP }}\right)$ and the Fo content of olivine in ureilites. 
Incremental melting: 2 increments

melt extracted at plagioclase exhaustion $(\mathrm{F}=15)$

with or without merrillite

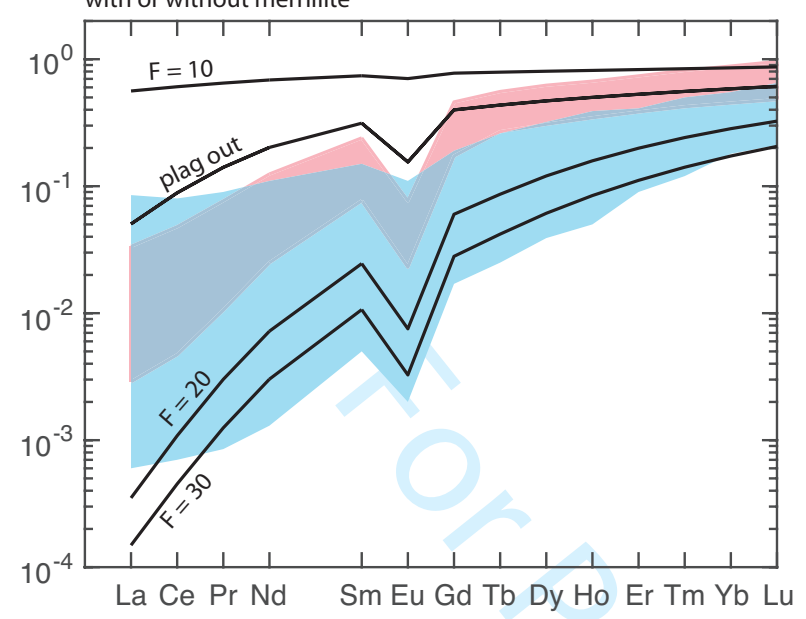

Dynamic/Continuous melting

$\Phi=0.02$

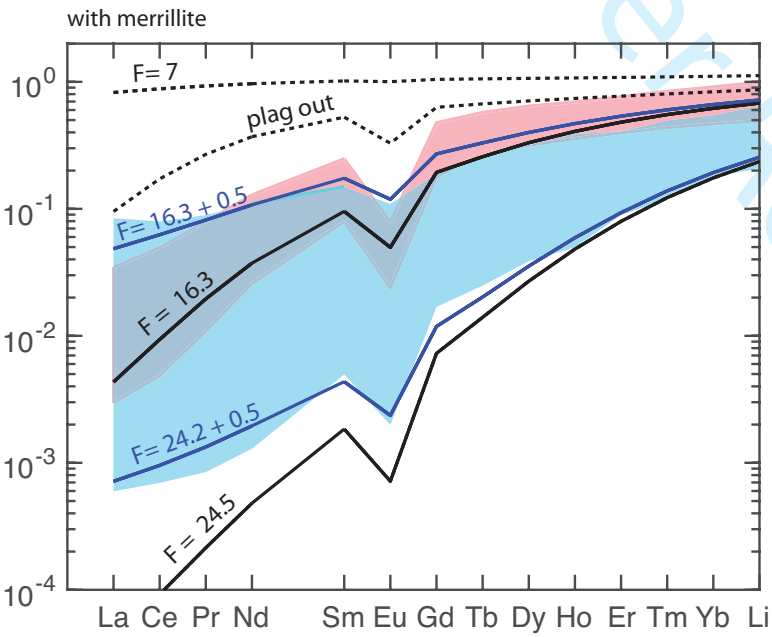

Incremental melting: 6 increments

melt extracted at $\mathrm{F}=5,10,15,16,20$

with merrilite

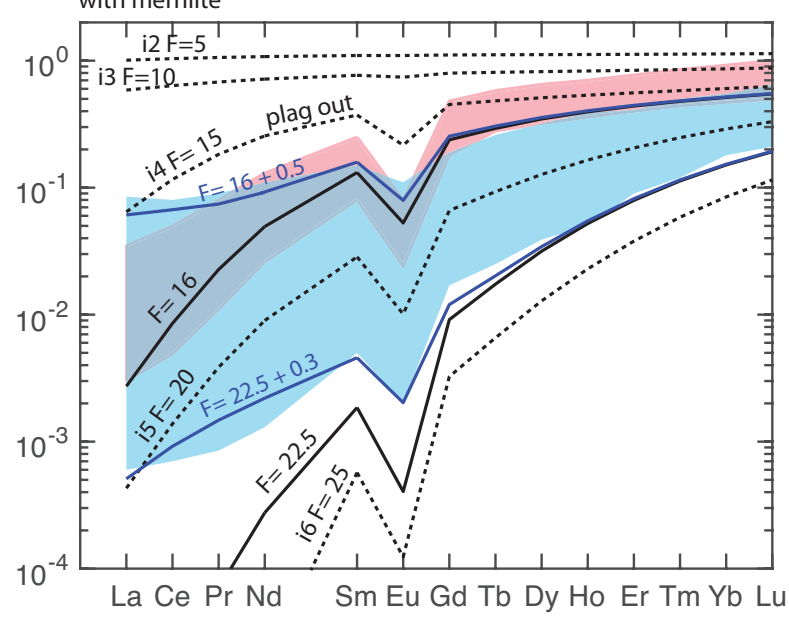

Dynamic/Continuous melting $\Phi=0.02$

without merrillite

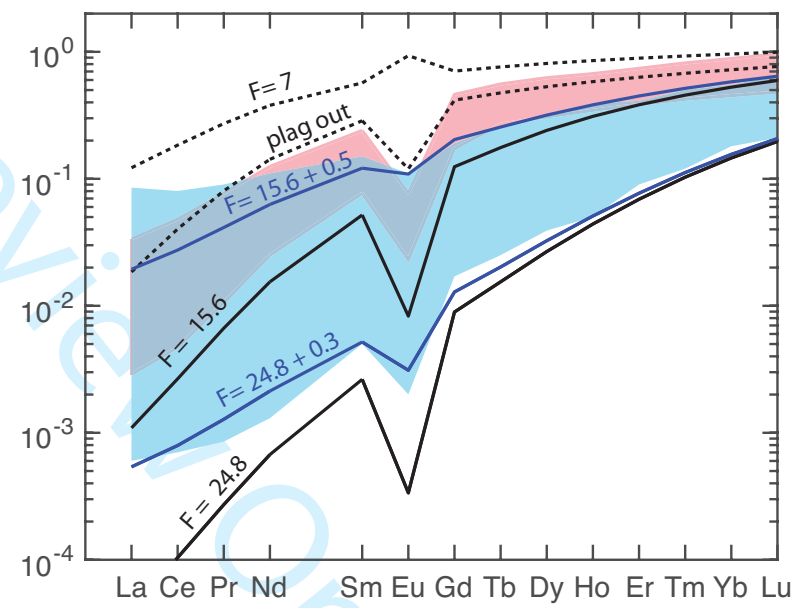

Figure S10. Additional REE models. Blue field represent the "group A" ureilites and red field represent the "group B" ureilites from Barrat et al. (2016). Continuous melting equations are from (Zou, 1998). 

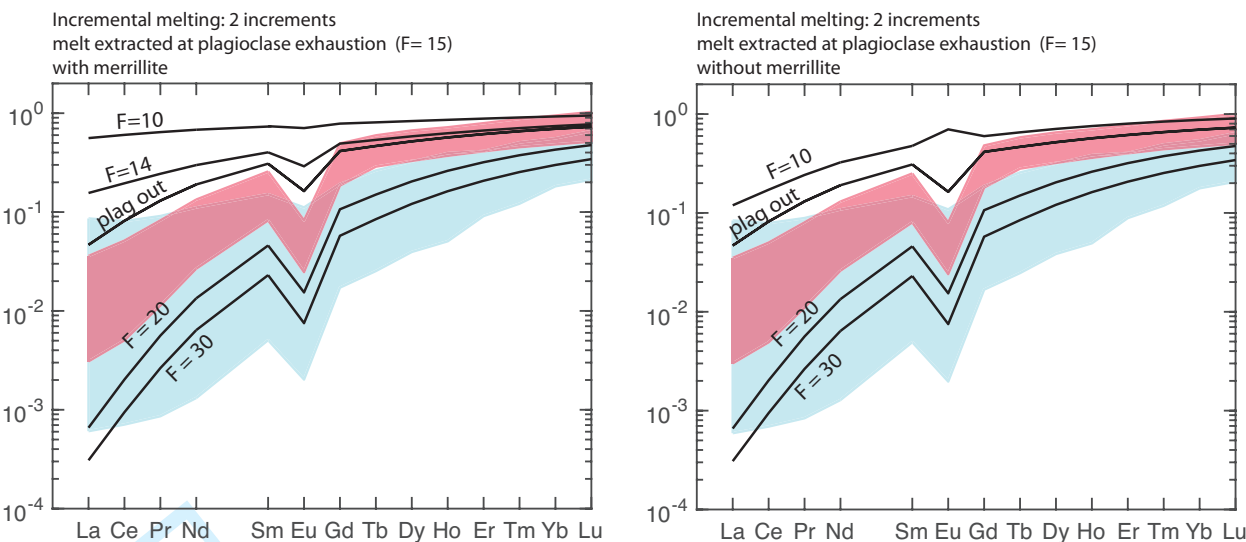

Incremental melting: 6 increments

melt extracted at $\mathrm{F}=5,10,15,16,20$

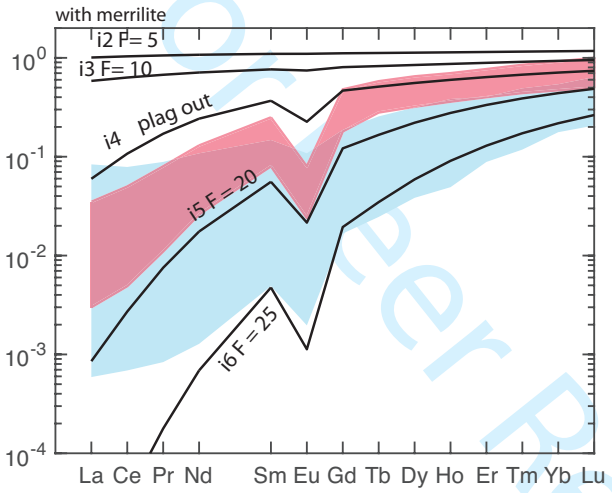

melt extracted at $\mathrm{F}=5,10,15,16,20$

without merrilite

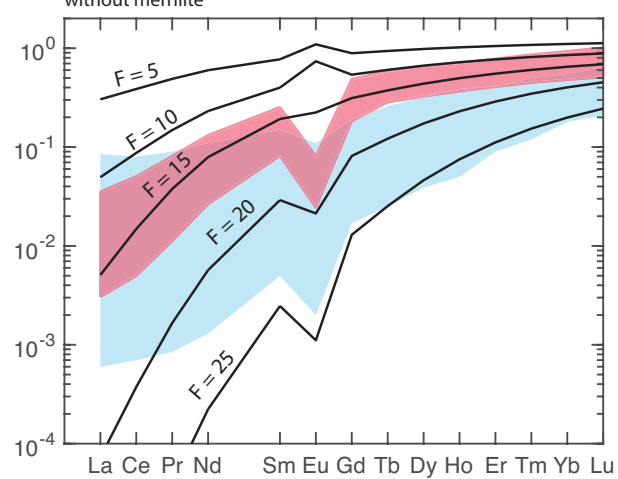

Dynamic/Continuous melting
$\Phi=0.02$

with merrillit

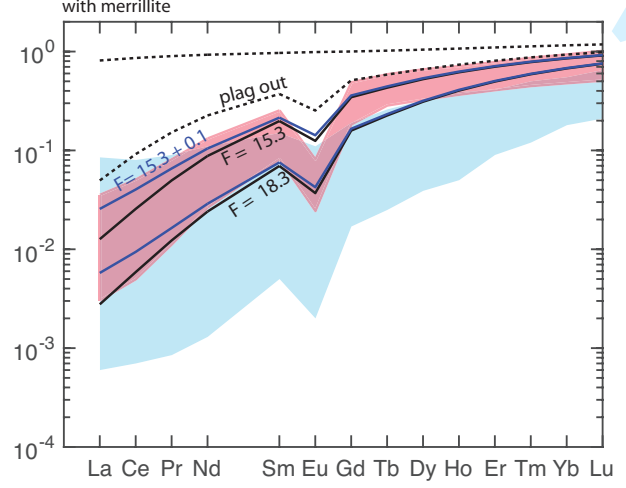

Dynamic/Continuous melting
$\Phi=0.02$

$$
\text { without }
$$

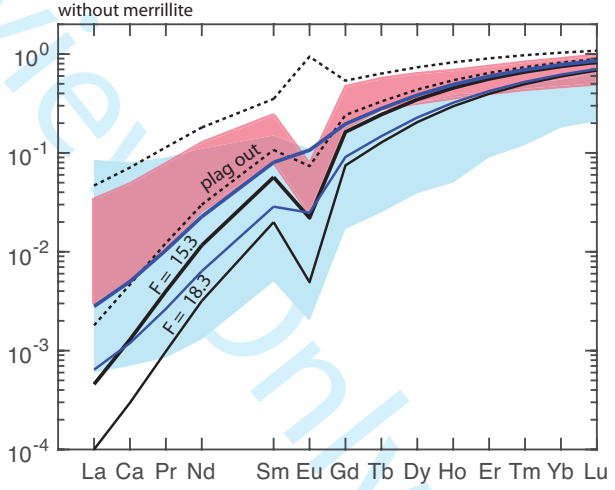

Fractional melting with merrillite
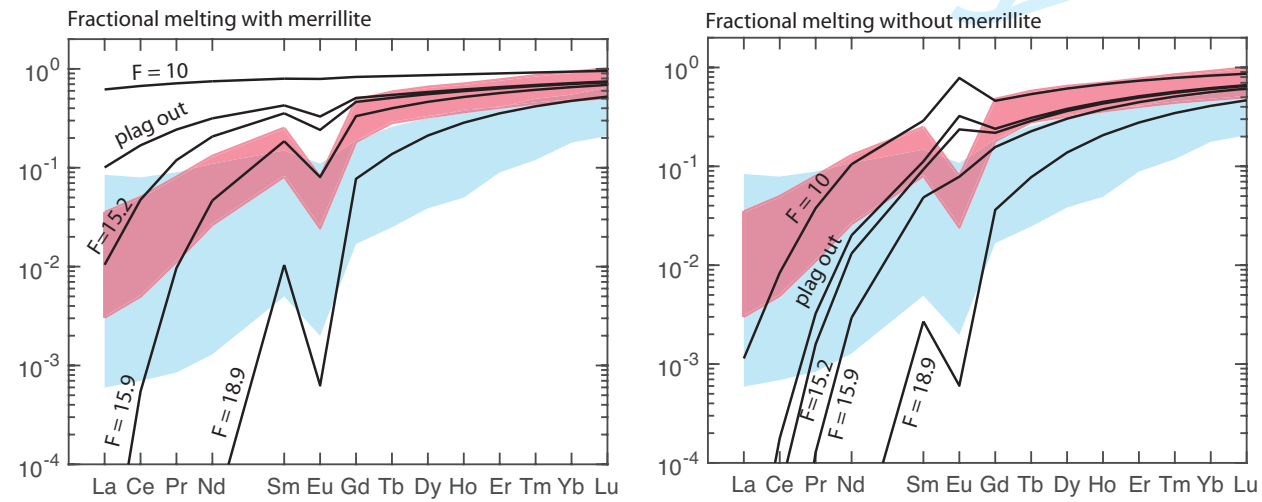

Figure S10. (continued) 


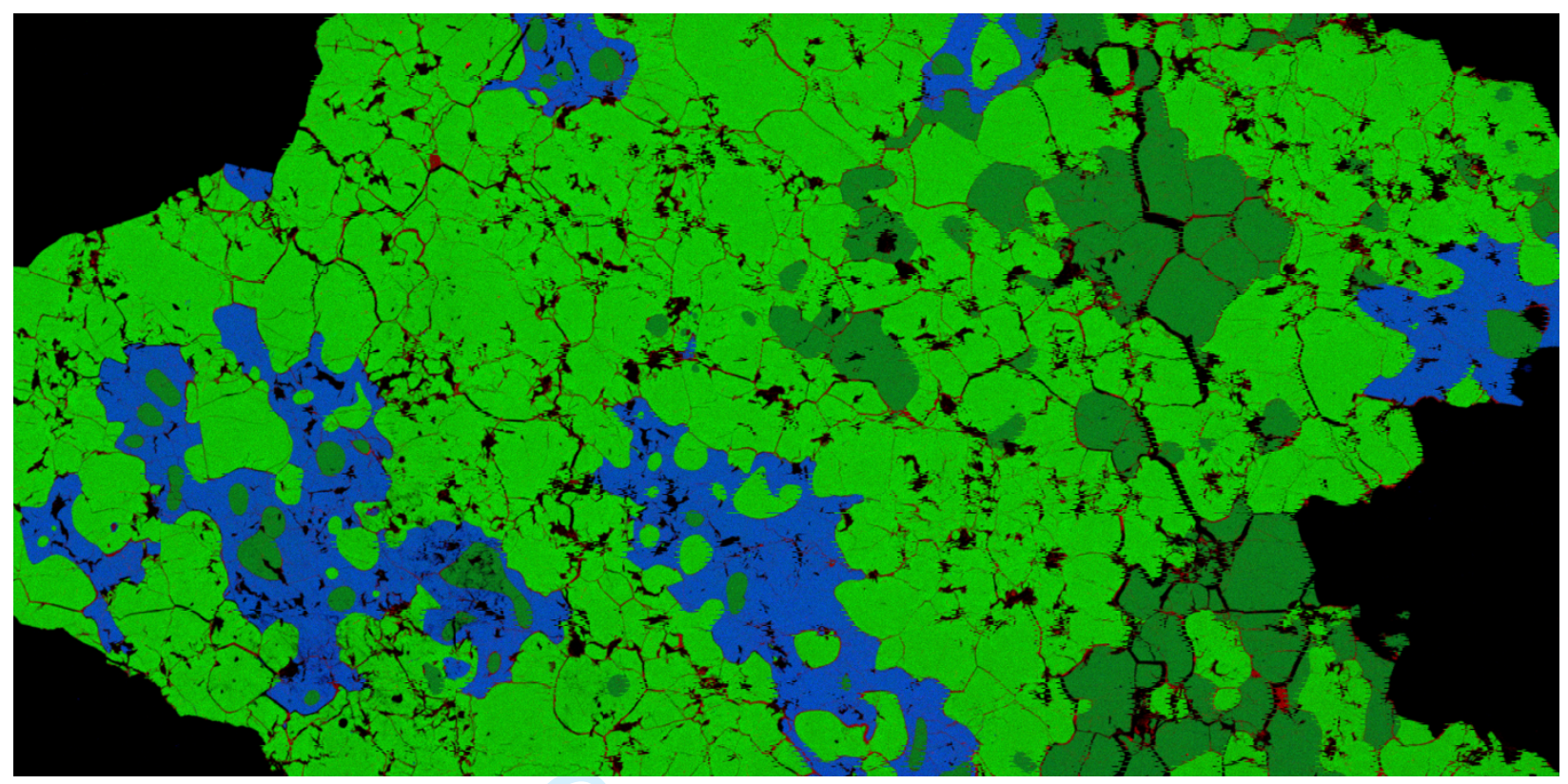

Figure S11. RGB (FeMgCa) image of anomalous (poikilitic) sample MET 01083 Blue=augite, dark green $=$ opx, light green $=$ olivine.

\section{pMELTS simulations (1): melting of a LL chondrite at IW -1}

The melting temperatures, temperatures of phase disappearance, the composition of batch melts and the composition of mineral phases calculated with pMELTS deviate significantly from experimental results. This is not surprising as pMELTS is not optimized to simulate the melting of chondritic material at low pressure. Nevertheless, pMELTS simulations are valuable for visualizing some of the relative differences between batch and fractional melting. For nearfractional melting, the melt is continuously extracted from the residue while maintaining a 0.2 wt.\% critical melt fraction (i.e. retained melt fraction). The composition of cumulates and aggregate melts at a given total melt fraction are identical (except for $\mathrm{K}_{2} \mathrm{O}$ contents) for the different melting behaviors (right column). Following the exhaustion of plagioclase ( $\mathrm{F}=17 \mathrm{wt} . \%)$, the melt productivity essentially drops to zero in near-fractional melting. Note that the concentration of alkali elements in instantaneous near-fractional melts becomes negligible after the exhaustion of plagioclase and the concentration of $\mathrm{Al}_{2} \mathrm{O}_{3}$ decreases as well. At the same time, the $\mathrm{CaO}$ contents of instantaneous melts increase sharply (right column). However, due to the low melt productivity, this transition is stretched over $\sim 100{ }^{\circ} \mathrm{C}$ where very little melt is actually produced (left column). The equivalence of melting residues between the different melting behavior shows that increasing fractions of batch melts can be extracted from a chondritic composition to simulate incremental melting, which is how we calculate CIR1-3 and LLR1-2 
compositions (Table 2 of the main manuscript). Following the exhaustion of plagioclase and the extraction of low-degree melts, ureilites essentially stopped melting, not just because they became depleted in ${ }^{26} \mathrm{Al}$, but also because the melt productivity became negligible over a significant temperature interval and pigeonite remained stable. The few percent of "late-stage melts" of ureilites, produced after the exhaustion of plagioclase were enriched in $\mathrm{CaO}$, depleted in alkali elements and probably slightly depleted in $\mathrm{Al}_{2} \mathrm{O}_{3}$.
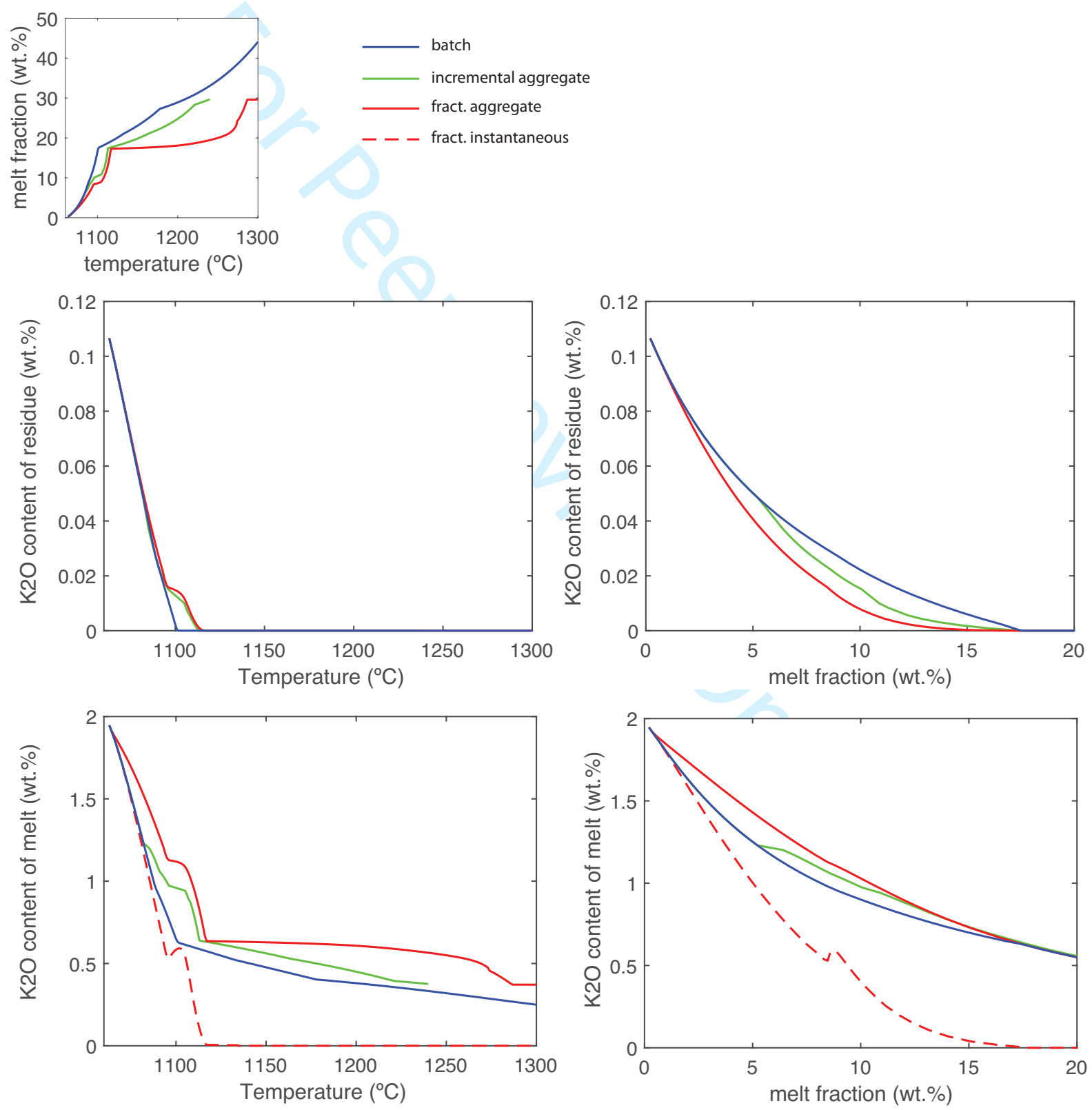

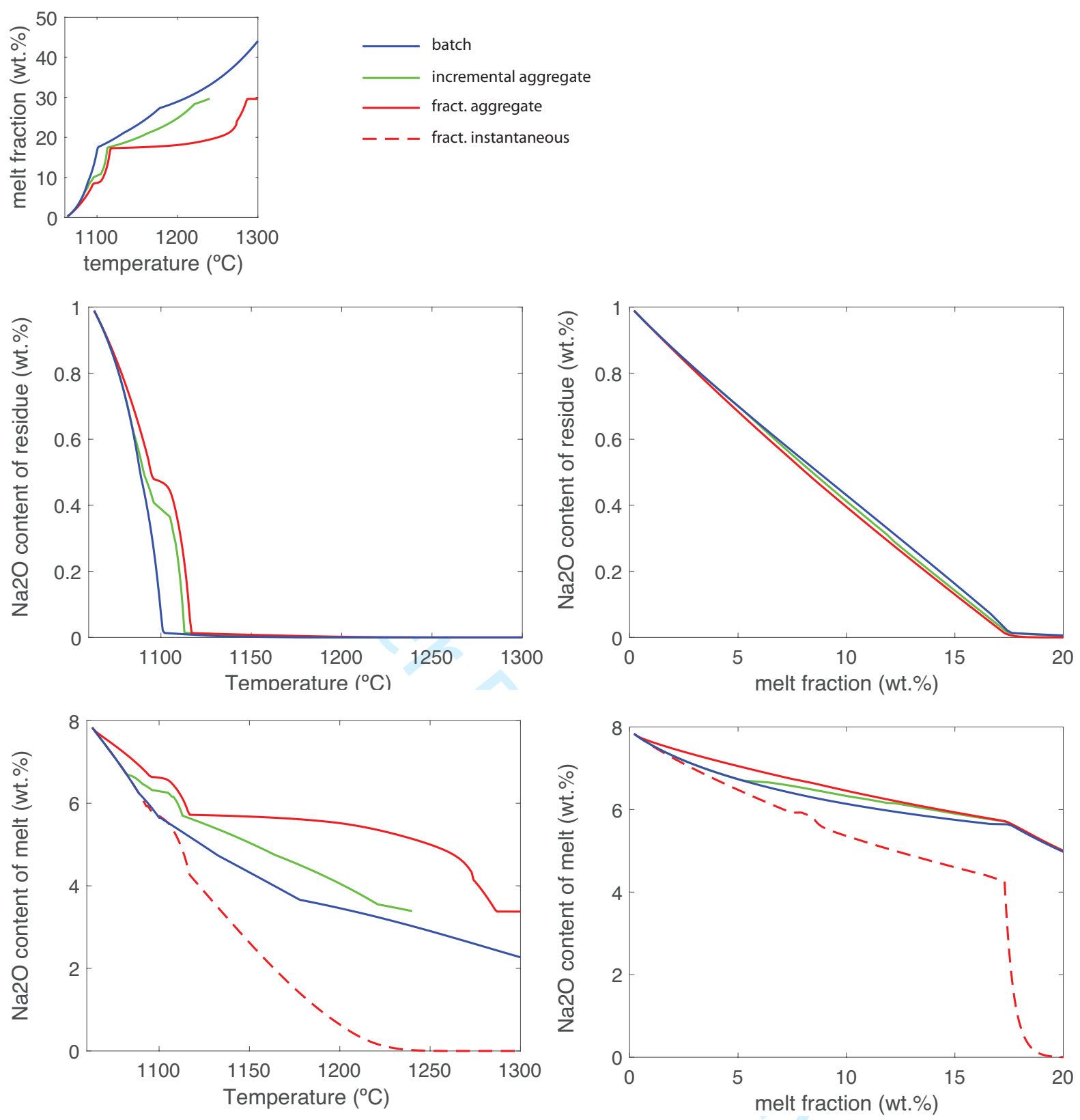

41 

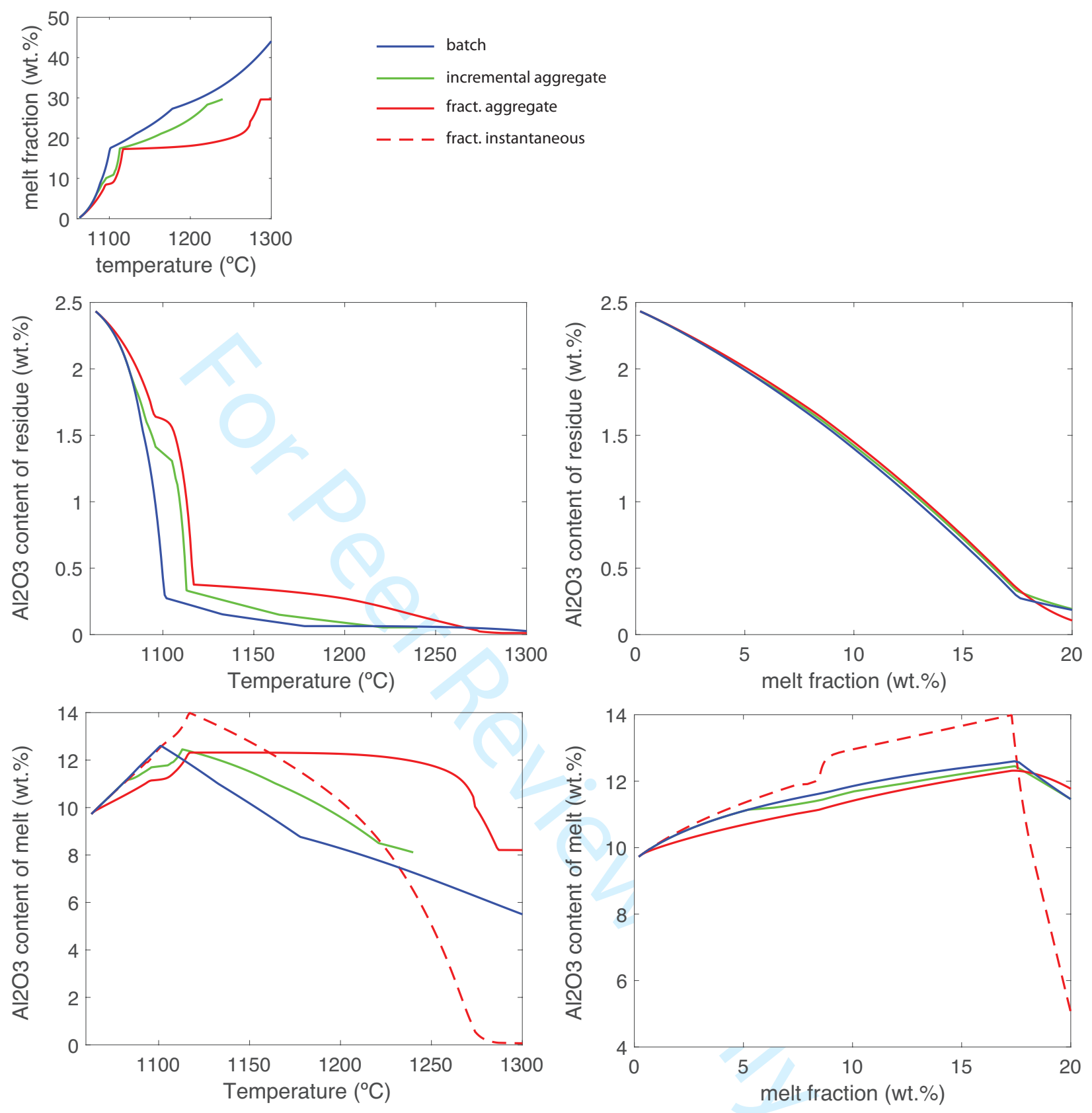

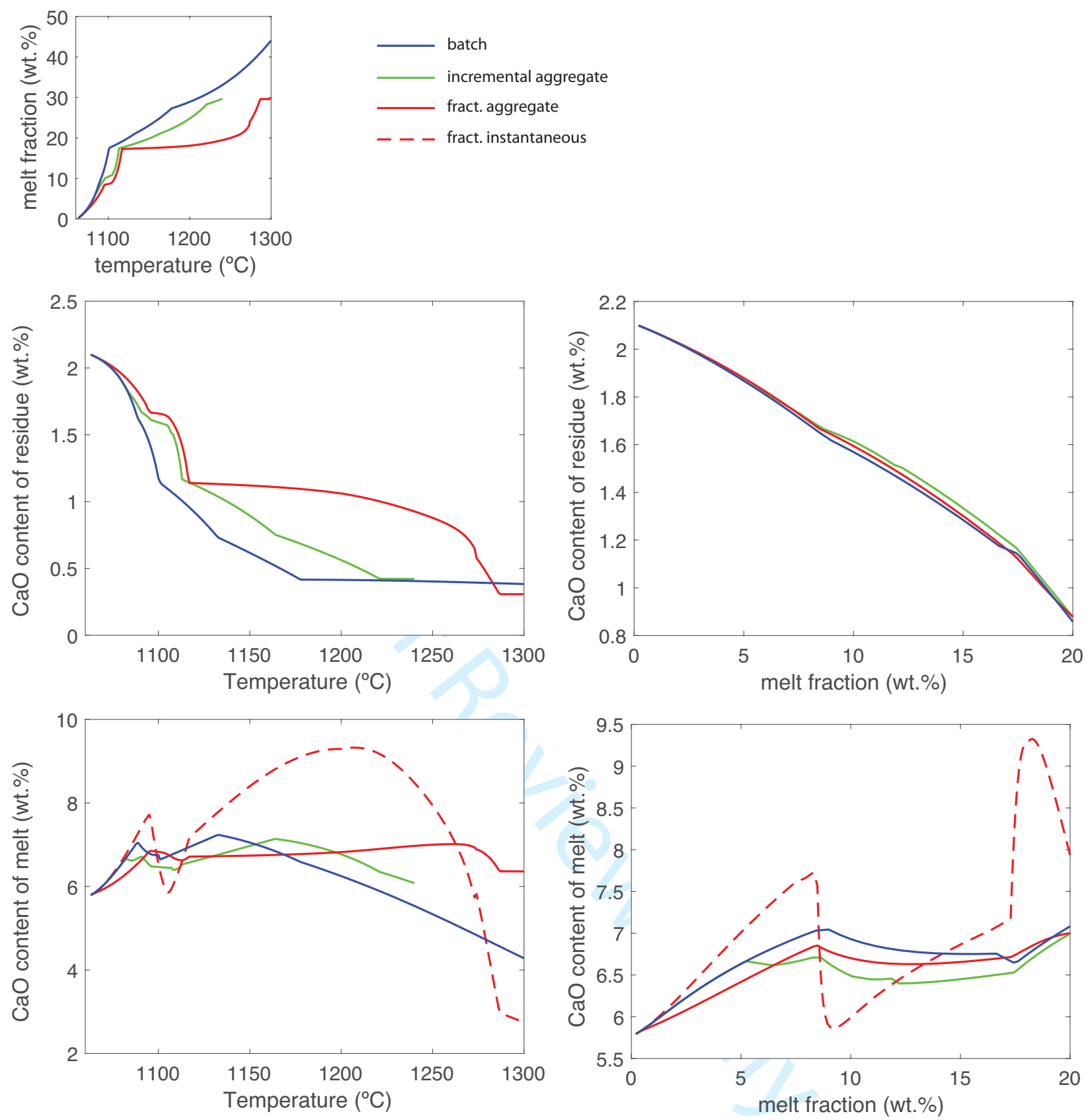


\section{pMELTS simulations (2): melting of a CI chondrite at IW -1.5}
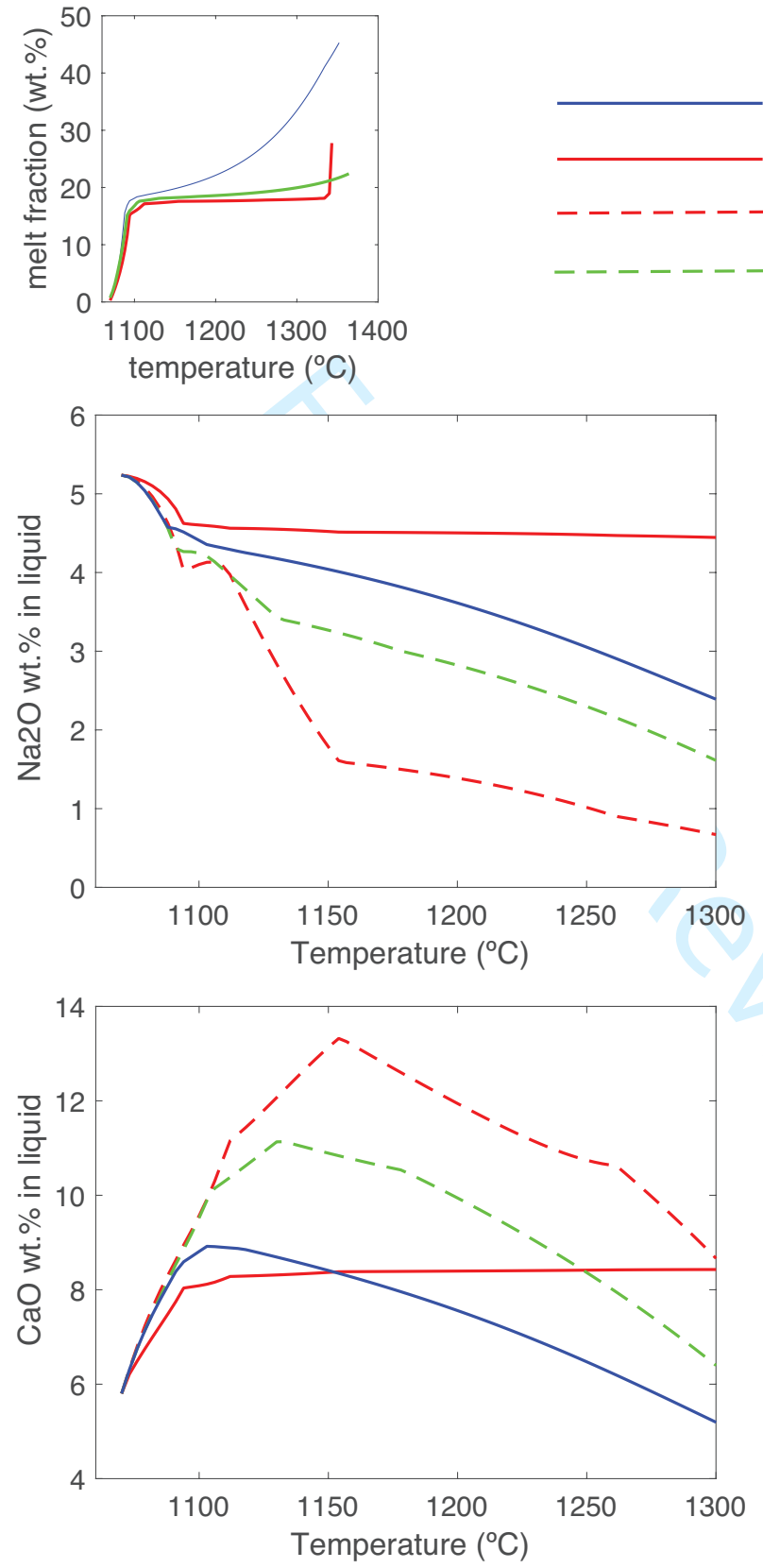
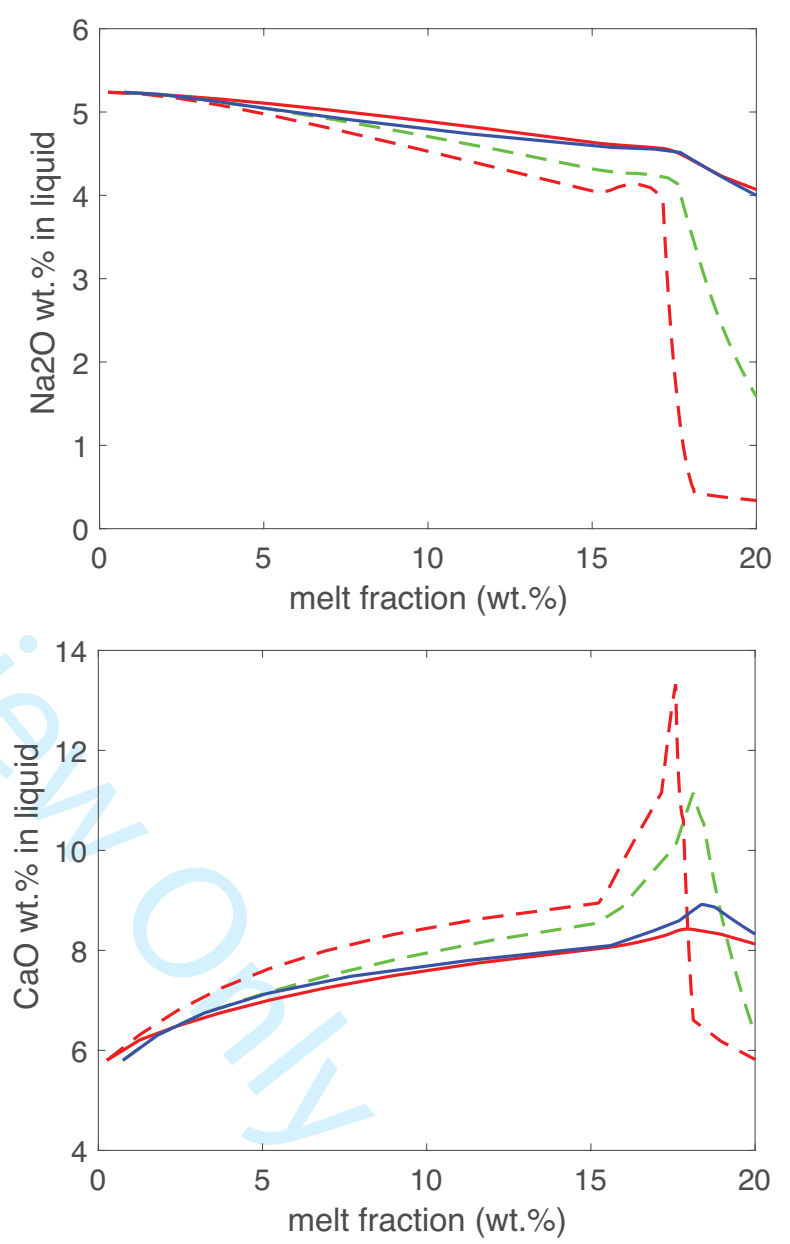
All supplementary tables are also available in an Excel file included in the .zip folder

\begin{tabular}{|c|c|c|c|c|c|c|c|c|c|c|c|c|}
\hline comp. & $\exp \#$ & $\mathrm{~T}\left(\mathrm{O}^{\mathrm{C}}\right)$ & $\Delta \mathrm{IW}$ & total px & oliv & liq & agg. liq & metal & py & Fo & Wo px1 & Wo $p \times 2$ \\
\hline LLR1 & CHS 46 & 1191 & -1.61 & 31.5 & 48.4 & 8.0 & 15.8 & 9.0 & 39.45 & 78.73 & 6.30 & \\
\hline LLR1 & CHS 47 & 1200 & -1.63 & 35.7 & 42.1 & 9.9 & 17.5 & 11.0 & 45.90 & 81.34 & 5.49 & \\
\hline LLR1 & CHS 48 & 1194 & -1.98 & 42.1 & 32.6 & 7.5 & 15.3 & 16.2 & 56.40 & 88.35 & 5.73 & \\
\hline LLR1 & $\mathrm{CHS} 49$ & 1248 & -1.62 & 34.8 & 39.1 & 12.1 & 19.6 & 12.6 & 47.09 & 83.90 & 4.05 & \\
\hline LLR1 & CHS 51 & 1217 & -1.58 & 33.3 & 43.7 & 10.4 & 18.0 & 11.1 & 43.23 & 80.85 & 4.72 & \\
\hline LLR1 & CHS 71 & 1216 & -1.59 & 34.8 & 41.0 & 10.7 & 18.4 & 12.1 & 45.91 & 82.88 & 4.11 & \\
\hline LLR2 & CHS 47 & 1200 & -1.63 & 37.3 & 46.4 & 2.8 & 18.0 & 12.1 & 44.57 & 81.64 & 5.22 & \\
\hline LLR2 & CHS 49 & 1248 & -1.62 & 37.0 & 43.1 & 4.6 & 19.4 & 14.0 & 46.16 & 84.24 & 4.15 & \\
\hline LLR2 & CHS 51 & 1217 & -1.58 & 33.5 & 50.1 & 3.3 & 18.4 & 11.6 & 40.07 & 80.58 & 5.27 & \\
\hline CIR1 & $\mathrm{CHS} 47$ & 1200 & -1.63 & 16.8 & 62.7 & 10.6 & 21.4 & 8.5 & 19.13 & 81.34 & 7.20 & \\
\hline CIR1 & $\mathrm{CHS} 48$ & 1194 & -1.98 & 27.4 & 49.0 & 9.3 & 19.6 & 14.5 & 33.83 & 88.35 & 6.69 & \\
\hline CIR1 & CHS 49 & 1248 & -1.62 & 14.0 & 62.1 & 12.4 & 22.9 & 9.2 & 16.45 & 83.90 & 4.05 & \\
\hline CIR1 & CHS 50 & 1248 & -1.89 & 21.9 & 51.2 & 11.2 & 21.9 & 14.2 & 27.96 & 88.37 & 5.04 & \\
\hline CIR1 & CHS 51 & 1217 & -1.58 & 15.0 & 64.2 & 10.6 & 21.4 & 8.7 & 16.89 & 81.19 & 6.39 & \\
\hline CIR1 & CHS 53 & 1248 & -1.47 & 19.8 & 59.1 & 10.5 & 20.9 & 8.4 & 20.07 & 81.04 & 4.33 & \\
\hline CIR1 & CHS 65 & 1201 & -2.27 & 31.3 & 41.8 & 9.5 & 20.1 & 17.4 & 40.76 & 92.59 & 6.53 & \\
\hline CIR1 & CHS 66 & 1250 & -2.53 & 33.4 & 37.3 & 9.5 & 20.2 & 18.9 & 45.27 & 94.64 & 4.73 & \\
\hline CIR1 & CHS 67 & 1274 & -1.59 & 21.0 & 52.1 & 13.5 & 24.0 & 11.8 & 26.78 & 85.39 & 6.83 & \\
\hline CIR1 & CHS 71 & 1216 & -1.59 & 18.1 & 59.2 & 11.1 & 21.4 & 10.1 & 21.47 & 83.40 & 5.15 & \\
\hline CIR2a & CHS 50 & 1248 & -1.89 & 22.6 & 57.1 & 3.8 & 19.2 & 14.8 & 28.35 & 88.94 & 9.49 & \\
\hline CIR2a & CHS 51 & 1217 & -1.58 & 17.8 & 69.5 & 2.3 & 17.9 & 8.5 & 20.35 & 80.99 & 10.4 & \\
\hline CIR2a & CHS 53 & 1248 & -1.47 & 16.5 & 70.6 & 3.7 & 19.1 & 7.4 & 18.96 & 80.06 & 10.3 & \\
\hline CIR2a & CHS 53 & 1248 & -1.47 & 17.8 & 68.4 & 3.9 & 19.3 & 8.1 & 20.61 & 80.86 & 9.83 & \\
\hline $\mathrm{CIR} 2 \mathrm{~b}$ & CHS 63 & 1202 & -1.38 & 17.5 & 65.4 & 3.5 & 19.0 & 10.0 & 21.15 & 80.02 & 11.5 & \\
\hline $\mathrm{CIR} 2 \mathrm{~b}$ & CHS 65 & 1201 & -2.27 & 30.2 & 43.0 & 3.0 & 18.5 & 19.8 & 41.22 & 92.80 & 7.89 & 34.6 \\
\hline $\mathrm{CIR} 2 \mathrm{~b}$ & CHS 66 & 1250 & -2.53 & 30.0 & 41.1 & 5.0 & 19.9 & 21.3 & 42.18 & 94.96 & 6.95 & \\
\hline $\mathrm{CIR} 2 \mathrm{~b}$ & CHS 67 & 1274 & -1.59 & 17.3 & 57.6 & 8.6 & 23.4 & 13.4 & 23.08 & 84.50 & 5.18 & \\
\hline $\mathrm{CIR} 2 \mathrm{~b}$ & CHS 68 & 1159 & -1.53 & 16.5 & 67.1 & 2.5 & 18.0 & 10.2 & 19.71 & 79.91 & 8.86 & \\
\hline $\mathrm{CIR} 2 \mathrm{~b}$ & CHS 69 & 1301 & -2.44 & 21.1 & 45.3 & 9.8 & 24.4 & 20.5 & 31.79 & 94.50 & 5.03 & \\
\hline $\mathrm{CIR} 2 \mathrm{~b}$ & CHS 71 & 1216 & -1.59 & 17.2 & 61.6 & 5.5 & 20.3 & 12.8 & 21.82 & 83.75 & 8.09 & \\
\hline CIR3 & CHS 49 & 1248 & -1.62 & 19.9 & 63.0 & 4.6 & 22.8 & 11.0 & 21.03 & 83.60 & 5.58 & \\
\hline CIR3 & CHS 50 & 1248 & -1.89 & 23.9 & 55.8 & 3.8 & 22.1 & 14.7 & 27.01 & 88.27 & 5.58 & \\
\hline CIR3 & CHS 51 & 1217 & -1.58 & 16.6 & 69.0 & 3.5 & 21.8 & 9.0 & 16.41 & 81.34 & 6.79 & \\
\hline CIR3 & CHS 53 & 1248 & -1.47 & 17.9 & 67.6 & 4.2 & 22.4 & 8.9 & 17.91 & 81.11 & 5.63 & \\
\hline
\end{tabular}




\begin{tabular}{|c|c|c|c|c|c|c|c|c|c|c|c|c|c|c|c|c|c|c|c|c|c|c|c|}
\hline comp. & $\exp \#$ & $\mathrm{~T}\left({ }^{\circ} \mathrm{C}\right)$ & $\Delta \mathrm{IW}$ & $\mathrm{SiO}_{2}$ & & $\mathrm{TiO}_{2}$ & $\mathrm{Al}_{2} \mathrm{O}_{3}$ & $\mathrm{Cr}_{2} \mathrm{O}_{3}$ & & $\mathrm{FeO}$ & & $\mathrm{MnO}$ & & $\mathrm{MgO}$ & & $\mathrm{CaO}$ & & $\mathrm{P}_{2} \mathrm{O}_{5}$ & & $\mathrm{NiO}$ & & total & $\mathrm{n}$ \\
\hline LLR1 & CHS 46 & 1191 & -1.61 & 38.7 & 0.14 & bdl & bdl & 0.56 & 0.01 & 19.5 & 0.21 & 0.32 & 0.02 & 40.5 & 0.09 & 0.31 & 0.01 & 0.06 & 0.02 & 0.08 & 0.07 & 101.0 & 6 \\
\hline LLR1 & CHS 47 & 1200 & -1.63 & 38.5 & 0.07 & bdl & bdl & 0.55 & 0.02 & 17.4 & 0.09 & 0.37 & 0.02 & 42.6 & 0.21 & 0.30 & 0.01 & 0.06 & 0.02 & 0.13 & 0.03 & 101.5 & 5 \\
\hline LLR1 & CHS 48 & 1194 & -1.98 & 40.4 & 0.48 & bdl & bdl & 0.54 & 0.01 & 11.1 & 0.16 & 0.37 & 0.03 & 47.2 & 0.30 & 0.28 & 0.04 & 0.04 & 0.02 & 0.06 & 0.04 & 101.2 & 5 \\
\hline LLR1 & CHS 49 & 1248 & -1.62 & 39.0 & 0.28 & bdl & bdl & 0.56 & 0.02 & 15.2 & 0.19 & 0.37 & 0.05 & 44.4 & 0.18 & 0.30 & 0.01 & 0.05 & 0.04 & 0.08 & 0.06 & 101.7 & 4 \\
\hline LLR1 & CHS 51 & 1217 & -1.58 & 39.0 & 0.18 & bdl & bdl & 0.57 & 0.02 & 17.7 & 0.41 & 0.36 & 0.03 & 41.9 & 0.38 & 0.31 & 0.01 & bdl & & 0.11 & 0.09 & 101.3 & 5 \\
\hline LLR1 & CHS 71 & 1216 & -1.59 & 38.9 & 0.87 & bdl & bdl & 0.57 & 0.03 & 16.1 & 0.09 & 0.40 & 0.04 & 43.7 & 0.30 & 0.31 & 0.01 & bdl & & bdl & & 101.4 & 6 \\
\hline LLR2 & CHS 47 & 1200 & -1.63 & 38.8 & 0.19 & bdl & bdl & 0.59 & 0.02 & 17.1 & 0.15 & 0.44 & 0.02 & 42.7 & 0.19 & 0.30 & 0.01 & 0.02 & 0.01 & bdl & & 101.3 & 7 \\
\hline LLR2 & CHS 49 & 1248 & -1.62 & 39.1 & 0.17 & bdl & bdl & 0.61 & 0.03 & 14.8 & 0.07 & 0.46 & 0.04 & 44.5 & 0.20 & 0.30 & 0.02 & 0.03 & 0.02 & 0.08 & 0.05 & 101.0 & 6 \\
\hline LLR2 & CHS 51 & 1217 & -1.58 & 39.5 & 0.56 & bdl & bdl & 0.60 & 0.02 & 17.8 & 0.26 & 0.44 & 0.02 & 41.3 & 0.93 & 0.29 & 0.02 & bdl & & bdl & & 100.9 & 6 \\
\hline CIR1 & CHS 47 & 1200 & -1.63 & 38.7 & 0.07 & bdl & bdl & 0.56 & 0.01 & 17.4 & 0.06 & 0.32 & 0.02 & 42.5 & 0.15 & 0.32 & 0.01 & 0.03 & 0.02 & 0.06 & 0.07 & 101.7 & 6 \\
\hline CIR1 & CHS 48 & 1194 & -1.98 & 40.1 & 0.20 & bdl & bdl & 0.53 & 0.01 & 11.1 & 0.10 & 0.35 & 0.02 & 47.4 & 0.21 & 0.27 & 0.01 & 0.03 & 0.01 & 0.10 & 0.07 & 100.9 & 5 \\
\hline CIR1 & CHS 49 & 1248 & -1.62 & 39.0 & 0.13 & bdl & bdl & 0.56 & 0.02 & 15.2 & 0.15 & 0.37 & 0.03 & 44.4 & 0.18 & 0.30 & 0.01 & 0.05 & 0.03 & 0.08 & 0.06 & 101.7 & 4 \\
\hline CIR1 & CHS 50 & 1248 & -1.89 & 40.7 & 0.13 & bdl & bdl & 0.52 & 0.02 & 11.0 & 0.14 & 0.34 & 0.03 & 47.1 & 0.13 & 0.29 & 0.01 & 0.03 & 0.02 & bdl & & 100.2 & 4 \\
\hline CIR1 & CHS 51 & 1217 & -1.58 & 39.1 & 0.09 & bdl & bdl & 0.59 & 0.03 & 17.4 & 0.05 & 0.32 & 0.02 & 42.2 & 0.14 & 0.33 & 0.01 & bdl & & 0.06 & 0.05 & 101.4 & 5 \\
\hline CIR1 & CHS 53 & 1248 & -1.47 & 37.8 & 0.60 & bdl & bdl & 0.61 & 0.04 & 17.9 & 0.13 & 0.34 & 0.04 & 43.0 & 0.20 & 0.31 & 0.01 & bdl & & bdl & & 100.7 & 4 \\
\hline CIR1 & CHS 65 & 1201 & -2.27 & 40.4 & 0.07 & bdl & bdl & 0.48 & 0.03 & 7.29 & 0.10 & 0.33 & 0.03 & 51.1 & 0.17 & 0.27 & 0.01 & bdl & & bdl & & 100.6 & 6 \\
\hline CIR1 & CHS 66 & 1250 & -2.53 & 40.4 & 0.27 & bdl & bdl & 0.55 & 0.02 & 5.35 & 0.08 & 0.37 & 0.04 & 53.0 & 0.16 & 0.28 & 0.02 & bdl & & bdl & & 100.5 & 7 \\
\hline CIR1 & CHS 67 & 1274 & -1.59 & 38.0 & 1.14 & bdl & bdl & 0.57 & 0.02 & 14.2 & 0.20 & 0.36 & 0.03 & 46.5 & 0.23 & 0.40 & 0.02 & bdl & & bdl & & 99.9 & 7 \\
\hline CIR1 & CHS 71 & 1216 & -1.59 & 39.1 & 0.18 & bdl & bdl & 0.57 & 0.03 & 15.6 & 0.13 & 0.35 & 0.04 & 44.0 & 0.09 & 0.33 & 0.02 & bdl & & bdl & & 101.2 & 7 \\
\hline
\end{tabular}

numbers in italic represent the analytical standard errors $(1 \sigma)$

bdl: below detection limit. Detection limits as follow (in ppm): Si 195, Ti 296, Al 161, Cr 406, Fe 223, Mn 217, Mg 212, Ca 145, Na 459, K 111, P 254 , Ni 341 
Table S2 olivine composition in experiments

\begin{tabular}{|c|c|c|c|c|c|c|c|c|c|c|c|c|c|c|c|c|c|c|c|c|c|c|}
\hline comp. & $\exp \#$ & $\mathrm{~T}\left({ }^{\circ} \mathrm{C}\right)$ & $\Delta \mathrm{IW}$ & $\mathrm{SiO}_{2}$ & & $\mathrm{TiO}_{2}$ & $\mathrm{Al}_{2} \mathrm{O}_{3}$ & $\mathrm{Cr}_{2} \mathrm{O}_{3}$ & & $\mathrm{FeO}$ & & $\mathrm{MnO}$ & & $\mathrm{MgO}$ & & $\mathrm{CaO}$ & & $\mathrm{P}_{2} \mathrm{O}_{5}$ & $\mathrm{NiO}$ & & total & $\mathrm{n}$ \\
\hline CIR2a & CHS 50 & 1248 & -1.89 & 40.7 & 0.29 & bdl & bdl & 0.50 & 0.02 & 10.5 & 0.16 & 0.40 & 0.02 & 47.5 & 0.07 & 0.39 & 0.05 & bdl & bdl & & 100.1 & 3 \\
\hline CIR2a & CHS 51 & 1217 & -1.58 & 38.9 & 0.08 & bdl & bdl & 0.60 & 0.02 & 17.6 & 0.13 & 0.40 & 0.02 & 42.0 & 0.23 & 0.37 & 0.02 & bdl & bdl & & 101.3 & 5 \\
\hline CIR2a & CHS 53 & 1248 & -1.47 & 38.1 & 0.32 & bdl & bdl & 0.66 & 0.00 & 18.6 & 0.01 & 0.40 & 0.01 & 41.8 & 0.08 & 0.45 & 0.02 & bdl & bdl & & 101.5 & 3 \\
\hline CIR2a & CHS 53 & 1248 & -1.47 & 38.1 & 0.31 & bdl & bdl & 0.59 & 0.02 & 17.9 & 0.14 & 0.41 & 0.02 & 42.4 & 0.35 & 0.47 & 0.01 & bdl & bdl & & 101.2 & 5 \\
\hline CIR2b & CHS 63 & 1202 & -1.38 & 38.1 & 0.25 & bdl & bdl & 0.68 & 0.02 & 18.6 & 0.28 & 0.28 & 0.03 & 41.8 & 0.23 & 0.38 & 0.02 & bdl & 0.07 & 0.05 & 99.7 & 5 \\
\hline CIR2b & CHS 65 & 1201 & -2.27 & 40.4 & 0.28 & bdl & bdl & 0.66 & 0.04 & 7.06 & 0.06 & 0.39 & 0.04 & 51.0 & 0.23 & 0.33 & 0.04 & bdl & 0.07 & 0.02 & 101.1 & 6 \\
\hline CIR2b & CHS 66 & 1250 & -2.53 & 40.7 & 0.40 & bdl & bdl & 0.70 & 0.02 & 4.99 & 0.06 & 0.39 & 0.02 & 52.8 & 0.42 & 0.38 & 0.08 & bdl & 0.05 & 0.02 & 100.8 & 7 \\
\hline CIR2b & CHS 67 & 1274 & -1.59 & 38.7 & 0.12 & bdl & bdl & 0.73 & 0.02 & 14.7 & 0.07 & 0.38 & 0.03 & 45.1 & 0.22 & 0.34 & 0.01 & bdl & bdl & & 101.0 & 5 \\
\hline $\mathrm{CIR} 2 \mathrm{~b}$ & CHS 68 & 1159 & -1.53 & 38.9 & 0.11 & bdl & bdl & 0.47 & 0.03 & 18.5 & 0.11 & 0.38 & 0.02 & 41.3 & 0.20 & 0.36 & 0.05 & bdl & bdl & & 101.4 & 7 \\
\hline CIR2b & CHS 69 & 1301 & -2.44 & 40.6 & 0.15 & bdl & bdl & 0.74 & 0.02 & 5.44 & 0.04 & 0.44 & 0.04 & 52.4 & 0.16 & 0.35 & 0.02 & bdl & bdl & & 100.8 & 7 \\
\hline CIR2b & CHS 71 & 1216 & -1.59 & 39.1 & 0.27 & bdl & 0.09 & 0.77 & 0.02 & 15.2 & 0.21 & 0.41 & 0.04 & 43.9 & 0.73 & 0.43 & 0.12 & bdl & bdl & & 101.4 & 7 \\
\hline CIR3 & CHS 49 & 1248 & -1.62 & 38.9 & 0.22 & bdl & bdl & 0.59 & 0.03 & 15.47 & 0.21 & 0.41 & 0.02 & 44.2 & 0.06 & 0.34 & 0.01 & bdl & bdl & & 100.8 & 3 \\
\hline CIR3 & CHS 50 & 1248 & -1.89 & 40.4 & 0.19 & bdl & bdl & 0.56 & 0.01 & 11.14 & 0.10 & 0.44 & 0.03 & 47.0 & 0.53 & 0.33 & 0.02 & bdl & 0.07 & 0.06 & 99.4 & 3 \\
\hline CIR3 & CHS 51 & 1217 & -1.58 & 39.0 & 0.10 & bdl & bdl & 0.59 & 0.01 & 17.30 & 0.16 & 0.42 & 0.01 & 42.3 & 0.25 & 0.34 & 0.03 & bdl & bdl & & 101.4 & 5 \\
\hline CIR3 & CHS 53 & 1248 & -1.47 & 38.4 & 0.02 & bdl & bdl & 0.64 & 0.02 & 17.64 & 0.14 & 0.42 & 0.01 & 42.5 & 0.12 & 0.36 & 0.01 & bdl & bdl & & 101.2 & 3 \\
\hline $\mathrm{RCa}$ & CHS 65 & 1201 & -2.27 & 40.6 & 0.37 & bdl & bdl & 0.49 & 0.02 & 6.97 & 0.09 & 0.38 & 0.03 & 51.1 & 0.41 & 0.34 & 0.08 & bdl & bdl & & 100.0 & 8 \\
\hline $\mathrm{RCa}$ & CHS 66 & 1250 & -2.53 & 40.8 & 0.31 & bdl & bdl & 0.52 & 0.03 & 4.69 & 0.07 & 0.37 & 0.02 & 53.2 & 0.45 & 0.40 & 0.09 & bdl & bdl & & 100.6 & 9 \\
\hline $\mathrm{RCa}$ & CHS 68 & 1159 & -1.53 & 38.6 & 0.71 & bdl & bdl & 0.49 & 0.01 & 17.70 & 0.16 & 0.32 & 0.02 & 42.3 & 0.31 & 0.40 & 0.01 & bdl & 0.04 & 0.01 & 100.8 & 7 \\
\hline $\mathrm{RCa}$ & CHS 69 & 1301 & -2.44 & 41.2 & 0.32 & bdl & bdl & 0.53 & 0.01 & 5.65 & 0.08 & 0.37 & 0.05 & 51.7 & 0.24 & 0.46 & 0.02 & bdl & 0.05 & 0.02 & 100.2 & 6 \\
\hline $\mathrm{RCa}$ & CHS 70 & 1205 & -1.84 & 38.9 & 0.20 & bdl & bdl & 0.52 & 0.01 & 15.23 & 0.21 & 0.35 & 0.04 & 44.5 & 0.21 & 0.34 & 0.01 & bdl & bdl & & 101.6 & 3 \\
\hline $\mathrm{RCa} 2$ & CHS 68 & 1159 & -1.53 & 39.2 & 0.15 & bdl & bdl & 0.40 & 0.02 & 17.7 & 0.08 & 0.36 & 0.04 & 42.0 & 0.17 & 0.39 & 0.09 & bdl & bdl & & 101.4 & 7 \\
\hline $\mathrm{RCa} 2$ & CHS 69 & 1301 & -2.44 & 41.3 & 0.23 & bdl & bdl & 0.71 & 0.04 & 5.15 & 0.08 & 0.33 & 0.03 & 51.9 & 0.38 & 0.48 & 0.06 & bdl & bdl & & 100.3 & 6 \\
\hline $\mathrm{RCa} 2$ & CHS 70 & 1205 & -1.84 & 39.1 & 0.17 & bdl & bdl & 0.53 & 0.03 & 14.0 & 0.02 & 0.41 & 0.04 & 45.5 & 0.10 & 0.31 & 0.03 & bdl & bdl & & 101.4 & 4 \\
\hline
\end{tabular}

numbers in italic represent the analytical standard errors $(1 \sigma)$

bdl: below detection limit. Detection limits as follow (in ppm): Si 195, Ti 296, Al 161, Cr 406, Fe 223, Mn 217, Mg 212, Ca 145, Na 459, K 111, P 254 , Ni 341 


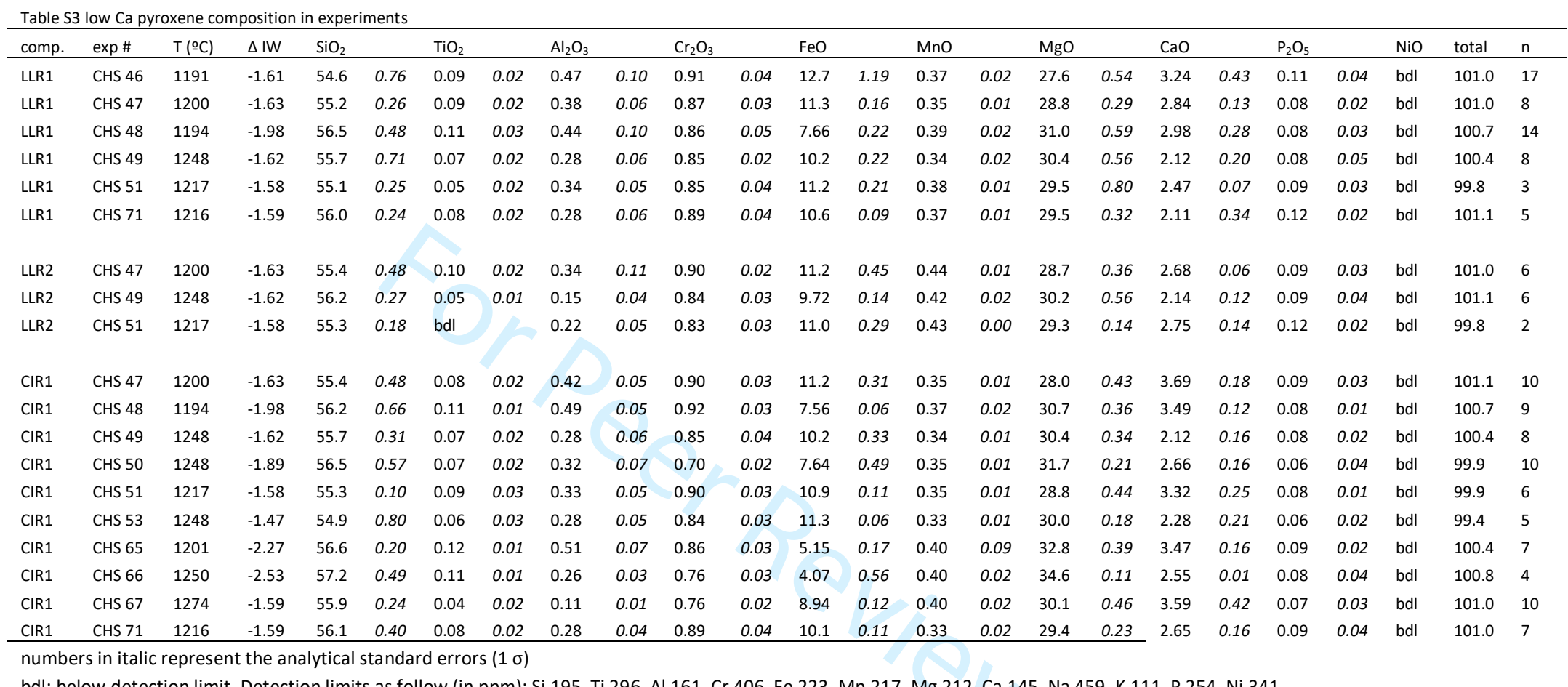

bdl: below detection limit. Detection limits as follow (in ppm): Si 195, Ti 296, Al 161, Cr 406, Fe 223, Mn 217, Mg 212, Ca 145, Na 459, K 111, P 254 , Ni 341 


\begin{tabular}{|c|c|c|c|c|c|c|c|c|c|c|c|c|c|c|c|c|c|c|c|c|c|c|c|c|}
\hline comp. & $\exp \#$ & $\mathrm{~T}\left(\mathrm{O}^{\mathrm{C}}\right)$ & $\Delta \mathrm{IW}$ & $\mathrm{SiO}_{2}$ & & $\mathrm{TiO}_{2}$ & & $\mathrm{Al}_{2} \mathrm{O}_{3}$ & & $\mathrm{Cr}_{2} \mathrm{O}_{3}$ & & $\mathrm{FeO}$ & & $\mathrm{MnO}$ & & $\mathrm{MgO}$ & & $\mathrm{CaO}$ & & $\mathrm{P}_{2} \mathrm{O}_{5}$ & & $\mathrm{NiO}$ & total & $\mathrm{n}$ \\
\hline CIR2a & CHS 50 & 1248 & -1.89 & 56.3 & 0.44 & 0.06 & 0.01 & 0.24 & 0.04 & 0.70 & 0.04 & 7.23 & 0.21 & 0.43 & 0.02 & 29.9 & 0.31 & 4.96 & 0.20 & 0.10 & 0.02 & bdl & 99.9 & 11 \\
\hline CIR2a & CHS 51 & 1217 & -1.58 & 55.0 & 0.38 & 0.08 & 0.02 & 0.32 & 0.04 & 0.89 & 0.03 & 10.9 & 0.41 & 0.39 & 0.02 & 27.0 & 0.64 & 5.32 & 0.46 & 0.12 & 0.05 & bdl & 100.2 & 6 \\
\hline CIR2a & CHS 53 & 1248 & -1.47 & 55.4 & 0.48 & 0.05 & 0.02 & 0.17 & 0.01 & 0.83 & 0.04 & 10.8 & 0.18 & 0.38 & 0.01 & 27.0 & 0.59 & 5.30 & 0.43 & 0.07 & 0.04 & bdl & 100.7 & 8 \\
\hline CIR2a & CHS 53 & 1248 & -1.47 & 55.4 & 0.29 & 0.03 & 0.02 & 0.13 & 0.02 & 0.81 & 0.04 & 10.5 & 0.27 & 0.38 & 0.02 & 27.6 & 0.33 & 5.08 & 0.45 & 0.09 & 0.02 & bdl & 100.6 & 8 \\
\hline CIR2b & CHS 63 & 1202 & -1.38 & 54.3 & 0.48 & 0.11 & 0.03 & 0.44 & 0.06 & 1.13 & 0.04 & 10.9 & 0.34 & 0.42 & 0.02 & 26.6 & 0.54 & 5.92 & 0.56 & 0.10 & 0.03 & bdl & 99.7 & 4 \\
\hline CIR2b & CHS 65 & 1201 & -2.27 & 55.6 & 0.97 & 0.12 & 0.02 & 0.65 & 0.05 & 1.09 & 0.02 & 5.28 & 0.30 & 0.51 & 0.02 & 32.4 & 0.43 & 4.22 & 0.26 & 0.12 & 0.04 & bdl & 99.4 & 2 \\
\hline CIR2b & CHS 66 & 1250 & -2.53 & 56.8 & 0.75 & 0.07 & 0.02 & 0.33 & 0.09 & 0.99 & 0.03 & 3.71 & 0.17 & 0.47 & 0.01 & 33.8 & 0.85 & 3.73 & 0.23 & 0.09 & 0.02 & bdl & 101.0 & 14 \\
\hline CIR2b & CHS 68 & 1159 & -1.53 & 54.8 & 0.54 & 0.12 & 0.02 & 0.47 & 0.04 & 0.84 & 0.03 & 11.8 & 0.27 & 0.43 & 0.04 & 26.8 & 0.34 & 4.52 & 0.15 & 0.14 & 0.03 & bdl & 99.7 & 5 \\
\hline CIR2b & CHS 69 & 1301 & -2.44 & 57.3 & 0.31 & 0.04 & 0.02 & 0.16 & 0.03 & 0.92 & 0.03 & 4.24 & 0.28 & 0.45 & 0.02 & 34.2 & 0.32 & 2.69 & 0.12 & 0.04 & 0.02 & bdl & 101.0 & 7 \\
\hline CIR2b & CHS 71 & 1216 & -1.59 & 55.8 & 0.74 & 0.06 & 0.02 & 0.31 & 0.07 & 1.12 & 0.03 & 9.59 & 0.24 & 0.41 & 0.03 & 28.4 & 0.41 & 4.14 & 0.35 & 0.11 & 0.03 & bdl & 101.2 & 12 \\
\hline CIR3 & CHS 49 & 1248 & -1.62 & 55.7 & 0.46 & 0.04 & 0.02 & 0.17 & 0.02 & 0.84 & 0.03 & 10.2 & 0.12 & 0.40 & 0.02 & 29.6 & 0.34 & 2.91 & 0.20 & 0.08 & 0.03 & bdl & 100.7 & 8 \\
\hline CIR3 & CHS 50 & 1248 & -1.89 & 56.3 & 0.46 & 0.06 & 0.02 & 0.25 & 0.06 & 0.76 & 0.03 & 7.75 & 0.41 & 0.44 & 0.02 & 31.4 & 0.33 & 2.94 & 0.10 & 0.14 & 0.06 & bdl & 100.0 & 7 \\
\hline CIR3 & CHS 51 & 1217 & -1.58 & 55.8 & 1.20 & 0.08 & 0.02 & 0.32 & 0.09 & 0.84 & 0.03 & 10.9 & 0.25 & 0.41 & 0.01 & 28.1 & 0.71 & 3.46 & 0.26 & 0.13 & 0.03 & bdl & 100.1 & 4 \\
\hline CIR3 & CHS 53 & 1248 & -1.47 & 55.6 & 0.15 & 0.06 & 0.01 & 0.23 & 0.07 & 0.85 & 0.02 & 11.1 & 0.23 & 0.40 & 0.02 & 28.8 & 0.38 & 2.91 & 0.26 & 0.06 & 0.03 & bdl & 100.7 & 15 \\
\hline $\mathrm{RCa}$ & CHS 66 & 1250 & -2.53 & 57.1 & 0.20 & bdl & & 0.39 & 0.04 & 0.74 & 0.04 & 3.25 & 0.08 & 0.44 & 0.03 & 32.6 & 0.43 & 5.38 & 0.40 & 0.08 & 0.02 & bdl & 100.9 & 9 \\
\hline $\mathrm{RCa}$ & CHS 68 & 1159 & -1.53 & 55.1 & 0.31 & 0.05 & 0.01 & 0.96 & 0.26 & 0.92 & 0.08 & 10.4 & 0.25 & 0.34 & 0.02 & 25.8 & 0.68 & 6.23 & 0.87 & 0.16 & 0.09 & bdl & 100.1 & 12 \\
\hline $\mathrm{RCa}$ & CHS 69 & 1301 & -2.44 & 56.5 & 0.73 & bdl & & 0.12 & 0.01 & 0.66 & 0.04 & 5.28 & 1.16 & 0.39 & 0.01 & 32.3 & 0.59 & 4.69 & 0.37 & bdl & & bdl & 99.8 & 5 \\
\hline $\mathrm{RCa}$ & CHS 70 & 1205 & -1.84 & 55.6 & 0.26 & 0.05 & 0.02 & 0.81 & 0.11 & 0.89 & 0.04 & 9.44 & 0.35 & 0.34 & 0.01 & 27.8 & 0.40 & 4.97 & 0.20 & 0.13 & 0.05 & bdl & 100.4 & 8 \\
\hline $\mathrm{RCa}_{2}$ & CHS 69 & 1301 & -2.44 & 57.4 & 0.15 & bdl & & 0.14 & 0.03 & 0.87 & 0.03 & 4.26 & 0.51 & 0.33 & 0.03 & 32.4 & 0.30 & 4.77 & 0.09 & bdl & & bdl & 99.4 & 6 \\
\hline
\end{tabular}

numbers in italic represent the analytical standard errors $(1 \sigma)$

bdl: below detection limit. Detection limits as follow (in ppm): Si 195, Ti 296, Al 161, Cr 406, Fe 223, Mn 217, Mg 212, Ca 145, Na 459, K 111, P 254 , Ni 341 


\begin{tabular}{|c|c|c|c|c|c|c|c|c|c|c|c|c|c|c|c|c|c|c|c|c|c|c|c|c|c|c|}
\hline comp. & $\exp \#$ & $T\left({ }^{\circ} \mathrm{C}\right)$ & $\Delta \mathrm{IW}$ & $\mathrm{SiO}_{2}$ & & $\mathrm{TiO}_{2}$ & & $\mathrm{Al}_{2} \mathrm{O}_{3}$ & & $\mathrm{Cr}_{2} \mathrm{O}_{3}$ & & $\mathrm{FeO}$ & & $\mathrm{MnO}$ & & $\mathrm{MgO}$ & & $\mathrm{CaO}$ & & $\mathrm{Na}_{2} \mathrm{O}$ & & $\mathrm{P}_{2} \mathrm{O}_{5}$ & & $\mathrm{NiO}$ & total & $n$ \\
\hline CIR2b & CHS 65 & 1201 & -2.27 & 54.4 & & 0.11 & & 0.98 & & 0.86 & & 2.90 & & 0.34 & & 22.5 & & 17.8 & & 0.19 & & 0.19 & & bdl & 101.1 & 1 \\
\hline $\mathrm{RCa}$ & CHS 65 & 1201 & -2.27 & 54.2 & 0.24 & 0.12 & 0.02 & 1.28 & 0.09 & 0.82 & 0.02 & 2.78 & 0.12 & 0.33 & 0.02 & 21.7 & 0.21 & 18.5 & 0.28 & 0.18 & 0.02 & 0.18 & 0.02 & bdl & 100.8 & 7 \\
\hline RCa & CHS 66 & 1250 & -2.53 & 55.2 & 0.33 & 0.08 & 0.04 & 0.75 & 0.13 & 0.66 & 0.03 & 2.29 & 0.15 & 0.33 & 0.04 & 23.4 & 1.17 & 17.0 & 1.59 & 0.16 & 0.06 & 0.16 & 0.06 & bdl & 101.3 & 11 \\
\hline $\mathrm{RCa}$ & CHS 68 & 1159 & -1.53 & 53.4 & 0.91 & 0.09 & 0.02 & 1.44 & 0.09 & 1.14 & 0.09 & 6.93 & 0.16 & 0.24 & 0.01 & 20.4 & 0.25 & 16.1 & 0.66 & 0.24 & 0.02 & 0.24 & 0.02 & bdl & 100.3 & 2 \\
\hline RCa & CHS 69 & 1301 & -2.44 & 55.2 & 0.04 & 0.15 & 0.01 & 0.97 & 0.25 & 1.01 & 0.11 & 3.43 & 0.02 & 0.36 & 0.04 & 25.7 & 0.35 & 13.1 & 0.32 & 0.09 & 0.04 & 0.09 & 0.04 & bdl & 100.8 & 3 \\
\hline $\mathrm{RCa}$ & CHS 70 & 1205 & -1.84 & 53.0 & 0.04 & 0.10 & 0.01 & 1.60 & 0.11 & 1.17 & 0.04 & 5.92 & 0.03 & 0.24 & 0.02 & 19.5 & 0.51 & 18.3 & 0.53 & 0.21 & 0.00 & 0.21 & 0.00 & bdl & 101.3 & 8 \\
\hline RCa2 & CHS 68 & 1159 & -1.53 & 52.9 & 0.10 & 0.22 & 0.01 & 1.50 & 0.06 & 1.09 & 0.02 & 6.39 & 0.09 & 0.24 & 0.02 & 18.0 & 0.59 & 19.2 & 0.44 & 0.27 & 0.05 & 0.27 & 0.05 & bdl & 100.3 & 3 \\
\hline RCa2 & CHS 69 & 1301 & -2.44 & 55.7 & 0.14 & 0.09 & 0.01 & 0.81 & 0.08 & 1.37 & 0.09 & 3.21 & 0.17 & 0.35 & 0.00 & 25.6 & 0.13 & 12.8 & 0.06 & 0.09 & 0.01 & 0.09 & 0.01 & bdl & 100.3 & 4 \\
\hline $\mathrm{RCa} 2$ & CHS 70 & 1205 & -1.84 & 52.8 & 0.78 & 0.18 & 0.03 & 1.58 & 0.09 & 1.19 & 0.11 & 5.80 & 0.16 & 0.25 & 0.01 & 20.4 & 0.03 & 17.6 & 0.10 & 0.20 & 0.05 & 0.20 & 0.05 & bdl & 101.4 & 5 \\
\hline
\end{tabular}

numbers in italic represent the analytical standard errors $(1 \sigma)$

bdl: below detection limit. Detection limits as follow (in ppm): Si 195, Ti 296, Al 161, Cr 406, Fe 223, Mn 217, Mg 212, Ca 145, Na 459, K 111, P 254 , Ni 341 
Table S5 melt compositon in experiments

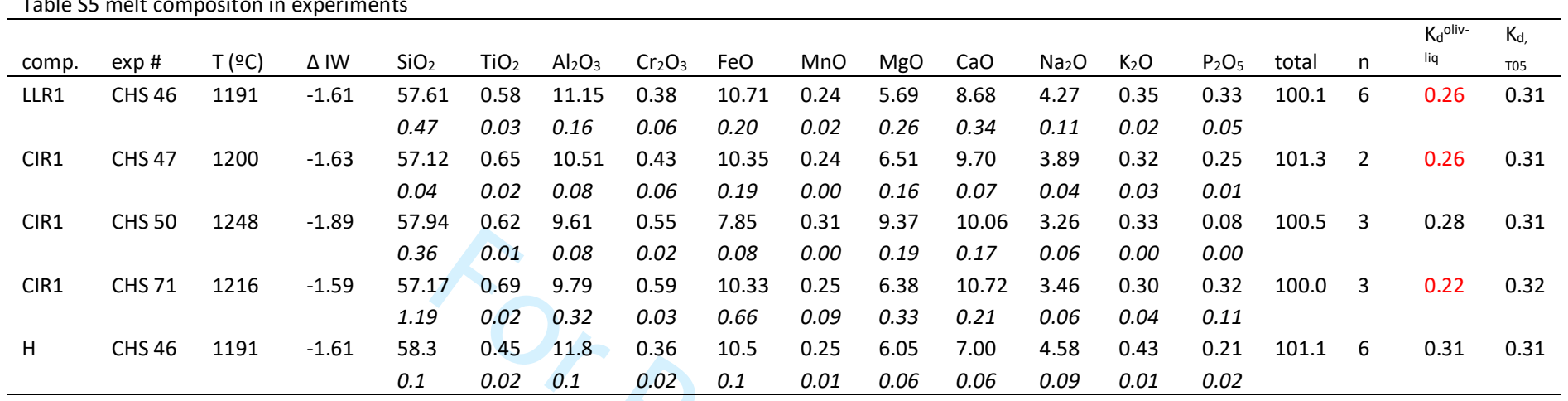

the numbers in italic represent the standard deviation of EPMA analyses

Kd T05 are the Kd oliv-liq calculated with Toplis (2005), note that several compositions display lower apparent Kd and are likely quenched modified

$\mathrm{H}$ melt from Collinet and Grove (submitted) for comparison 
Table S6 experiments used for the calibration of the DCr oliv-LCP thermometer

\begin{tabular}{|c|c|c|c|c|c|c|c|c|c|c|c|c|c|c|c|c|}
\hline \multirow[b]{2}{*}{ Name } & \multirow[b]{2}{*}{ Mat } & \multirow[b]{2}{*}{$\mathrm{T}$} & \multirow[b]{2}{*}{ IIW } & \multirow[b]{2}{*}{$\mathrm{DCr}$} & \multicolumn{12}{|c|}{ Ooivine } \\
\hline & & & & & $\mathrm{SiO} 2$ & $\mathrm{TiO} 2$ & $\mathrm{Al} 2 \mathrm{O} 3$ & $\mathrm{Cr} 2 \mathrm{O} 3$ & $\mathrm{FeO}$ & $\mathrm{MnO}$ & $\mathrm{MgO}$ & $\mathrm{CaO}$ & $\mathrm{Na} 2 \mathrm{O}$ & $\mathrm{K} 2 \mathrm{O}$ & P2O5 & $\mathrm{NIO}$ \\
\hline
\end{tabular}

$\begin{array}{lllllllllllllllll}\text { CHS 71 } & \text { LLR1 } & 1216 & -1.59 & 0.64 & 38.88 & \text { bdl } & \text { bdl } & 0.57 & 16.08 & 0.40 & 43.68 & 0.31 & \text { n.a. } & \text { n.a. } & \text { bdl } & \text { bdl }\end{array}$

$\begin{array}{lllllllllllllllll}\text { CHS } 71 & \text { CIR1 } & 1216 & -1.59 & 0.65 & 39.07 & \text { bdl } & \text { bdl } & 0.57 & 15.62 & 0.35 & 44.03 & 0.33 & \text { n.a. } & \text { n.a. } & \text { bdl } & \text { bdl }\end{array}$

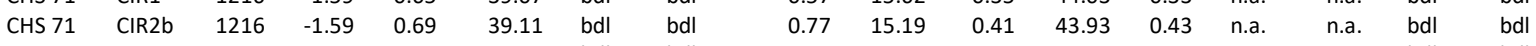

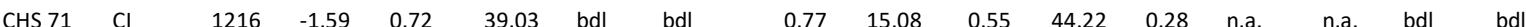

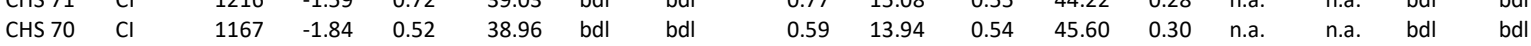

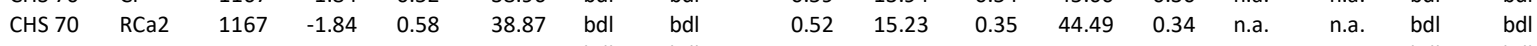

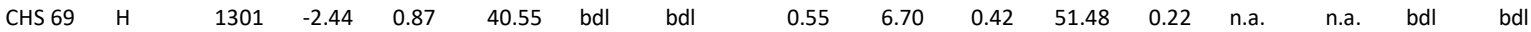

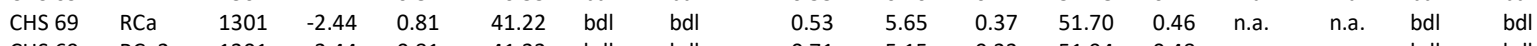

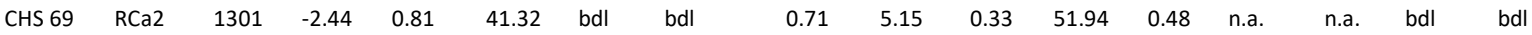

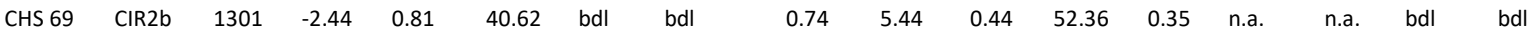

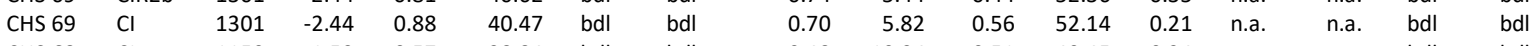

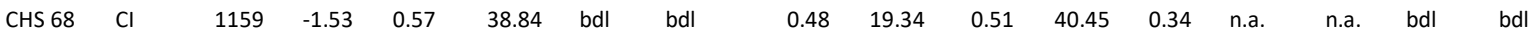

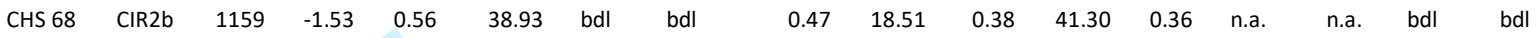

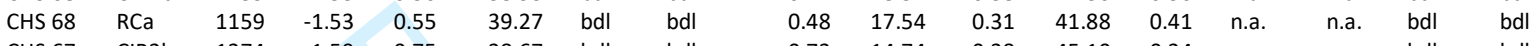

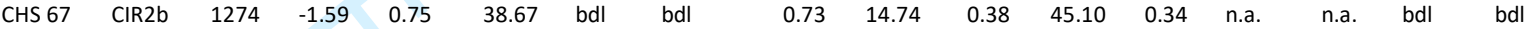

$\begin{array}{lllllllllllllllll}\text { CHS } 67 & \text { CIR1 } & 1274 & -1.59 & 0.75 & 37.99 & \text { bdl } & \text { bdl } & 0.57 & 14.17 & 0.36 & 46.46 & 0.40 & \text { n.a. } & \text { n.a. } & \text { bdl } & \text { bdl }\end{array}$

$\begin{array}{lllllllllllllllll}\text { CHS } 66 & \text { CIR1 } & 1250 & -2.53 & 0.71 & 40.41 & \text { bdl } & \text { bdl } & 0.55 & 5.35 & 0.37 & 52.97 & 0.28 & \text { n.a. } & \text { n.a. } & \text { bdl } & \text { bdl }\end{array}$

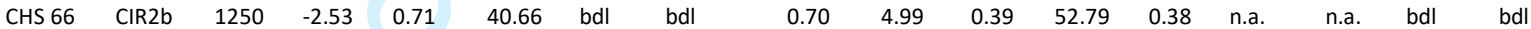

$\begin{array}{lllllllllllllllll}\text { CHS 66 } & \text { RCa } & 1250 & -2.53 & 0.71 & 40.78 & \text { bdl } & \text { bdl } & 0.52 & 4.69 & 0.37 & 53.17 & 0.40 & \text { n.a. } & \text { n.a. } & \text { bdl } & \text { bdl }\end{array}$

$\begin{array}{lllllllllllllllll}\text { CHS } 65 & \text { CIR2b } & 1201 & -2.27 & 0.60 & 40.36 & \text { bdl } & \text { bdl } & 0.66 & 7.06 & 0.38 & 51.13 & 0.32 & \text { n.a. } & \text { n.a. } & \text { bdl } & 0.06\end{array}$

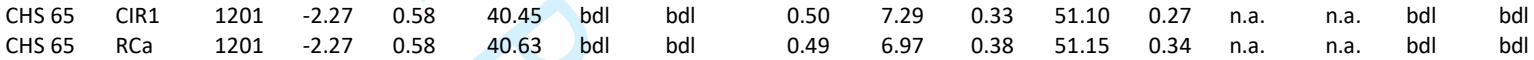

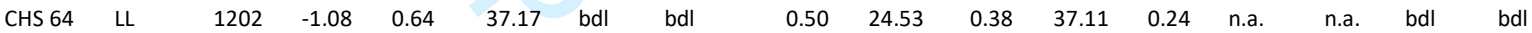

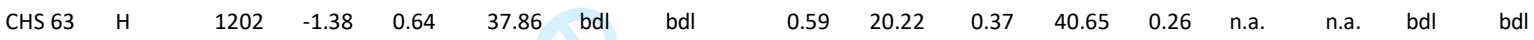

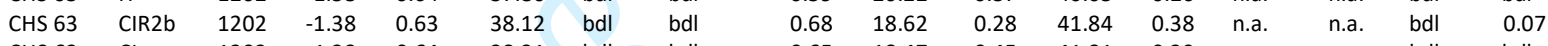

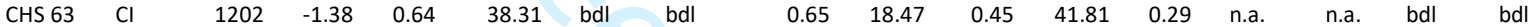

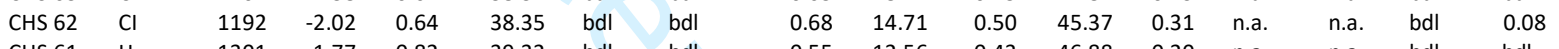

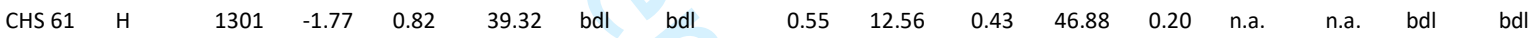

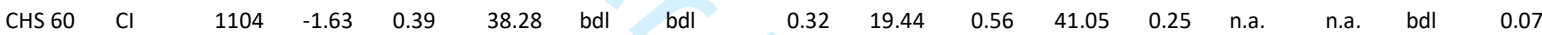

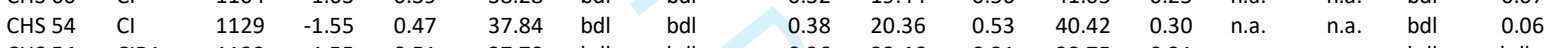

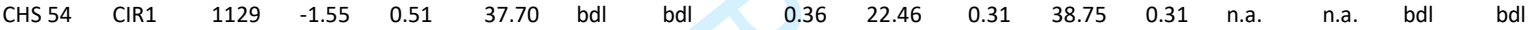

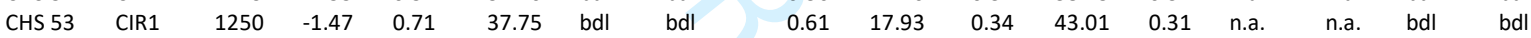

$\begin{array}{lllllllllllllllll}\text { CHS 53 } & \text { CIR2a } & 1250 & -1.47 & 0.72 & 38.14 & \text { bdl } & \text { bdl } & 0.59 & 17.91 & 0.41 & 42.44 & 0.47 & \text { n.a. } & \text { n.a. } & \text { bdl } & \text { bdl }\end{array}$

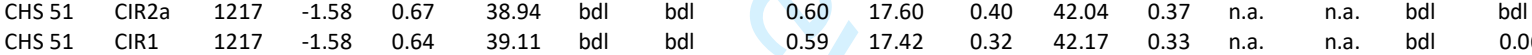

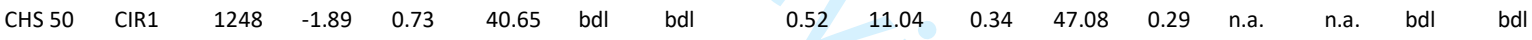

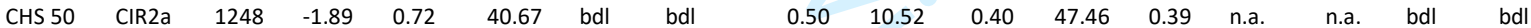

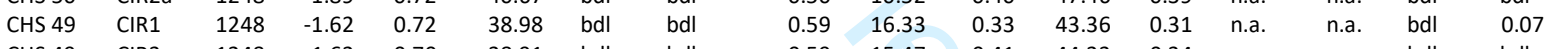

$\begin{array}{lllllllllllllllll}\text { CHS } 49 & \text { CIR3 } & 1248 & -1.62 & 0.70 & 38.91 & \text { bdl } & \text { bdl } & 0.59 & 15.47 & 0.41 & 44.23 & 0.34 & \text { n.a. } & \text { n.a. } & \text { bdl } & \text { bdl }\end{array}$

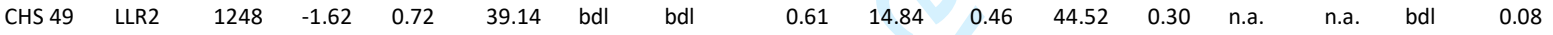

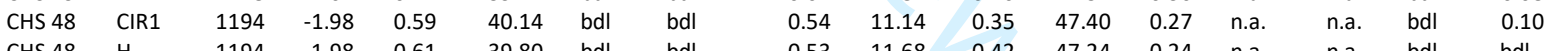

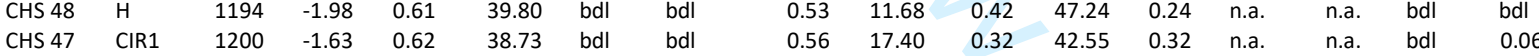

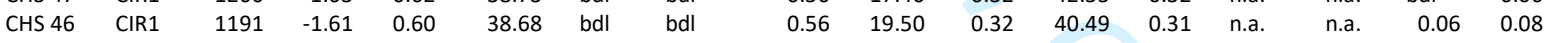

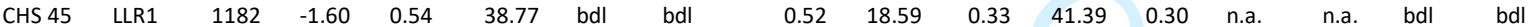

$\begin{array}{lllllllllllllllll}\text { CHS } 44 & \mathrm{H} & 1161 & -1.86 & 0.55 & 39.76 & \text { bdl } & \text { bdl } & 0.47 & 13.59 & 0.48 & 45.34 & 0.24 & \text { n.a. } & \text { n.a. } & 0.08 & \text { bdl }\end{array}$

$\begin{array}{lllllllllllllllll}\text { CHS } 43 & \mathrm{H} & 1163 & -2.06 & 0.50 & 40.59 & \text { bdl } & \text { bdl } & 0.41 & 9.65 & 0.47 & 48.46 & 0.22 & \text { n.a. } & \text { n.a. } & 0.08 & 0.07\end{array}$

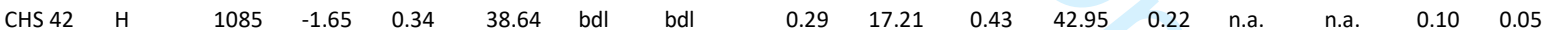

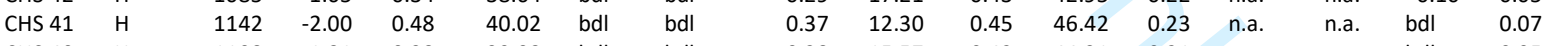

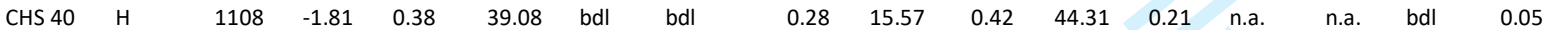

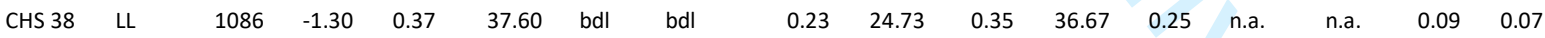

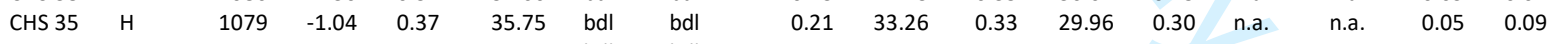

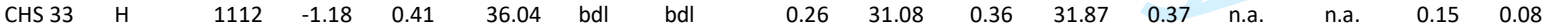

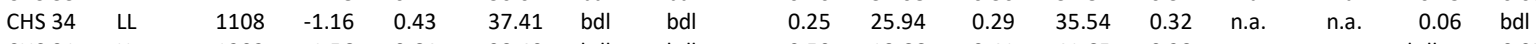

$\begin{array}{lllllllllllllllll}\text { CHS } 31 & \mathrm{H} & 1202 & -1.56 & 0.64 & 38.40 & \text { bdl } & \text { bdl } & 0.50 & 18.66 & 0.41 & 41.65 & 0.28 & \text { n.a. } & \text { n.a. } & \text { bdl } & 0.05\end{array}$

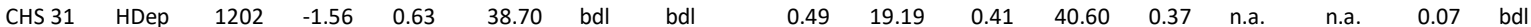

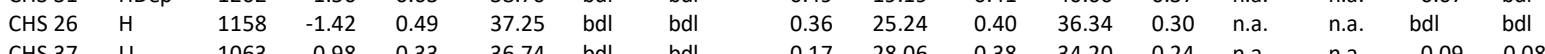

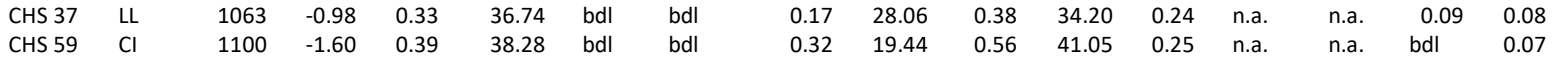

\begin{tabular}{|c|c|c|}
\hline & $\mathrm{Cl}$ & 1136 \\
\hline
\end{tabular}

n.a. not analyzed

bdl: below detection limit

see Table S2, S3 and S4 for standard deviations 
Table S6 experiments used for the calibration of the DCr oliv-LCP thermometer (continued)

\begin{tabular}{|c|c|c|c|c|c|c|c|c|c|c|c|c|c|c|c|c|}
\hline \multirow[b]{2}{*}{ Name } & \multirow[b]{2}{*}{ Mat } & \multirow[b]{2}{*}{$\mathrm{T}$} & \multirow[b]{2}{*}{ dIW } & \multirow[b]{2}{*}{$\mathrm{DCr}$} & \multicolumn{12}{|c|}{ low Ca pyroxene } \\
\hline & & & & & $\mathrm{SiO} 2$ & $\mathrm{TiO} 2$ & $\mathrm{Al} 2 \mathrm{O} 3$ & $\mathrm{Cr} 2 \mathrm{O} 3$ & $\mathrm{FeO}$ & $\mathrm{MnO}$ & $\mathrm{MgO}$ & $\mathrm{CaO}$ & $\mathrm{Na2O}$ & $\mathrm{K} 2 \mathrm{O}$ & $\mathrm{P} 2 \mathrm{O5}$ & $\mathrm{NIO}$ \\
\hline CHS 71 & LLR1 & 1216 & -1.59 & 0.639 & 56.04 & 0.08 & 0.28 & 0.89 & 10.63 & 0.37 & 29.48 & 2.11 & 0.12 & bdl & bdl & bdl \\
\hline CHS 71 & CIR1 & 1216 & -1.59 & 0.645 & 56.12 & 0.08 & 0.28 & 0.89 & 10.15 & 0.33 & 29.40 & 2.65 & 0.09 & bdl & bdl & bdl \\
\hline CHS 71 & $\mathrm{CIR} 2 \mathrm{~b}$ & 1216 & -1.59 & 0.686 & 55.85 & 0.06 & 0.31 & 1.12 & 9.59 & 0.41 & 28.42 & 4.14 & 0.11 & bdl & bdl & bdl \\
\hline CHS 71 & $\mathrm{Cl}$ & 1216 & -1.59 & 0.719 & 55.98 & 0.05 & 0.32 & 1.07 & 9.70 & 0.55 & 30.71 & 1.56 & 0.10 & bdl & bdl & bdl \\
\hline CHS 70 & $\mathrm{Cl}$ & 1167 & -1.84 & 0.524 & 55.09 & 0.10 & 0.62 & 1.13 & 9.39 & 0.60 & 28.64 & 4.32 & 0.13 & bdl & bdl & bdl \\
\hline CHS 70 & $\mathrm{RCa} 2$ & 1167 & -1.84 & 0.585 & 55.56 & 0.05 & 0.81 & 0.89 & 9.44 & 0.34 & 27.80 & 4.97 & 0.13 & bdl & bdl & bdl \\
\hline CHS 69 & $\mathrm{H}$ & 1301 & -2.44 & 0.871 & 58.29 & 0.05 & 0.22 & 0.63 & 4.09 & 0.40 & 35.83 & 0.49 & 0.00 & bdl & bdl & bdl \\
\hline CHS 69 & $\mathrm{RCa}$ & 1301 & -2.44 & 0.81 & 56.50 & 0.03 & 0.12 & 0.66 & 5.28 & 0.39 & 32.29 & 4.69 & 0.05 & bdl & bdl & bdl \\
\hline CHS 69 & $\mathrm{RCa} 2$ & 1301 & -2.44 & 0.815 & 57.39 & 0.01 & 0.14 & 0.87 & 4.26 & 0.33 & 32.38 & 4.58 & 0.03 & bdl & bdl & bdl \\
\hline CHS 69 & $\mathrm{CIR} 2 \mathrm{~b}$ & 1301 & -2.44 & 0.809 & 57.29 & 0.04 & 0.16 & 0.92 & 4.24 & 0.45 & 34.16 & 2.69 & 0.04 & bdl & bdl & bdl \\
\hline CHS 69 & $\mathrm{Cl}$ & 1301 & -2.44 & 0.878 & 57.67 & 0.06 & 0.19 & 0.80 & 5.34 & 0.43 & 35.08 & 0.40 & 0.02 & bdl & bdl & bdl \\
\hline CHS 68 & $\mathrm{Cl}$ & 1159 & -1.53 & 0.569 & 55.11 & 0.09 & 0.47 & 0.84 & 12.64 & 0.53 & 26.16 & 4.05 & 0.10 & bdl & bdl & bdl \\
\hline CHS 68 & $\mathrm{CIR} 2 \mathrm{~b}$ & 1159 & -1.53 & 0.557 & 54.82 & 0.12 & 0.47 & 0.84 & 11.82 & 0.43 & 26.83 & 4.52 & 0.14 & bdl & bdl & bdl \\
\hline CHS 68 & $\mathrm{RCa}$ & 1159 & -1.53 & 0.551 & 55.20 & 0.04 & 0.97 & 0.88 & 10.47 & 0.34 & 25.82 & 6.09 & 0.16 & bdl & bdl & bdl \\
\hline CHS 67 & $\mathrm{CIR} 2 \mathrm{~b}$ & 1274 & -1.586 & 0.75 & 55.61 & 0.05 & 0.20 & 0.97 & 9.55 & 0.39 & 30.43 & 2.72 & 0.08 & bdl & bdl & bdl \\
\hline CHS 67 & CIR1 & 1274 & -1.586 & 0.75 & 55.93 & 0.04 & 0.11 & 0.76 & 8.94 & 0.40 & 30.14 & 3.59 & 0.07 & bdl & bdl & bdl \\
\hline CHS 66 & CIR1 & 1250 & -2.535 & 0.713 & 57.19 & 0.11 & 0.26 & 0.76 & 4.07 & 0.40 & 34.57 & 2.55 & 0.08 & bdl & bdl & bdl \\
\hline CHS 66 & $\mathrm{CIR} 2 \mathrm{~b}$ & 1250 & -2.535 & 0.709 & 56.81 & 0.07 & 0.33 & 0.99 & 3.71 & 0.47 & 33.82 & 3.73 & 0.09 & bdl & bdl & bdl \\
\hline CHS 66 & $\mathrm{RCa}$ & 1250 & -2.535 & 0.711 & 57.08 & 0.02 & 0.39 & 0.74 & 3.25 & 0.44 & 32.62 & 5.38 & 0.08 & bdl & bdl & bdl \\
\hline CHS 65 & $\mathrm{CIR} 2 \mathrm{~b}$ & 1201 & -2.27 & 0.598 & 56.17 & 0.10 & 0.66 & 1.10 & 5.19 & 0.49 & 32.14 & 4.06 & 0.12 & bdl & bdl & bdl \\
\hline CHS 65 & CIR1 & 1201 & -2.27 & 0.583 & 56.69 & 0.12 & 0.43 & 0.86 & 5.10 & 0.40 & 32.86 & 3.46 & 0.06 & bdl & bdl & bdl \\
\hline CHS 65 & $\mathrm{RCa}$ & 1201 & -2.27 & 0.579 & 56.52 & 0.05 & 0.72 & 0.84 & 4.68 & 0.51 & 32.05 & 4.53 & 0.09 & bdl & bdl & bdl \\
\hline CHS 64 & LL & 1202 & -1.08 & 0.639 & 54.46 & 0.02 & 0.35 & 0.78 & 15.21 & 0.32 & 26.76 & 2.08 & 0.03 & bdl & bdl & bdl \\
\hline CHS 63 & $\mathrm{H}$ & 1202 & -1.375 & 0.637 & 54.83 & 0.08 & 0.44 & 0.92 & 12.78 & 0.45 & 28.68 & 1.82 & 0.02 & bdl & bdl & bdl \\
\hline CHS 63 & $\mathrm{CIR} 2 \mathrm{~b}$ & 1202 & -1.375 & 0.634 & 54.36 & 0.08 & 0.44 & 1.07 & 11.19 & 0.40 & 26.74 & 5.61 & 0.10 & bdl & bdl & bdl \\
\hline CHS 63 & $\mathrm{Cl}$ & 1202 & -1.375 & 0.643 & 55.21 & 0.01 & 0.42 & 1.01 & 11.67 & 0.51 & 28.69 & 2.37 & 0.07 & bdl & bdl & bdl \\
\hline CHS 62 & $\mathrm{Cl}$ & 1192 & -2.02 & 0.638 & 54.57 & 0.10 & 0.59 & 1.07 & 10.75 & 0.57 & 29.17 & 3.01 & 0.13 & bdl & bdl & bdl \\
\hline CHS 61 & $\mathrm{H}$ & 1301 & -1.77 & 0.823 & 57.12 & 0.01 & 0.24 & 0.67 & 8.06 & 0.41 & 32.59 & 0.85 & 0.05 & bdl & bdl & bdl \\
\hline CHS 60 & $\mathrm{Cl}$ & 1104 & -1.63 & 0.394 & 54.97 & 0.09 & 0.56 & 0.81 & 11.40 & 0.56 & 28.78 & 2.68 & 0.14 & bdl & bdl & bdl \\
\hline CHS 54 & $\mathrm{Cl}$ & 1129 & -1.55 & 0.471 & 54.28 & 0.10 & 0.73 & 0.80 & 12.72 & 0.55 & 26.16 & 4.62 & 0.13 & bdl & bdl & bdl \\
\hline CHS 54 & CIR1 & 1129 & -1.55 & 0.507 & 54.39 & 0.11 & 0.61 & 0.71 & 13.76 & 0.36 & 26.40 & 3.55 & 0.11 & bdl & bdl & bdl \\
\hline CHS 53 & CIR1 & 1250 & -1.47 & 0.708 & 54.87 & 0.06 & 0.28 & 0.85 & 11.29 & 0.33 & 29.98 & 2.28 & 0.06 & bdl & bdl & bdl \\
\hline CHS 53 & CIR2a & 1250 & -1.47 & 0.719 & 55.42 & 0.03 & 0.13 & 0.81 & 10.49 & 0.38 & 27.56 & 5.08 & 0.09 & bdl & bdl & bdl \\
\hline CHS 51 & CIR2a & 1217 & -1.582 & 0.673 & 55.02 & 0.08 & 0.32 & 0.89 & 10.88 & 0.39 & 26.96 & 5.32 & 0.12 & bdl & bdl & bdl \\
\hline CHS 51 & CIR1 & 1217 & -1.582 & 0.64 & 55.27 & 0.09 & 0.33 & 0.92 & 10.88 & 0.35 & 28.78 & 3.32 & 0.08 & bdl & bdl & bdl \\
\hline CHS 50 & CIR1 & 1248 & -1.89 & 0.728 & 56.53 & 0.07 & 0.32 & 0.71 & 7.64 & 0.35 & 31.66 & 2.66 & 0.06 & bdl & bdl & bdl \\
\hline CHS 50 & CIR2a & 1248 & -1.89 & 0.723 & 56.33 & 0.06 & 0.24 & 0.70 & 7.23 & 0.43 & 29.95 & 4.96 & 0.10 & bdl & bdl & bdl \\
\hline CHS 49 & CIR1 & 1248 & -1.62 & 0.722 & 55.71 & 0.07 & 0.25 & 0.81 & 10.74 & 0.31 & 29.77 & 2.27 & 0.05 & bdl & bdl & bdl \\
\hline CHS 49 & CIR3 & 1248 & -1.62 & 0.701 & 55.71 & 0.04 & 0.17 & 0.84 & 10.20 & 0.40 & 29.60 & 2.91 & 0.08 & bdl & bdl & bdl \\
\hline CHS 49 & LLR2 & 1248 & -1.62 & 0.725 & 56.19 & 0.05 & 0.15 & 0.84 & 9.72 & 0.42 & 30.17 & 2.14 & 0.09 & bdl & bdl & bdl \\
\hline CHS 48 & CIR1 & 1194 & -1.98 & 0.594 & 56.25 & 0.11 & 0.49 & 0.91 & 7.56 & 0.37 & 30.71 & 3.49 & 0.08 & bdl & bdl & bdl \\
\hline CHS 48 & $\mathrm{H}$ & 1194 & -1.98 & 0.613 & 56.47 & 0.12 & 0.51 & 0.86 & 8.12 & 0.49 & 31.08 & 2.29 & 0.05 & bdl & bdl & bdl \\
\hline CHS 47 & CIR1 & 1200 & -1.63 & 0.624 & 55.38 & 0.08 & 0.38 & 0.90 & 11.17 & 0.35 & 27.98 & 3.69 & 0.09 & bdl & bdl & bdl \\
\hline CHS 46 & CIR1 & 1191 & -1.61 & 0.603 & 54.58 & 0.09 & 0.47 & 0.92 & 12.65 & 0.37 & 27.56 & 3.24 & 0.11 & bdl & bdl & bdl \\
\hline CHS 45 & LLR1 & 1182 & -1.6 & 0.541 & 54.64 & 0.10 & 0.48 & 0.96 & 11.72 & 0.37 & 28.10 & 3.51 & 0.10 & bdl & bdl & bdl \\
\hline CHS 44 & $\mathrm{H}$ & 1161 & -1.86 & 0.551 & 55.48 & 0.12 & 0.43 & 0.85 & 9.27 & 0.55 & 29.88 & 3.29 & 0.11 & bdl & bdl & bdl \\
\hline CHS 43 & $\mathrm{H}$ & 1163 & -2.06 & 0.503 & 55.68 & 0.15 & 0.65 & 0.81 & 6.99 & 0.57 & 31.44 & 3.56 & 0.12 & bdl & bdl & bdl \\
\hline CHS 42 & $\mathrm{H}$ & 1085 & -1.65 & 0.341 & 54.47 & 0.09 & 0.47 & 0.84 & 12.36 & 0.46 & 28.99 & 2.41 & 0.08 & bdl & bdl & bdl \\
\hline CHS 41 & $\mathrm{H}$ & 1142 & -2 & 0.475 & 55.46 & 0.12 & 0.59 & 0.78 & 9.53 & 0.60 & 30.46 & 2.38 & 0.10 & bdl & bdl & bdl \\
\hline CHS 40 & $\mathrm{H}$ & 1108 & -1.81 & 0.379 & 54.90 & 0.13 & 0.51 & 0.75 & 11.06 & 0.67 & 29.64 & 2.55 & 0.13 & bdl & bdl & bdl \\
\hline CHS 38 & $\mathrm{LL}$ & 1086 & -1.3 & 0.375 & 54.60 & 0.08 & 0.47 & 0.62 & 13.90 & 0.41 & 27.40 & 2.39 & 0.12 & bdl & bdl & bdl \\
\hline CHS 35 & $\mathrm{H}$ & 1079 & -1.04 & 0.368 & 53.24 & 0.07 & 0.39 & 0.57 & 18.33 & 0.38 & 25.45 & 1.45 & 0.07 & bdl & bdl & bdl \\
\hline CHS 33 & $\mathrm{H}$ & 1112 & -1.18 & 0.413 & 52.79 & 0.13 & 0.76 & 0.64 & 17.72 & 0.37 & 22.46 & 4.99 & 0.13 & bdl & bdl & bdl \\
\hline CHS 34 & LL & 1108 & -1.16 & 0.429 & 53.86 & 0.15 & 0.67 & 0.58 & 15.69 & 0.40 & 24.90 & 3.64 & 0.14 & bdl & bdl & bdl \\
\hline CHS 31 & $\mathrm{H}$ & 1202 & -1.56 & 0.643 & 55.09 & 0.08 & 0.48 & 0.78 & 11.70 & 0.45 & 29.27 & 2.06 & 0.08 & bdl & bdl & bdl \\
\hline CHS 31 & HDep & 1202 & -1.56 & 0.626 & 54.52 & 0.11 & 0.48 & 0.78 & 11.85 & 0.41 & 27.33 & 4.41 & 0.10 & bdl & bdl & bdl \\
\hline CHS 26 & $\mathrm{H}$ & 1158 & -1.42 & 0.491 & 53.59 & 0.10 & 0.58 & 0.73 & 14.98 & 0.42 & 26.51 & 3.01 & 0.08 & bdl & bdl & bdl \\
\hline CHS 37 & $\mathrm{LL}$ & 1063 & -0.98 & 0.325 & 54.16 & 0.06 & 0.38 & 0.52 & 15.08 & 0.38 & 27.13 & 2.17 & 0.10 & bdl & bdl & bdl \\
\hline CHS 59 & $\mathrm{Cl}$ & 1100 & -1.6 & 0.394 & 54.97 & 0.09 & 0.56 & 0.81 & 11.40 & 0.56 & 28.78 & 2.68 & 0.14 & bdl & bdl & bdl \\
\hline CHS 58 & $\mathrm{Cl}$ & 1136 & -2.27 & 0.491 & 56.15 & 0.14 & 0.74 & 1.11 & 6.92 & 0.65 & 30.57 & 3.58 & 0.12 & bdl & bdl & bdl \\
\hline
\end{tabular}


Table S6 experiments used for the calibration of the DCr oliv-LCP thermometer (continued)

\begin{tabular}{|c|c|c|c|c|c|c|c|c|c|c|c|c|c|c|c|c|}
\hline \multirow[b]{2}{*}{ Name } & \multirow[b]{2}{*}{ Mat } & \multirow[b]{2}{*}{$T$} & \multirow[b]{2}{*}{ dIW } & \multirow[b]{2}{*}{$\mathrm{DCr}$} & \multicolumn{12}{|l|}{ augite } \\
\hline & & & & & $\mathrm{SiO} 2$ & $\mathrm{TiO} 2$ & $\mathrm{Al} 2 \mathrm{O} 3$ & $\mathrm{Cr} 2 \mathrm{O} 3$ & $\mathrm{FeO}$ & $\mathrm{MnO}$ & $\mathrm{MgO}$ & $\mathrm{CaO}$ & $\mathrm{Na} 2 \mathrm{O}$ & $\mathrm{K} 2 \mathrm{O}$ & P2O5 & $\mathrm{NIO}$ \\
\hline CHS 71 & LLR1 & 1216 & -1.59 & 0.64 & & & & & & & & & & & & \\
\hline CHS 71 & CIR1 & 1216 & -1.59 & 0.65 & & & & & & & & & & & & \\
\hline CHS 71 & CIR2b & 1216 & -1.59 & 0.69 & & & & & & & & & & & & \\
\hline CHS 71 & $\mathrm{Cl}$ & 1216 & -1.59 & 0.72 & & & & & & & & & & & & \\
\hline CHS 70 & $\mathrm{Cl}$ & 1167 & -1.84 & 0.52 & & & & & & & & & & & & \\
\hline CHS 70 & RCa2 & 1167 & -1.84 & 0.58 & 52.96 & 0.10 & 1.60 & 1.17 & 5.92 & 0.24 & 19.47 & 18.30 & 0.21 & bdl & bdl & bdl \\
\hline CHS 69 & $\mathrm{H}$ & 1301 & -2.44 & 0.87 & & & & & & & & & & & & \\
\hline CHS 69 & $\mathrm{RCa}$ & 1301 & -2.44 & 0.81 & 55.22 & 0.15 & 0.97 & 1.01 & 3.43 & 0.36 & 25.66 & 13.10 & 0.09 & bdl & bdl & bdl \\
\hline CHS 69 & RCa2 & 1301 & -2.44 & 0.81 & 55.74 & 0.09 & 0.81 & 1.37 & 3.21 & 0.35 & 25.56 & 12.78 & 0.09 & bdl & bdl & bdl \\
\hline CHS 69 & CIR2b & 1301 & -2.44 & 0.81 & & & & & & & & & & & & \\
\hline CHS 69 & $\mathrm{Cl}$ & 1301 & -2.44 & 0.88 & & & & & & & & & & & & \\
\hline CHS 68 & $\mathrm{Cl}$ & 1159 & -1.53 & 0.57 & & & & & & & & & & & & \\
\hline CHS 68 & CIR2b & 1159 & -1.53 & 0.56 & & & & & & & & & & & & \\
\hline CHS 68 & $\mathrm{RCa}$ & 1159 & -1.53 & 0.55 & 53.40 & 0.09 & 1.44 & 1.14 & 6.93 & 0.24 & 20.41 & 16.11 & 0.24 & bdl & bdl & bdl \\
\hline CHS 67 & CIR2b & 1274 & -1.586 & 0.75 & & & & & & & & & & & & \\
\hline CHS 67 & CIR1 & 1274 & -1.586 & 0.75 & & & & & & & & & & & & \\
\hline CHS 66 & CIR1 & 1250 & -2.535 & 0.71 & & & & & & & & & & & & \\
\hline CHS 66 & $\mathrm{CIR} 2 \mathrm{~b}$ & 1250 & -2.535 & 0.71 & & & & & & & & & & & & \\
\hline CHS 66 & $\mathrm{RCa}$ & 1250 & -2.535 & 0.71 & 55.24 & 0.08 & 0.75 & 0.66 & 2.29 & 0.33 & 23.44 & 17.04 & 0.16 & bdl & bdl & bdl \\
\hline CHS 65 & $\mathrm{CIR} 2 \mathrm{~b}$ & 1201 & -2.27 & 0.60 & 54.38 & 0.11 & 0.98 & 0.86 & 2.90 & 0.34 & 22.46 & 17.77 & 0.19 & bdl & bdl & bdl \\
\hline CHS 65 & CIR1 & 1201 & -2.27 & 0.58 & & & & & & & & & & & & \\
\hline CHS 65 & $\mathrm{RCa}$ & 1201 & -2.27 & 0.58 & 54.20 & 0.12 & 1.28 & 0.82 & 2.78 & 0.33 & 21.74 & 18.53 & 0.18 & bdl & bdl & bdl \\
\hline CHS 64 & $\mathrm{LL}$ & 1202 & -1.08 & 0.64 & & & & & & & & & & & & \\
\hline CHS 63 & $\mathrm{H}$ & 1202 & -1.375 & 0.64 & & & & & & & & & & & & \\
\hline CHS 63 & CIR2b & 1202 & -1.375 & 0.63 & & & & & & & & & & & & \\
\hline CHS 63 & $\mathrm{Cl}$ & 1202 & -1.375 & 0.64 & & & & & & & & & & & & \\
\hline CHS 62 & $\mathrm{Cl}$ & 1192 & -2.02 & 0.64 & & & & & & & & & & & & \\
\hline CHS 61 & $\mathrm{H}$ & 1301 & -1.77 & 0.82 & & & & & & & & & & & & \\
\hline CHS 60 & $\mathrm{Cl}$ & 1104 & -1.63 & 0.39 & 52.90 & 0.43 & 2.54 & 1.69 & 6.88 & 0.45 & 18.60 & 15.97 & 0.51 & bdl & bdl & bdl \\
\hline CHS 54 & $\mathrm{Cl}$ & 1129 & -1.55 & 0.47 & & & & & & & & & & & & \\
\hline CHS 54 & CIR1 & 1129 & -1.55 & 0.51 & & & & & & & & & & & & \\
\hline CHS 53 & CIR1 & 1250 & -1.47 & 0.71 & & & & & & & & & & & & \\
\hline CHS 53 & CIR2a & 1250 & -1.47 & 0.72 & & & & & & & & & & & & \\
\hline CHS 51 & CIR2a & 1217 & -1.582 & 0.67 & & & & & & & & & & & & \\
\hline CHS 51 & CIR1 & 1217 & -1.582 & 0.64 & & & & & & & & & & & & \\
\hline CHS 50 & CIR1 & 1248 & -1.89 & 0.73 & & & & & & & & & & & & \\
\hline CHS 50 & CIR2a & 1248 & -1.89 & 0.72 & & & & & & & & & & & & \\
\hline CHS 49 & CIR1 & 1248 & -1.62 & 0.72 & & & & & & & & & & & & \\
\hline CHS 49 & CIR3 & 1248 & -1.62 & 0.70 & & & & & & & & & & & & \\
\hline CHS 49 & LLR2 & 1248 & -1.62 & 0.72 & & & & & & & & & & & & \\
\hline CHS 48 & CIR1 & 1194 & -1.98 & 0.59 & & & & & & & & & & & & \\
\hline CHS 48 & $\mathrm{H}$ & 1194 & -1.98 & 0.61 & & & & & & & & & & & & \\
\hline CHS 47 & CIR1 & 1200 & -1.63 & 0.62 & & & & & & & & & & & & \\
\hline CHS 46 & CIR1 & 1191 & -1.61 & 0.60 & & & & & & & & & & & & \\
\hline CHS 45 & LLR1 & 1182 & -1.6 & 0.54 & & & & & & & & & & & & \\
\hline CHS 44 & $\mathrm{H}$ & 1161 & -1.86 & 0.55 & & & & & & & & & & & & \\
\hline CHS 43 & $\mathrm{H}$ & 1163 & -2.06 & 0.50 & & & & & & & & & & & & \\
\hline CHS 42 & $\mathrm{H}$ & 1085 & -1.65 & 0.34 & 52.23 & 0.45 & 1.65 & 1.42 & 8.45 & 0.40 & 18.80 & 16.12 & 0.46 & bdl & bdl & bdl \\
\hline $\mathrm{CHS} 41$ & $\mathrm{H}$ & 1142 & -2 & 0.48 & 53.18 & 0.35 & 1.38 & 1.17 & 7.23 & 0.51 & 26.05 & 9.79 & 0.34 & bdl & bdl & bdl \\
\hline CHS 40 & $\mathrm{H}$ & 1108 & -1.81 & 0.38 & & & & & & & & & & & & \\
\hline CHS 38 & $\mathrm{LL}$ & 1086 & -1.3 & 0.37 & & & & & & & & & & & & \\
\hline CHS 35 & $\mathrm{H}$ & 1079 & -1.04 & 0.37 & 52.16 & 0.40 & 1.63 & 1.09 & 11.88 & 0.27 & 16.56 & 15.44 & 0.42 & bdl & bdl & bdl \\
\hline CHS 33 & $\mathrm{H}$ & 1112 & -1.18 & 0.41 & & & & & & & & & & & & \\
\hline CHS 34 & $\mathrm{LL}$ & 1108 & -1.16 & 0.43 & & & & & & & & & & & & \\
\hline CHS 31 & $\mathrm{H}$ & 1202 & -1.56 & 0.64 & & & & & & & & & & & & \\
\hline CHS 31 & HDep & 1202 & -1.56 & 0.63 & & & & & & & & & & & & \\
\hline CHS 26 & $\mathrm{H}$ & 1158 & -1.42 & 0.49 & & & & & & & & & & & & \\
\hline CHS 37 & $\mathrm{LL}$ & 1063 & -0.98 & 0.33 & 51.80 & 0.39 & 1.96 & 1.01 & 12.01 & 0.35 & 16.42 & 15.64 & 0.41 & bdl & bdl & bdl \\
\hline CHS 59 & $\mathrm{Cl}$ & 1100 & -1.6 & 0.39 & 52.90 & 0.43 & 2.54 & 1.69 & 6.88 & 0.45 & 18.60 & 15.97 & 0.51 & bdl & bdl & bdl \\
\hline CHS 58 & $\mathrm{Cl}$ & 1136 & -2.27 & 0.49 & 53.54 & 0.29 & 1.46 & 1.25 & 5.27 & 0.39 & 18.95 & 18.43 & 0.41 & bdl & bdl & bdl \\
\hline
\end{tabular}


Table S7a

\begin{tabular}{|c|c|c|c|c|c|c|c|c|c|c|c|c|c|c|c|c|c|c|}
\hline & $\mathrm{SiO2}$ & & $\mathrm{TiO} 2$ & Al2O3 & $\mathrm{Cr} 2 \mathrm{O3}$ & & $\mathrm{FeO}$ & & $\mathrm{MnO}$ & & $\mathrm{MgO}$ & & $\mathrm{CaO}$ & & Total & $n$ & Fo & \\
\hline LAP 03721 & 38.11 & 0.3 & bdl & bdl & 0.63 & 0.08 & 22.82 & 0.15 & 0.40 & 0.02 & 38.80 & 0.47 & 0.33 & 0.04 & 101.1 & 17 & 75.2 & ol-pig \\
\hline EET 90019 & 39.98 & 0.2 & bdl & bdl & 0.64 & 0.04 & 10.28 & 0.11 & 0.45 & 0.03 & 48.68 & 0.24 & 0.34 & 0.07 & 100.4 & 10 & 89.4 & ol-pig \\
\hline NWA 4852 & 39.47 & 0.3 & bdl & bdl & 0.64 & 0.03 & 12.05 & 0.15 & 0.45 & 0.03 & 47.25 & 0.31 & 0.31 & 0.01 & 100.2 & 15 & 87.5 & ol-pig \\
\hline MIL 090076 & 38.37 & 0.1 & bdl & bdl & 0.73 & 0.06 & 19.92 & 0.21 & 0.43 & 0.05 & 41.58 & 0.14 & 0.36 & 0.03 & 101.5 & 7 & 78.8 & ol-pig \\
\hline MIL 07447_10 & 39.28 & 0.3 & bdl & bdl & 0.71 & 0.02 & 16.82 & 0.07 & 0.41 & 0.05 & 43.72 & 0.12 & 0.34 & 0.01 & 101.3 & 9 & 82.2 & ol-pig \\
\hline DOM 08012_15 & 39.09 & 0.1 & bdl & bdl & 0.71 & 0.03 & 20.55 & 0.15 & 0.44 & 0.03 & 39.92 & 0.12 & 0.36 & 0.02 & 101.1 & 5 & 77.6 & ol-pig \\
\hline ЕET 96042_60 & 39.34 & 0.1 & bdl & bdl & 0.84 & 0.05 & 17.40 & 0.10 & 0.43 & 0.03 & 42.92 & 0.11 & 0.36 & 0.02 & 101.4 & 10 & 81.5 & ol-pig \\
\hline NWA 11755 & 38.32 & 0.3 & bdl & bdl & 0.73 & 0.04 & 20.31 & 0.09 & 0.40 & 0.03 & 41.03 & 0.20 & 0.36 & 0.02 & 101.2 & 13 & 78.3 & ol-pig \\
\hline NWA 5555 & 40.35 & 0.1 & bdl & bdl & 0.64 & 0.03 & 8.86 & 0.07 & 0.44 & 0.04 & 49.44 & 0.15 & 0.31 & 0.02 & 100.1 & 14 & 90.9 & ol-pig-opx \\
\hline ALHA 82106 & 40.81 & 0.3 & bdl & bdl & 0.58 & 0.02 & 4.49 & 0.08 & 0.53 & 0.03 & 53.79 & 0.23 & 0.28 & 0.02 & 100.5 & 6 & 95.5 & ol-opx-aug \\
\hline NWA 11754" & 39.66 & 0.1 & bdl & bdl & 0.51 & 0.02 & 12.03 & 0.06 & 0.53 & 0.04 & 47.23 & 0.16 & 0.29 & 0.01 & 100.3 & 12 & 87.5 & ol-opx-aug \\
\hline EET 96293" & 39.33 & 0.1 & bdl & bdl & 0.48 & 0.05 & 12.34 & 0.10 & 0.56 & 0.03 & 46.93 & 0.11 & 0.29 & 0.02 & 101.4 & 10 & 87.1 & ol-opx-aug \\
\hline
\end{tabular}

"Hughes cluster samples

numbers in italic represent the analytical standard errors $(1 \sigma)$

bdl: below detection limit. Detection limits as follow (in ppm): Si 195, Ti 296, Al 161, Cr 406, Fe 223, Mn 217, Mg 212, Ca 145, Na 459, K 111, P 254, Ni 341

Table S7b

Pigeonite composition of ureilites analyzed for this study

\begin{tabular}{|c|c|c|c|c|c|c|c|c|c|c|c|c|c|c|c|c|c|c|c|c|c|c|}
\hline & SiO2 & & TiO2 & & Al2O3 & & $\mathrm{Cr} 2 \mathrm{O3}$ & & $\mathrm{FeO}$ & & $\mathrm{MnO}$ & & $\mathrm{MgO}$ & & $\mathrm{CaO}$ & & & & & & & \\
\hline LAP 03721 & 53.98 & 0.7 & 0.05 & 0.01 & 0.93 & 0.21 & 1.22 & 0.22 & 13.29 & 0.32 & 0.40 & 0.02 & 25.84 & 1.10 & 5.27 & 1.19 & 0.07 & 0.02 & 101.1 & 14 & 77.6 & 10.2 \\
\hline EET 90019 & 56.27 & 0.3 & 0.12 & 0.02 & 0.81 & 0.02 & 1.04 & 0.06 & 6.27 & 0.12 & 0.48 & 0.03 & 31.04 & 0.24 & 4.77 & 0.07 & 0.07 & 0.03 & 100.9 & 10 & 89.8 & 9.0 \\
\hline NWA 4852 & 56.33 & 0.2 & 0.11 & 0.02 & 0.75 & 0.01 & 1.04 & 0.04 & 7.26 & 0.10 & 0.47 & 0.02 & 30.27 & 0.21 & 4.36 & 0.11 & 0.05 & 0.03 & 100.6 & 11 & 88.1 & 8.4 \\
\hline MIL 090076 & 54.69 & 0.3 & 0.10 & 0.01 & 0.95 & 0.07 & 1.39 & 0.05 & 11.55 & 0.11 & 0.42 & 0.01 & 27.01 & 0.24 & 5.54 & 0.10 & 0.10 & 0.04 & 101.7 & 16 & 80.7 & 10.6 \\
\hline MIL 07447_10 & 55.01 & 0.4 & 0.08 & 0.02 & 0.89 & 0.01 & 1.25 & 0.03 & 9.78 & 0.09 & 0.45 & 0.02 & 26.93 & 0.10 & 5.28 & 0.09 & bdl & & 99.7 & 9 & 83.1 & 10.5 \\
\hline DOM 08012_15 & 55.64 & 0.1 & 0.04 & 0.03 & 0.51 & 0.03 & 1.08 & 0.04 & 12.33 & 0.03 & 0.40 & 0.02 & 26.52 & 0.01 & 3.56 & 0.02 & bdl & & 100.2 & 3 & 79.3 & 7.1 \\
\hline ЕET 96042_60 & 55.54 & 0.1 & 0.11 & 0.01 & 0.73 & 0.02 & 1.37 & 0.01 & 10.18 & 0.11 & 0.46 & 0.01 & 27.01 & 0.11 & 4.58 & 0.04 & 0.11 & 0.03 & 100.1 & 7 & 82.5 & 9.1 \\
\hline NWA 5555 & 56.51 & 0.5 & 0.12 & 0.01 & 0.55 & 0.02 & 1.03 & 0.03 & 5.51 & 0.06 & 0.47 & 0.02 & 30.92 & 0.13 & 4.53 & 0.05 & bdl & & 99.7 & 10 & 90.9 & 8.7 \\
\hline ALHA $82106^{*}$ & 57.16 & & 0.16 & & 0.54 & & 0.82 & & 2.74 & & 0.45 & & 33.66 & & 5.72 & & 0.08 & & 101.3 & n.a. & 95.6 & 10.5 \\
\hline
\end{tabular}


Table S7c

.

\begin{tabular}{|c|c|c|c|c|c|c|c|c|c|c|c|c|c|c|c|c|c|c|c|c|c|c|}
\hline & $\mathrm{SiO} 2$ & & $\mathrm{TiO} 2$ & & Al2O3 & & $\mathrm{Cr} 2 \mathrm{O}$ & & $\mathrm{FeO}$ & & $\mathrm{MnO}$ & & $\mathrm{MgO}$ & & $\mathrm{CaO}$ & & & & & & & \\
\hline NWA 5555 & 5720 & 0.9 & 013 & 001 & 0.57 & 0.02 & 0.95 & 0.04 & 5.41 & 0.04 & 0.42 & 0.01 & 3292 & 010 & 253 & 0.02 & bdl & & 1002 & 8 & 916 & 48 \\
\hline ALHA 82106 & 57.57 & 0.3 & 0.13 & 0.01 & 0.47 & 0.01 & 0.81 & 0.02 & 2.95 & 0.08 & 0.47 & 0.03 & 36.16 & 0.23 & 2.62 & 0.02 & bdl & & 101.2 & 5 & 95.6 & 4.8 \\
\hline NWA 11754" & 55.97 & 0.5 & 0.15 & 0.01 & 1.21 & 0.02 & 0.96 & 0.04 & 7.25 & 0.11 & 0.51 & 0.02 & 30.96 & 0.13 & 2.52 & 0.02 & bdl & & 99.5 & 12 & 88.4 & 4.9 \\
\hline EET 96293" & 56.31 & 0.2 & 0.13 & 0.02 & 1.24 & 0.02 & 1.09 & 0.02 & 7.45 & 0.08 & 0.52 & 0.02 & 32.14 & 0.21 & 2.53 & 0.03 & 0.05 & 0.02 & 101.5 & 10 & 88.5 & 4.8 \\
\hline \multicolumn{23}{|c|}{$\begin{array}{l}\text { Table S7d } \\
\text { Augite composition of ureilites analyzed for this study }\end{array}$} \\
\hline & SiO2 & & $\mathrm{TiO2}$ & & $\mathrm{Al} 2 \mathrm{O} 3$ & & $\mathrm{Cr} 2 \mathrm{O} 3$ & & $\mathrm{FeO}$ & & $\mathrm{MnO}$ & & $\mathrm{MgO}$ & & $\mathrm{CaO}$ & & $\mathrm{Na} 2 \mathrm{O}$ & & Total & $\mathrm{n}$ & Mg\# & Wo \\
\hline ALHA 82106 & 55.41 & 0.1 & 0.28 & 0.01 & 0.85 & 0.03 & 0.88 & 0.03 & 1.84 & 0.05 & 0.36 & 0.01 & 23.00 & 0.13 & 18.92 & 0.05 & 0.30 & 0.03 & 101.8 & 11 & 95.7 & 36.1 \\
\hline NWA 11754" & 53.17 & 0.5 & 0.28 & 0.02 & 1.91 & 0.04 & 1.20 & 0.03 & 4.17 & 0.05 & 0.39 & 0.02 & 20.48 & 0.14 & 18.25 & 0.09 & 0.20 & 0.02 & 100.0 & 5 & 89.7 & 36.5 \\
\hline EET 96293" & 53.75 & 0.0 & 0.27 & 0.03 & 1.90 & 0.06 & 1.35 & 0.05 & 4.22 & 0.07 & 0.40 & 0.02 & 20.44 & 0.13 & 18.78 & 0.03 & 0.23 & 0.03 & 101.3 & 5 & 89.6 & 37.2 \\
\hline
\end{tabular}

"Hughes cluster samples

Table S8: phase compositions of ureilites from the literature see .zip folder 